Universidad de Lima

Facultad de Ingeniería y Arquitectura

Carrera de Ingeniería Industrial

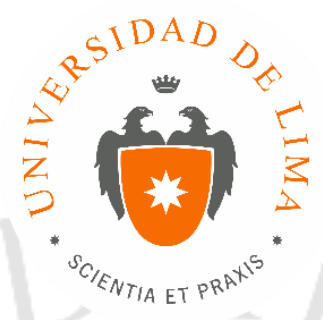

\title{
ESTUDIO DE PREFACTIBILIDAD PARA LA INSTALACIÓN DE UN CENTRO DE TERAPIA FÍSICA Y REHABILITACIÓN PARA DEPORTISTAS
}

Trabajo de investigación para optar el Título Profesional de Ingeniero Industrial

\author{
Brenda Cristina Carmelino Mendiola \\ Código 20100219 \\ Marcela Castillo Tokumori
}

Código 20102024

Asesor

Maria Teresa Noriega Aranibar

Lima - Perú

Noviembre del 2016 


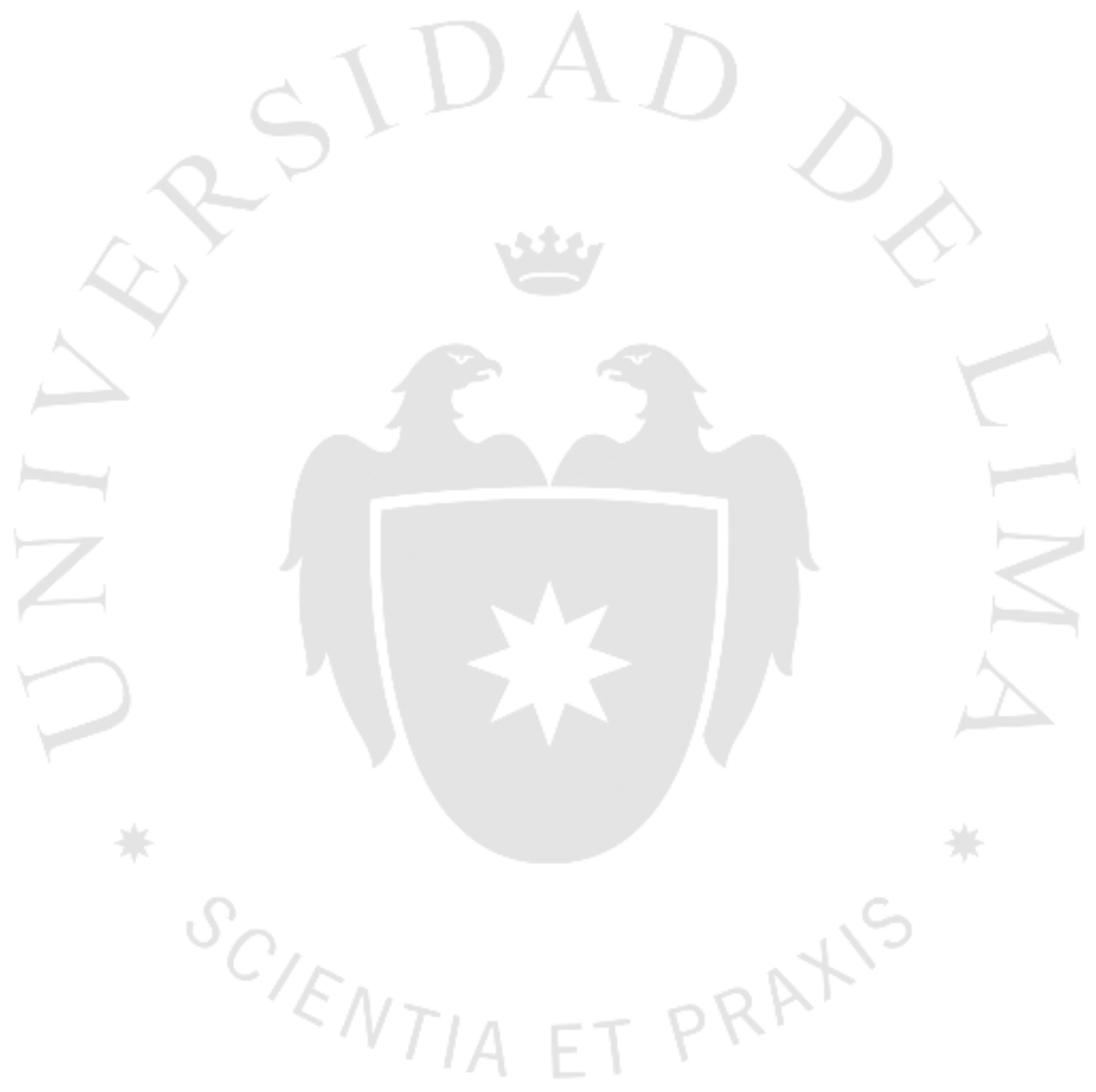




\section{ESTUDIO DE PREFACTIBILIDAD PARA LA}

INSTALACIÓN DE UN CENTRO DE TERAPIA FÍSICA Y REHABILITACIÓN

\section{PARA DEPORTISTAS}




\section{TABLA DE CONTENIDO}

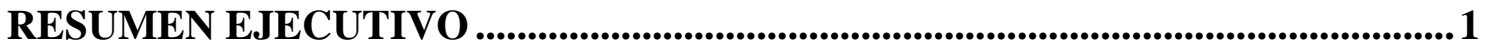

EXECUTIVE SUMMARY .........................................................................................2

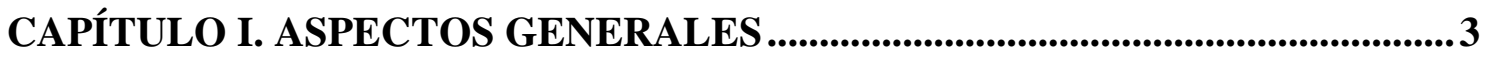

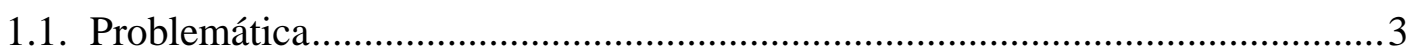

1.2. Objetivos de la investigación ................................................................. 4

1.3. Alcance y limitaciones de la investigación ......................................................

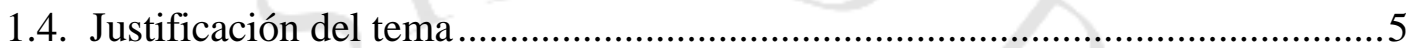

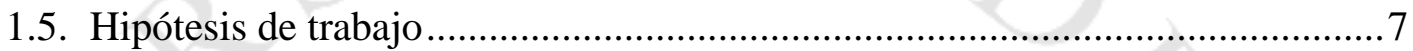

1.6. Marco referencial de la investigación ....................................................... 7

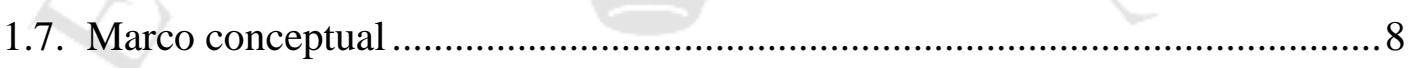

CAPÍTULO II. ESTUDIO DE MERCADO.............................................................10

2.1. Aspectos generales del estudio de mercado ................................................... 10

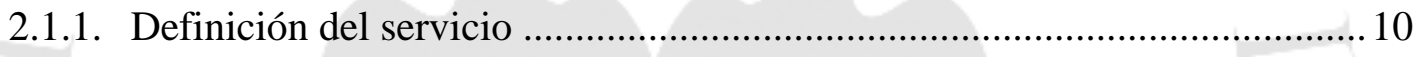

2.1.2. Principales características del servicio ................................................... 12

2.1.3. Determinación del área de influencia del servicio .................................... 14

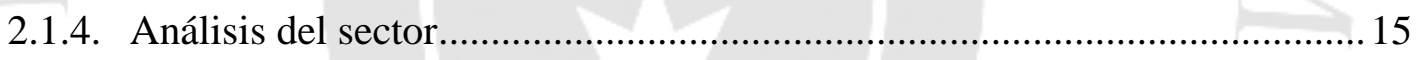

2.1.5. Determinación de la metodología que se empleará en la investigación de

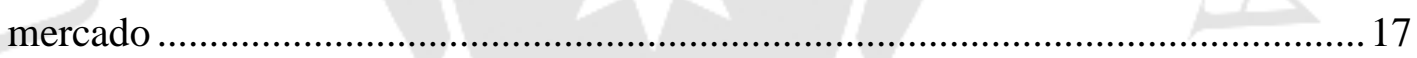

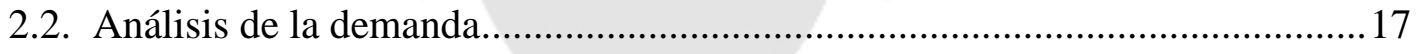

2.2.1. Cuantificación de los posibles mercados objetivos .................................... 17

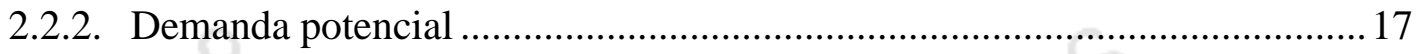

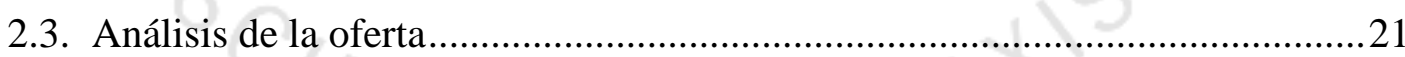

2.3.1. Análisis de la competencia. Número de operadores y ubicaciones ..............21

2.3.2. Características del servicio ofertado por los principales competidores........ 22

2.3.3. Planes de ampliación existentes .............................................................. 23

2.4. Determinación Demanda para el proyecto ......................................................22

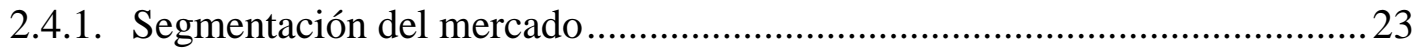

2.4.2. Selección de mercado meta ............................................................................ 24

2.4.3. Determinación de la demanda del proyecto ............................................... 30

2.5. Definición de la Estrategia de Comercialización .............................................. 31

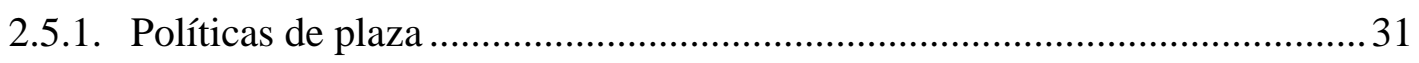


2.5.2. Publicidad y promoción

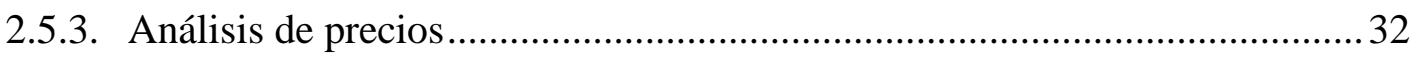

CAPÍTULO III. LOCALIZACIÓN DEL SERVICIO_...............................................34

3.1. Identificación y análisis detallado de los factores de localización....................34

3.2. Identificación y descripción de las alternativas de localización ........................35

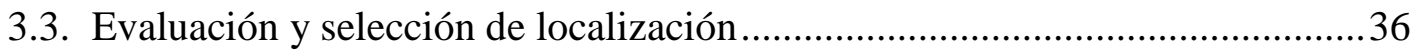

CAPÍTULO IV. DIMENSIONAMIENTO DEL SERVICIO.......................................38

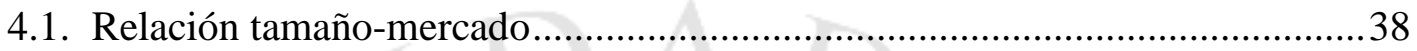

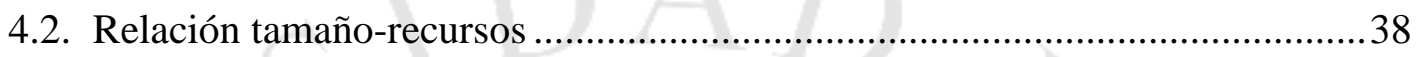

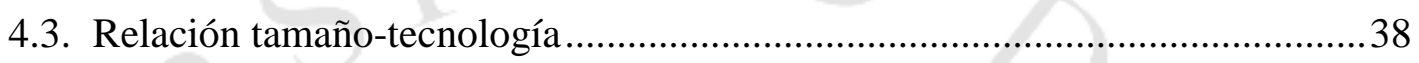

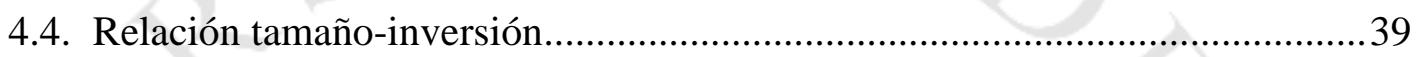

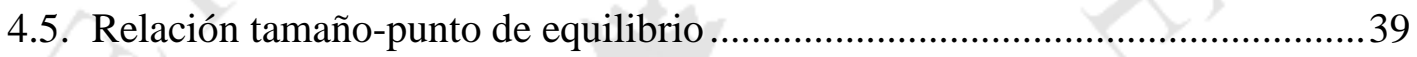

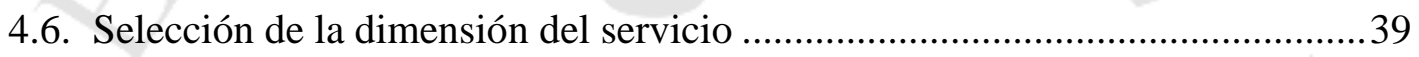

CAPÍTULO V. INGENIERÍA DEL PROYECTO..................................................4 40

5.1. Definición del servicio basada en sus características de operación ..................40

5.1.1. Especificaciones técnicas del servicio ................................................. 40

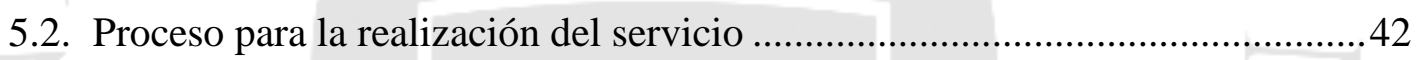

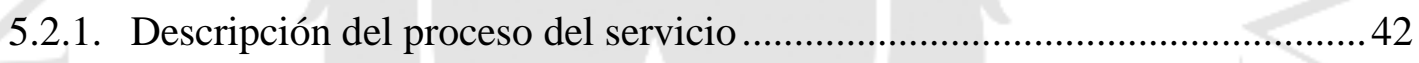

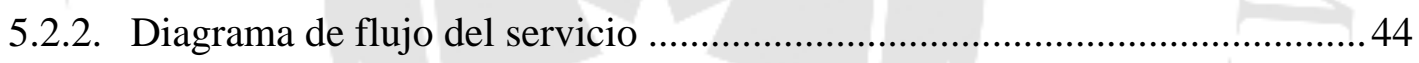

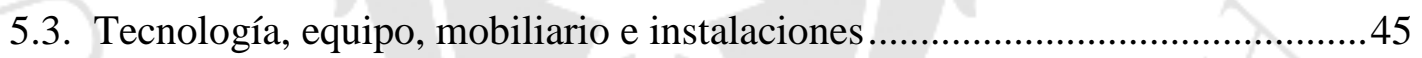

5.3.1. Selección de la tecnología, equipo, mobiliario e instalaciones ....................45

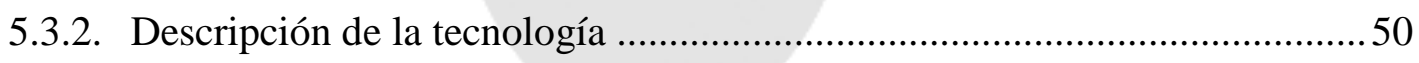

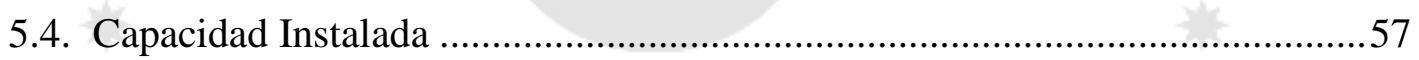

5.4.1. Cálculo de la capacidad instalada del servicio .........................................57

5.4.2. Cálculo detallado del número de recursos para el servicio ..........................61

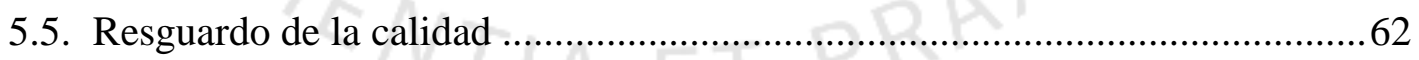

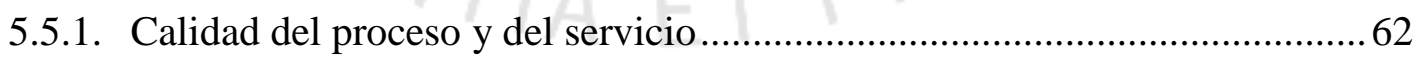

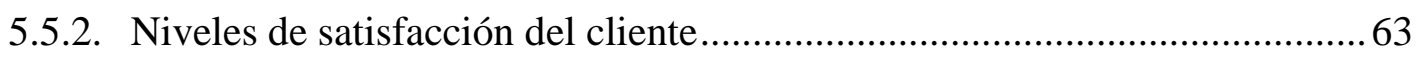

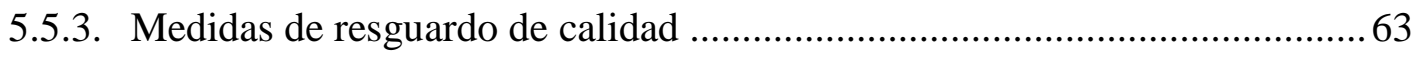

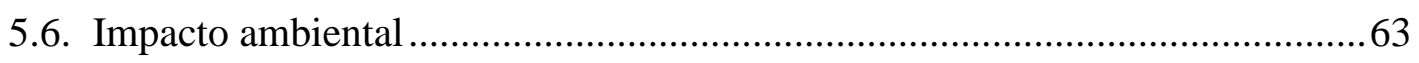

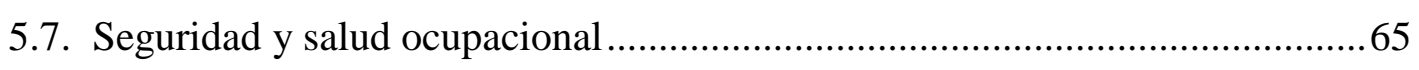

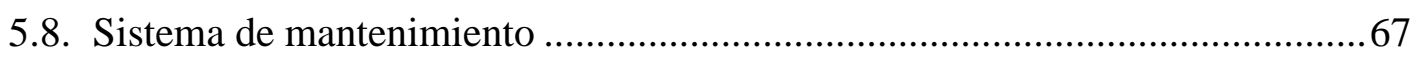

5.9. Programa de operaciones del servicio ...........................................................69 
5.9.1. Consideraciones sobre la vida útil del proyecto

5.9.2. Programa de operaciones del servicio durante la vida útil del proyecto ...... 70

5.10.Requerimiento de materiales, personal y servicios ........................................ 70

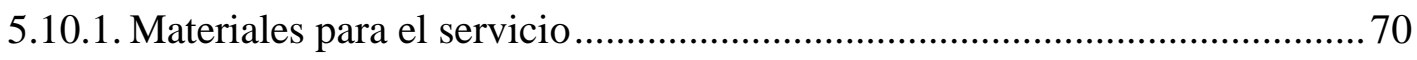

5.10.2. Determinación del requerimiento de personal de atención al cliente ........... 71

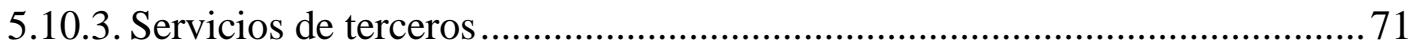

5.10.4. Otros: energía eléctrica, agua, transportes, etc.......................................... 72

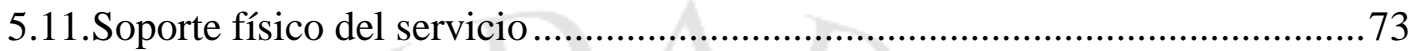

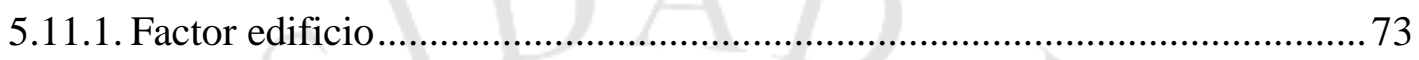

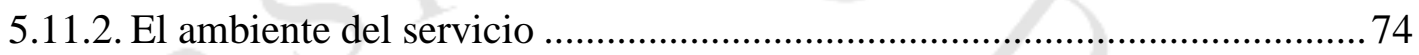

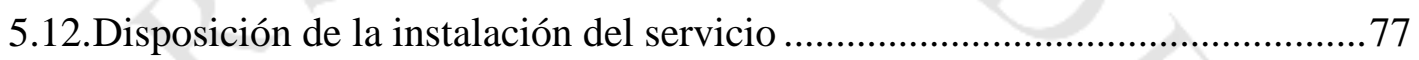

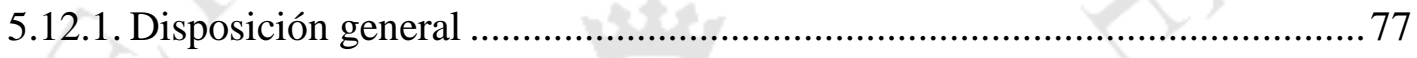

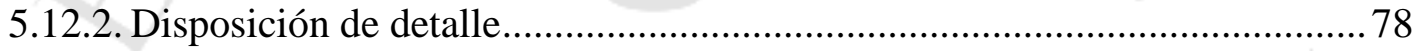

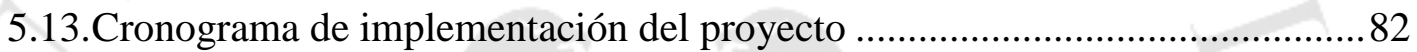

CAPÍTULO VI. ORGANIZACIÓN ADMINISTRATIVA ..........................................8 84

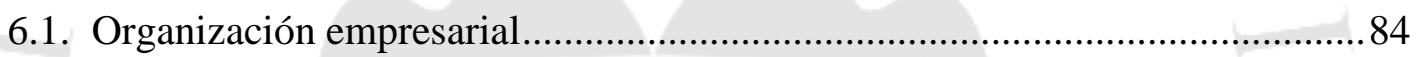

6.2. Requerimientos de personal directivo, administrativo y de soporte interno del

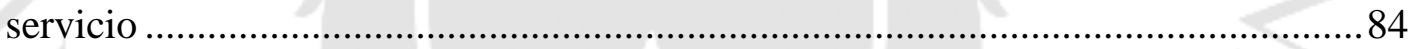

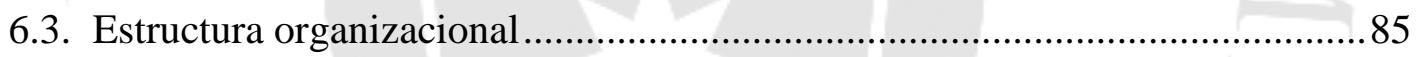

CAPÍTULO VII. ASPECTOS ECONÓMICOS .............................................................86 86

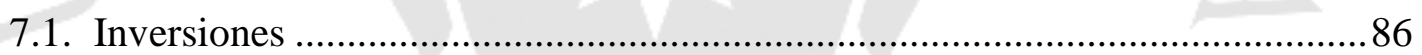

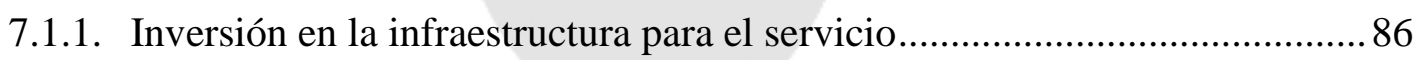

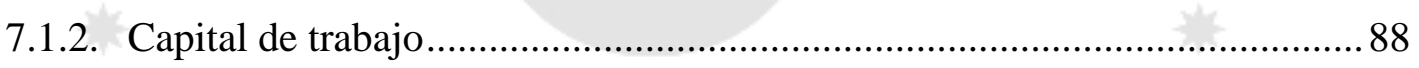

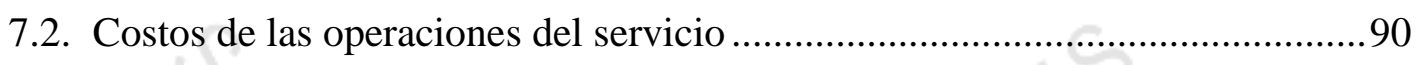

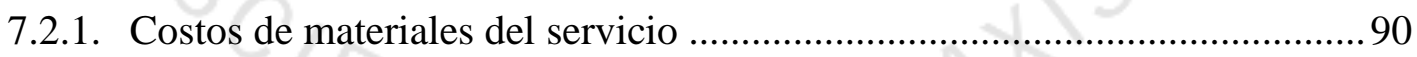

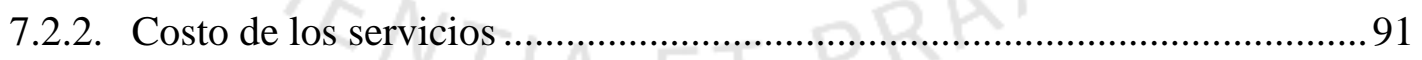

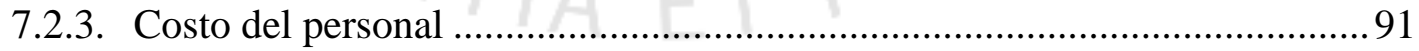

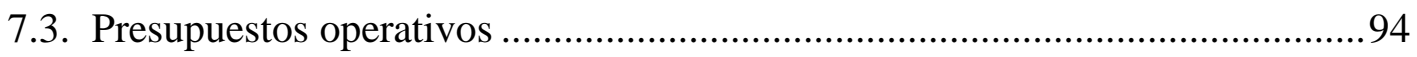

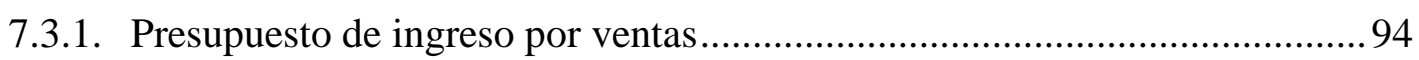

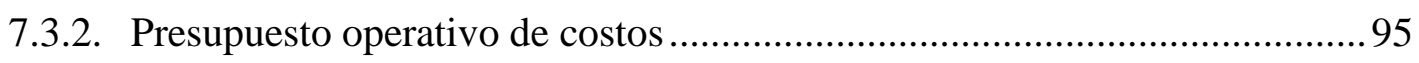

7.3.3. Presupuesto operativo de gastos administrativos ....................................... 95

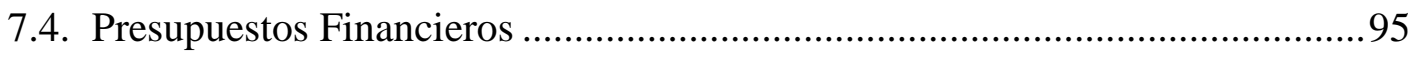

7.4.1. Presupuesto de Servicio de Deuda .............................................................. 95 
7.4.2. Presupuesto de Estado de Resultados

7.4.3. Presupuesto de Estado de Situación Financiera ......................................... 97

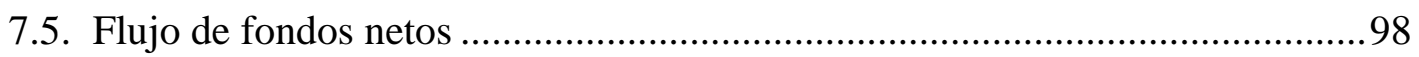

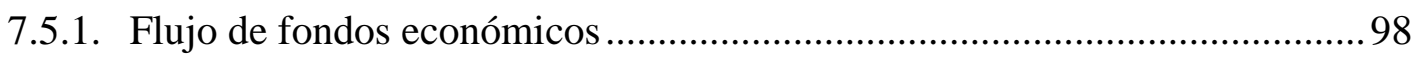

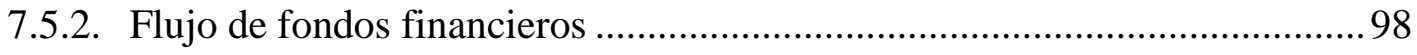

\section{CAPÍTULO VIII. EVALUACIÓN ECONÓMICA Y FINANCIERA DEL}

PROYECTO......................................................................................................100

8.1. Evaluación económica: VAN, TIR, B/C, PR ................................................. 100

8.2. Evaluación financiera: VAN, TIR, B/C, PR …........................................... 101

8.3. Análisis de ratios e indicadores económicos y financieros del proyecto ........101

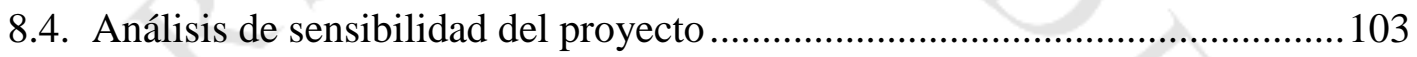

CAPÍTULO IX. EVALUACIÓN SOCIAL DEL PROYECTO .............................. 104

9.1. Identificación de las zonas y comunidades de influencia del proyecto ..........104

9.2. Análisis de indicadores sociales ................................................................ 104

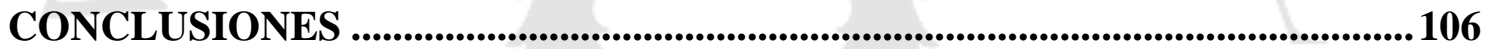

RECOMENDACIONES ........................................................................................107

REFERENCIAS ...................................................................................................... 108

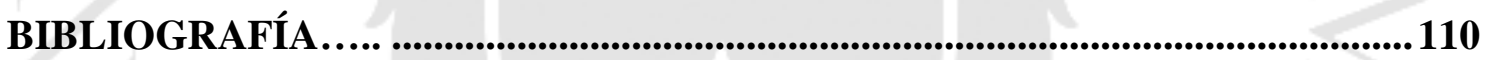

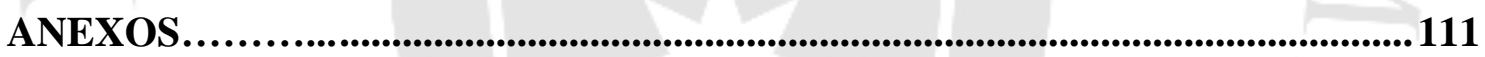




\section{ÍNDICE DE TABLAS}

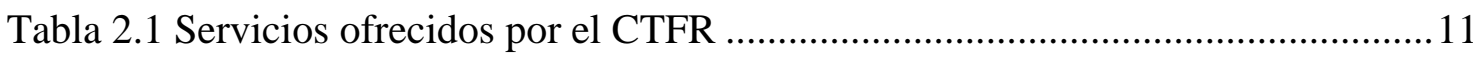

Tabla 2.2 Distribución de distritos por zonas .............................................................. 15

Tabla 2.3 Población entre 15 y 59 años en los distritos de la zona 7 (2016)..................20

Tabla 2.4 Distribución NSE A y B de la zona 7 (\% personas) ........................................20

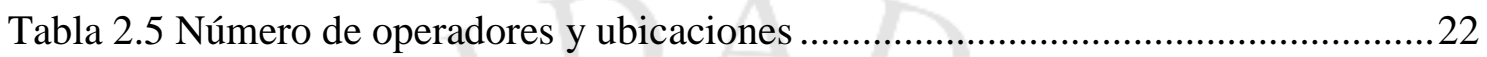

Tabla 2.6 Número de atenciones de principales competidores.....................................23

Tabla 2.7 Población histórica entre 15 y 59 años en los distritos de la zona 7 ...............28

Tabla 2.8 Población proyectada entre 15 y 59 en los distritos de la zona 7 ...................28

Tabla 2.9 Distribución histórica de niveles en la zona 7 (\% personas) ..........................29

Tabla 2.10 Distribución proyectada de niveles en la zona 7 (\% personas) ....................29

Tabla 2.11 Mercado meta, 2016-2021 ( $\mathrm{N}^{\circ}$ deportistas)............................................... 30

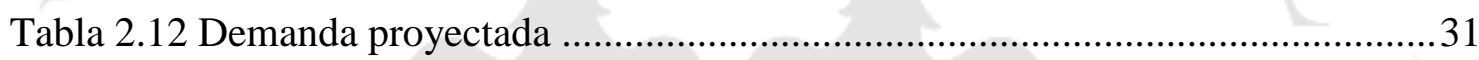

Tabla 2.13 Precio promedio por cita de las principales competencias ...........................33

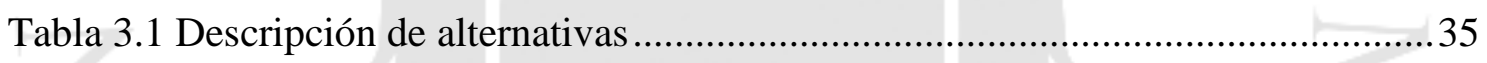

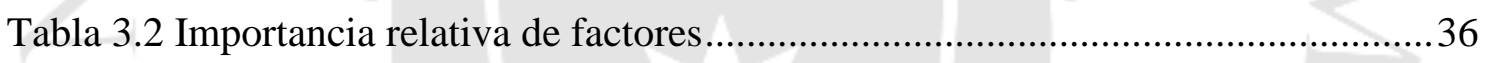

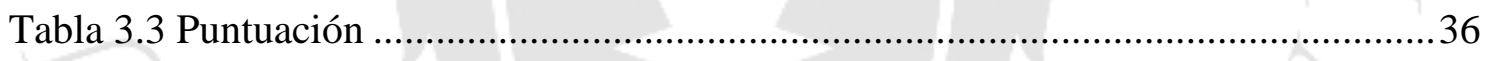

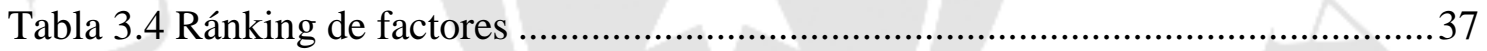

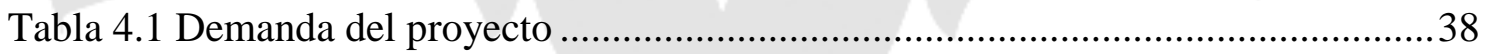

Tabla 5.1 Equipo y mobiliario seleccionado ........................................................ 48

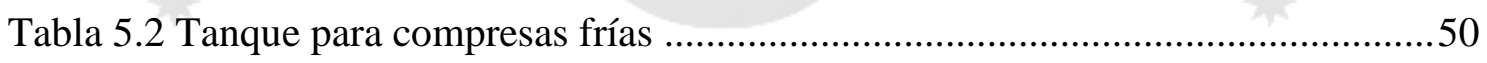

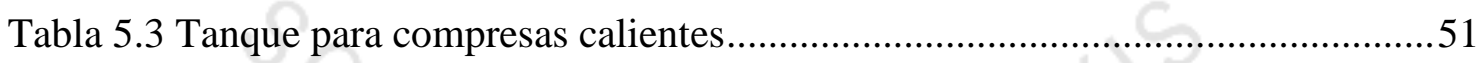

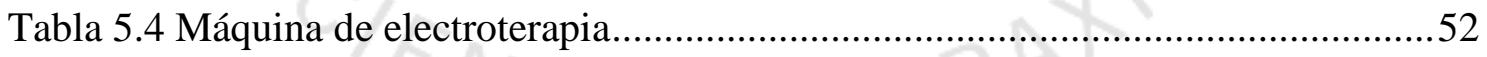

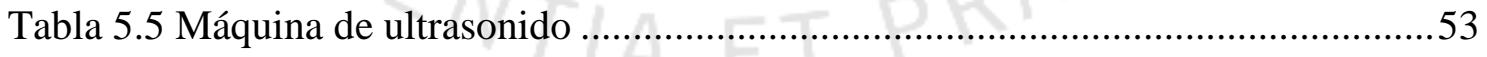

Tabla 5.6 Máquina de láser terapéutico .......................................................................54

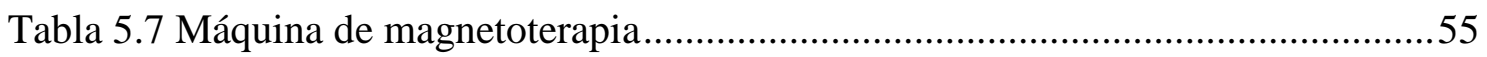

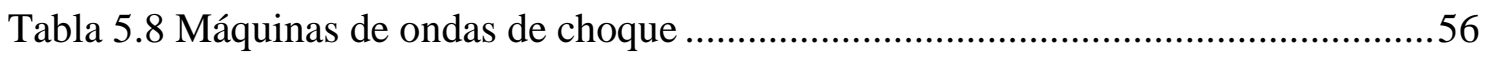

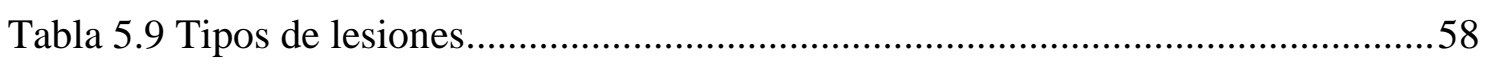

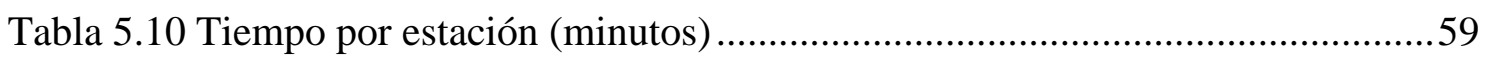

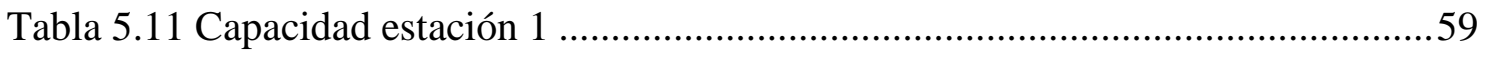

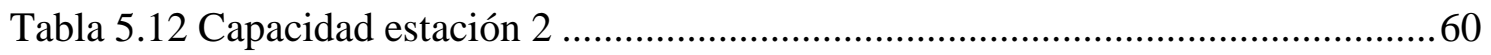


Tabla 5.13 Capacidad estación 3

Tabla 5.14 Capacidad estación 4

Tabla 5.15 Número de recursos necesarios ...............................................................62 62

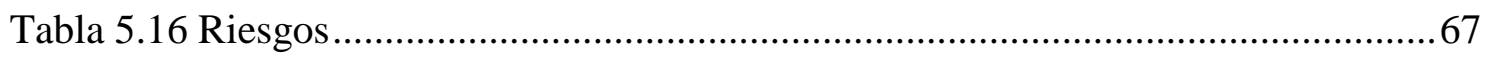

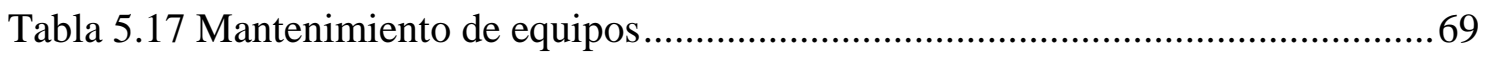

Tabla 5.18 Requerimiento de materiales al año........................................................ 70

Tabla 5.19 Requerimiento de personal ….................................................................. 71

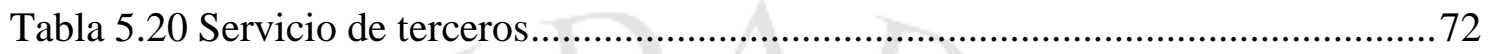

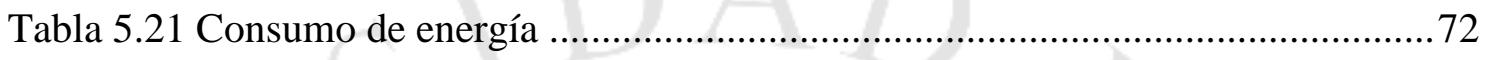

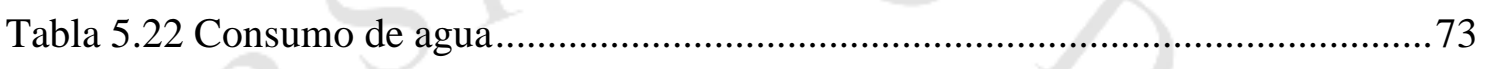

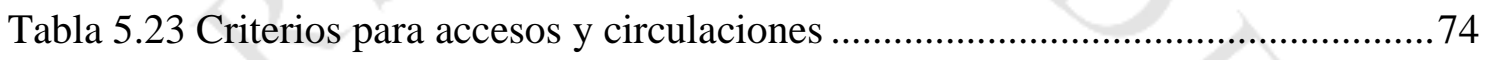

Tabla 5.24 Determinación de los servicios higiénicos ..................................................76

Tabla 5.25 Estimación del área teórica de terapia física, manual y rehabilitación .......... 77

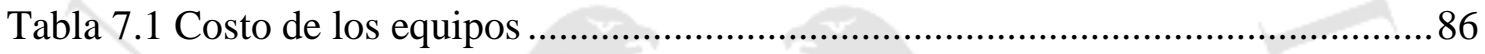

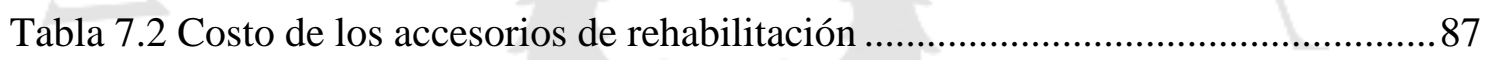

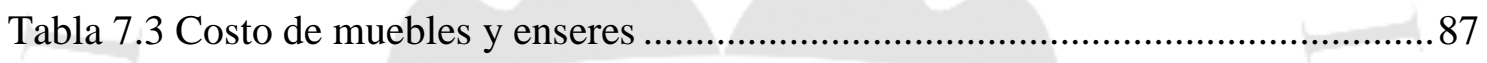

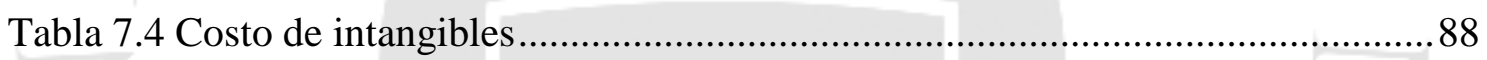

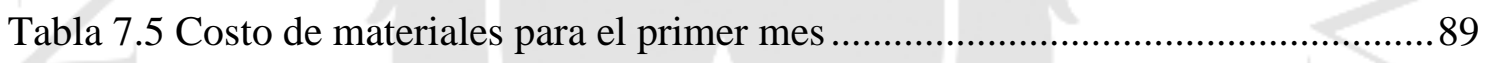

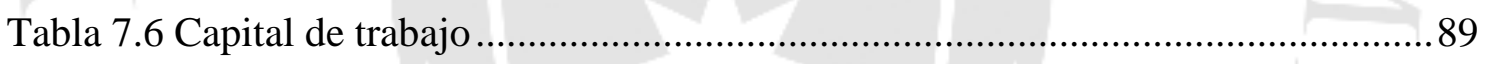

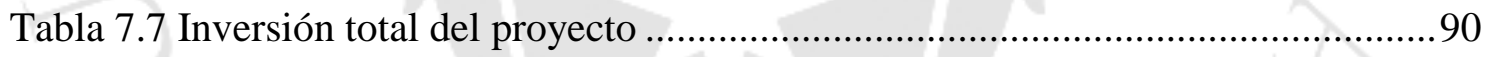

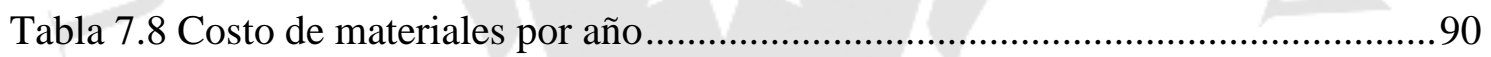

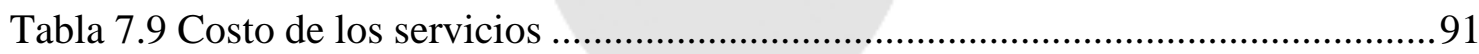

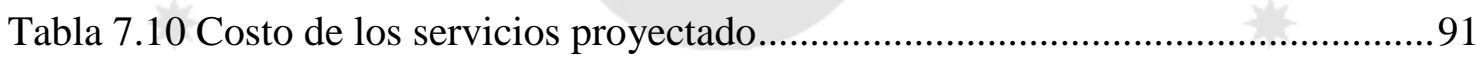

Tabla 7.11 Costo de remuneraciones a fisioterapeutas ............................................. 92

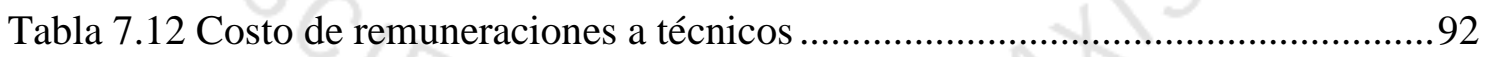

Tabla 7.13 Costo de remuneraciones a médico ........................................................ 92

Tabla 7.14 Costo de remuneraciones a asistente ........................................................93

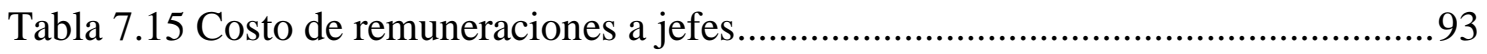

Tabla 7.16 Costo de remuneraciones a directos general ........................................... 93

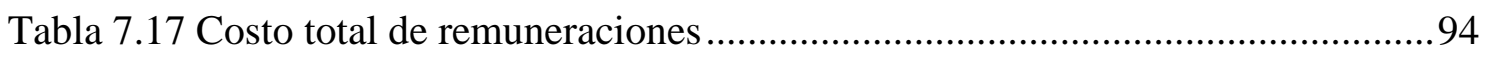

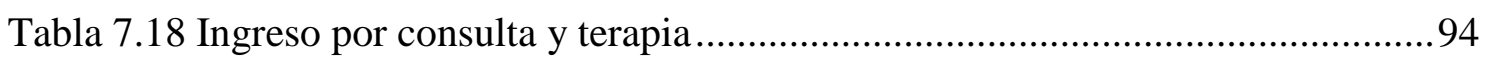

Tabla 7.19 Presupuesto operativo de costos ................................................................ 95

Tabla 7.20 Presupuesto operativo de gastos administrativos ........................................95 
Tabla 7.21 Tasas de empresas bancarias en moneda local ........................................96

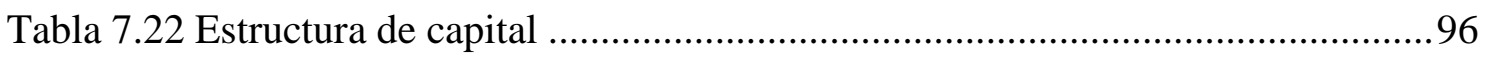

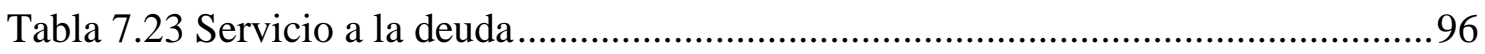

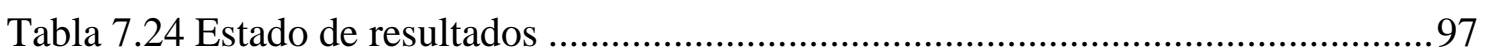

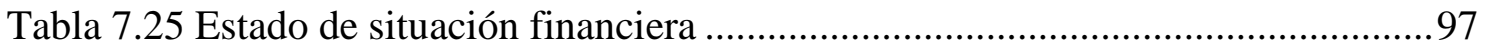

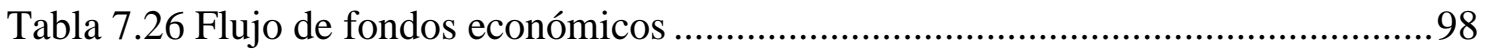

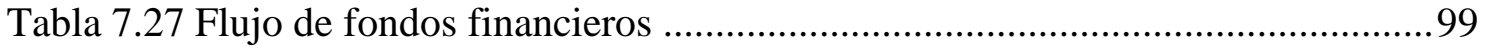

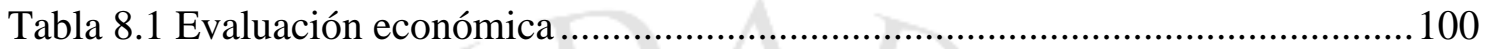

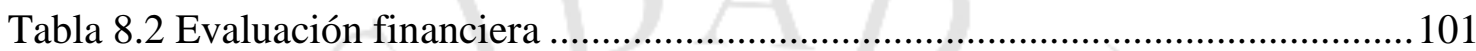

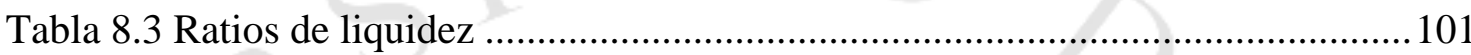

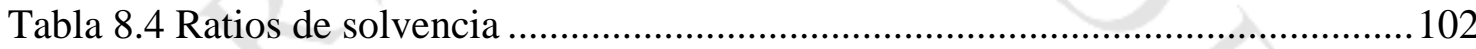

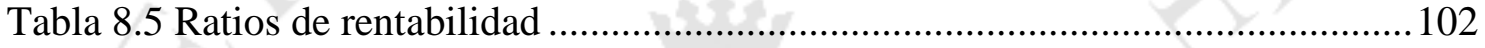

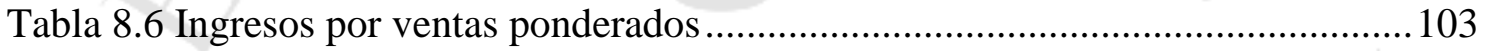

Tabla 8.7 Evaluación financiera - escenario .............................................................. 103

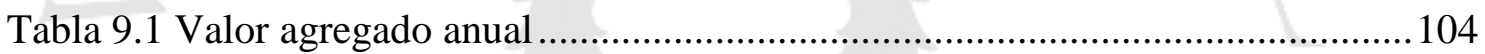




\section{ÍNDICE DE FIGURAS}

Figura 1.1 Gráfico comparativo de número de atenciones en Fisioterapia y

Rehabilitación Física. 6

Figura 2.1 Evolución anual de deportistas (2010-2015) ............................................. 18

Figura 2.2 Evolución de atenciones por servicio médico (2010-2015) ......................... 19

Figura 2.3 Distribución de atenciones médicas (2015)................................................. 19

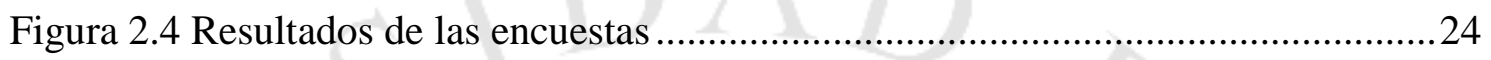

Figura 5.1 Diagrama de flujo para el proceso de inscripción y primera cita del paciente

Figura 5.2 Diagrama de flujo para el proceso de sesión de terapia del paciente ............45

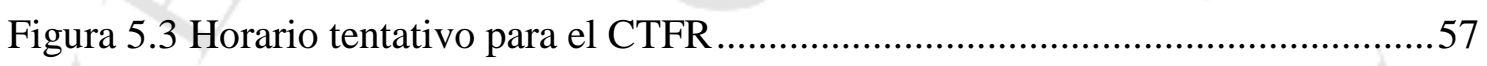

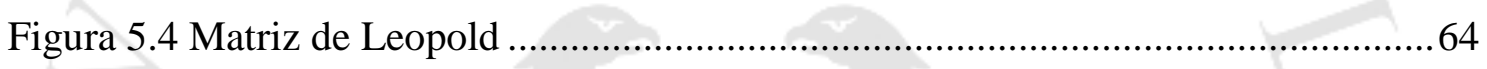

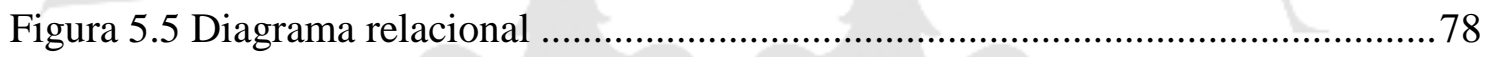

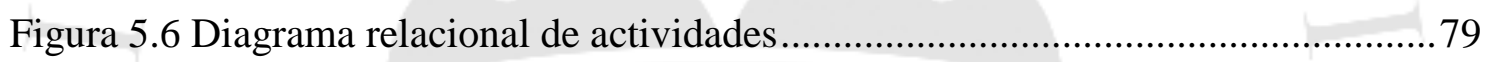

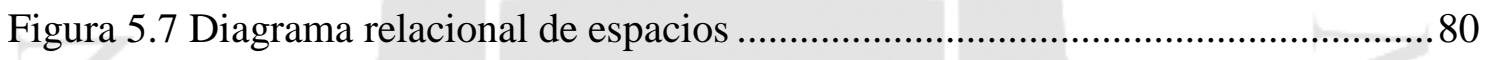

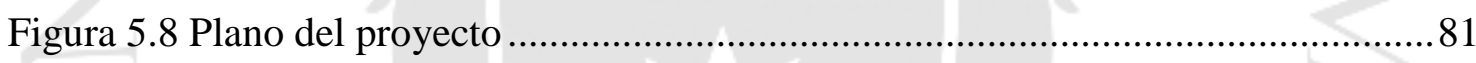

Figura 5.9 Programa de implementación del proyecto ................................................ 83

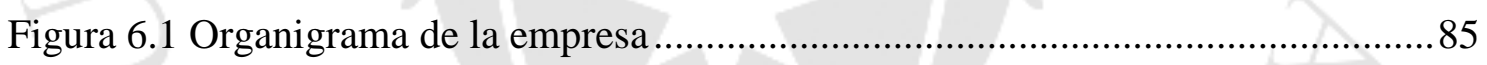




\section{ÍNDICE DE ANEXOS}

Anexo 1 Encuesta .

112

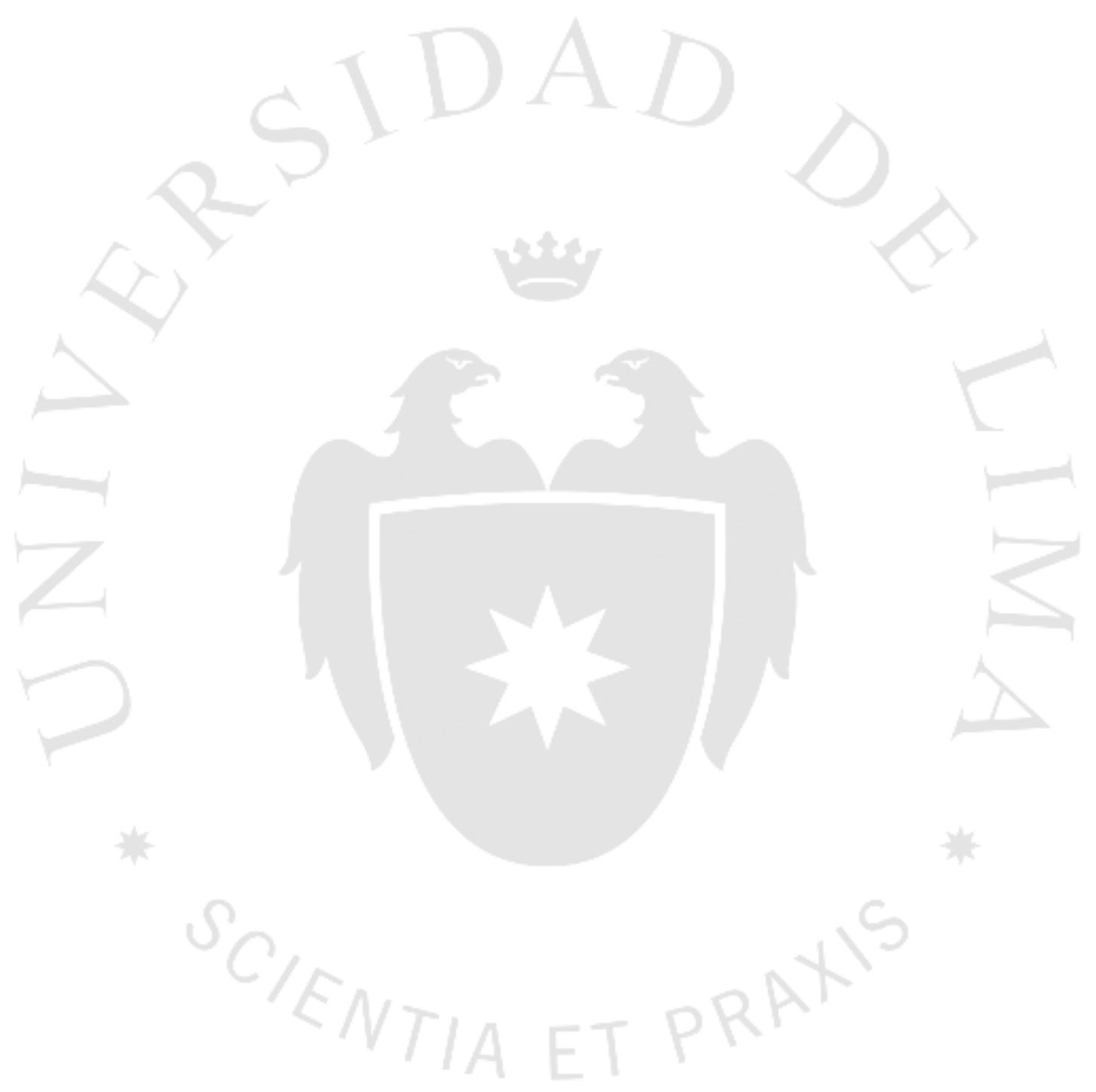




\section{RESUMEN EJECUTIVO}

El presente trabajo de investigación tiene como objetivo determinar si es viable y rentable la implementación de un centro de terapia y rehabilitación física para deportistas. En un contexto, donde la actividad física ha ido ganando mayores seguidores y donde los deportistas tienen más oportunidades de demostrar su potencial en diversas competencias, es importante tener en cuenta un elemento importante: mantener al deportista en su máxima capacidad física. Es por ello, que se plantea un servicio de atención al deportista, personalizado y con un valor agregado, que permita el desarrollo de los deportistas.

El trabajo de investigación se divide en nueve capítulos. En el primer capítulo, se presentan los aspectos generales de la investigación; entre ellos, la problemática, los objetivos, los alcances y las limitaciones, la justificación del tema, la hipótesis del trabajo, el marco referencial y el marco conceptual.

En el segundo capítulo, se desarrollará el estudio de mercado para determinar la viabilidad del proyecto y demostrar si es conveniente ingresar al mercado. Para familiarizarse con el mercado, se analizará tanto la oferta como la demanda, segmentando y seleccionando de manera adecuada el público objetivo. Igualmente, se definirán las estrategias de comercialización para lograr una posición importante en el mercado.

En los siguientes dos capítulos, se determinará la localización del servicio utilizando el método de ránking de factores, y el dimensionamiento del servicio; esto es, el tamaño adecuado teniendo en cuenta las relaciones entre el tamaño y el mercado, los recursos, la tecnología, la inversión y el punto de equilibrio.

En el quinto capítulo, se desarrollará la ingeniería del proyecto, donde se presentarán las especificaciones técnicas, los procesos para el servicio, la capacidad instalada, los requerimientos de recursos y la disposición para la instalación y correcto funcionamiento del centro. Luego, se presentará la organización administrativa, incluyendo la estructura organizacional.

En los tres últimos capítulos, luego de presentar la inversión total y los costos necesarios para la operación del servicio, se elaborarán los presupuestos respectivos para realizar la evaluación, tanto económica como financiera. Finalmente, se realizará la evaluación social del proyecto. 


\section{EXECUTIVE SUMMARY}

This research has the objective of determining if it is viable and rentable to implement a physical therapy and rehabilitation center for athletes. In a context where physical activity has been gaining more followers and where athletes have more chances to show their potential in diverse competitions, it is important to take into account an important element: to keep the athlete to his or her maximum capacity. Therefore, a personalized attention service is proposed with added value, allowing the development of athletes.

This research is divided into 9 chapters. In the first chapter the general aspects of the investigation are presented, including the problematic, the objectives, the scope and limitations, the justification of the subject, the work hypothesis, the referential framework and the conceptual framework.

In the second chapter, the market study is performed to determine the viability of the project. The demand and supply will be analyzed by segmenting and selecting adequately the target audience. In this chapter the commercialization strategies will be defined to accomplish a position in the market.

In the following two chapters, the localization of the service will be determined using the ranking of factors method. The dimensioning of the service will also be determined, that is, the adequate size considering the market, the resources, the technology, the inversion and the breakeven point.

On the fifth chapter, the engineering of the project will be developed, where the technical specifications, processes, capacity, resource requirement and disposition of the installation will be determined. Then, we will present the administrative organization, including the organization structure.

On the last three chapters, after presenting the total investment and cost necessary for the operation of the service, the corresponding budgets will be elaborated to perform the economic, financial and social evaluation. 


\section{CAPÍTULO I. ASPECTOS GENERALES}

\subsection{Problemática}

En la actualidad, el mercado de servicios deportivos no satisface a la creciente demanda de deportistas aficionados y de alto rendimiento, los cuales requieren de servicios médicos y terapéuticos con profesionales especializados en el área deportiva. Aproximadamente, son 60 los establecimientos formales, entre ellos clínicas y centros especializados, que ofrecen servicios de fisioterapia deportiva en Lima Metropolitana. Sin embargo, la mayoría de estos centros, sobre todo en las clínicas privadas, no brindan una atención personalizada; es decir, se establece un tipo de terapia para cada lesión sin tomar en cuenta la edad o estilo de vida de los pacientes para realizar los tratamientos correctos con la intensidad adecuada.

Asimismo, el contexto en que se presenta el presente negocio, se tiene al Perú siendo la principal sede de importantes eventos deportivos a nivel panamericano y mundial, y principalmente, la realización de los Juegos Panamericanos 2019, en donde se han trazado una serie de objetivos y metas con los deportistas nacionales. Son ellos los que requieren un servicio personalizado y con un valor agregado importante en cuanto a fisioterapia y rehabilitación deportiva, la cual es indispensable tenerla al alcance debido a que las lesiones y fatigas musculares están siempre presentes y deben tratarse de inmediato para que se pueda cumplir la planificación de entrenamientos y trabajos específicos. Las lesiones deportivas pueden ocurrir tanto en la práctica como accidentalmente. Otras pueden ser el resultado de malas prácticas de entrenamiento, uso inadecuado del equipo de entrenamiento, o incluso cuando las personas no están en buena condición física. Estas lesiones también se pueden presentar debido a la falta o escasez de calentamiento o estiramiento previo al ejercicio.

Entre las lesiones más frecuentes que presentan los deportistas, según el registro de atenciones médicas de La Videna (atención médica ofrecida por el Instituto Peruano del Deporte a deportistas pertenecientes a la selección nacional de las diferentes federaciones) están, los desgarros musculares, contracturas musculares, esguinces, luxaciones y contusiones. 
Para el tratamiento óptimo de estas lesiones se requieren tres técnicas en conjunto, terapia manual, terapia con agentes físicos y rehabilitación física. Según el fisioterapeuta de La Videna, especializado en lesiones deportivas, indica que las terapias más utilizadas para los diversos tratamientos son la electroterapia, magnetoterapia, el uso de agentes térmicos, ultrasonido y láser terapéutico, los cuales se entrará en detalle durante la presente investigación.

\subsection{Objetivos de la investigación}

Objetivo general

Determinar la viabilidad de mercado, técnica, económica, financiera, social y medioambiental para la instalación de un centro que ofrezca los servicios de terapia física y rehabilitación para deportistas, con un enfoque dirigido a la satisfacción del paciente.

Objetivos específicos

- Realizar un estudio de mercado que permita definir la viabilidad del proyecto.

- Determinar si el proyecto es técnicamente viable

- Determinar si el proyecto es económica y financieramente viable.

- Determinar si el proyecto es social y medioambientalmente viable.

- Diseñar un sistema de gestión dirigido a los procesos de atención al paciente.

\subsection{Alcance y limitaciones de la investigación}

Alcances:

- La investigación propone un beneficio tanto para deportistas aficionados como de alto rendimiento.

- El servicio propuesto en la investigación está focalizado en Lima Metropolitana, evaluando sólo a nivel de microlocalización.

- El presente proyecto tendrá un ciclo de vida de 5 años debido a que es un proyecto de pequeño tamaño. 
- El Colegio Tecnólogo Médico del Perú (CTMP) es la entidad que avala legalmente a los tecnólogos médicos, dentro de ellos, a los fisioterapeutas.

\section{Limitaciones:}

- La investigación presente no cuenta con información histórica, por ello se utilizará información recopilada de encuestas y consultas a especialistas de la rama.

- A lo largo del estudio se considerará un porcentaje constante de deportistas en relación a la población.

- Los datos sobre número de deportistas y de atenciones médicas brindados por el Instituto Peruano del Deporte (IPD) serán hasta el año 2015, debido que los Compendios Estadísticos de dicha organización son realizados durante el primer semestre del año siguiente.

\subsection{Justificación del tema}

Técnica

Hace un poco más de 70 años se creó la carrera de Terapia Física en el Perú, en la modalidad de Post Grado en la Universidad Mayor de San Marcos. Y no fue hasta 23 años después, que formó parte de la carrera de Tecnología Médica, en la misma universidad. Al año siguiente, en 1967, la carrera de Tecnología Médica se empieza a dictar en la Universidad Nacional Federico Villarreal. Actualmente, la carrera de Terapia Física se encuentra en distintas universidades, de las cuales destacan la Universidad Federico Villareal, Universidad Peruana Cayetano Heredia y la Universidad Peruana de Ciencias Aplicadas. Dicha carrera cuenta con especialistas en la rama de fisioterapia, y dentro de ella está el campo de fisioterapia deportiva el cual cada vez ha ido ganando mayores seguidores.

En cuanto a la tecnología, el centro del proyecto requiere de equipos de rehabilitación como magnetoterapia, láser, ultrasonido, ondas de choque, entre otros. Esta tecnología es accesible, pues se encuentra disponible en el mercado tanto extranjero como local. 


\section{Económica}

El financiamiento que requiere el proyecto es accesible. Por el lado económico, se espera que el proyecto genere utilidades ya que el interés por realizar actividades físicas y deportes está aumentando, con la ayuda de programas para la promoción de la actividad física como “Actívate-Perú”, Ministerio de Salud (MINSA, 2013). Asimismo, los deportistas le dan prioridad al tema de terapia física y rehabilitación, porque necesitan recuperar sus dolencias para continuar con la actividad física, teniendo que recurrir a estos servicios.

En la figura 1.1, del 2010 al 2015 se observa un incremento en atenciones de fisioterapia y rehabilitación física en el IPD; es decir, deportistas calificados que requieren de servicios médicos, específicamente en el tema de lesiones deportivas. Debido a este aumento de demanda en los servicios mencionados, se puede concluir que los deportistas seguirán necesitando los servicios de terapia y rehabilitación, por lo que acudirán a centros especializados, estando dispuestos a pagar por estos servicios.

\section{Figura 1.1}

Gráfico comparativo de número de atenciones en Fisioterapia y Rehabilitación Física

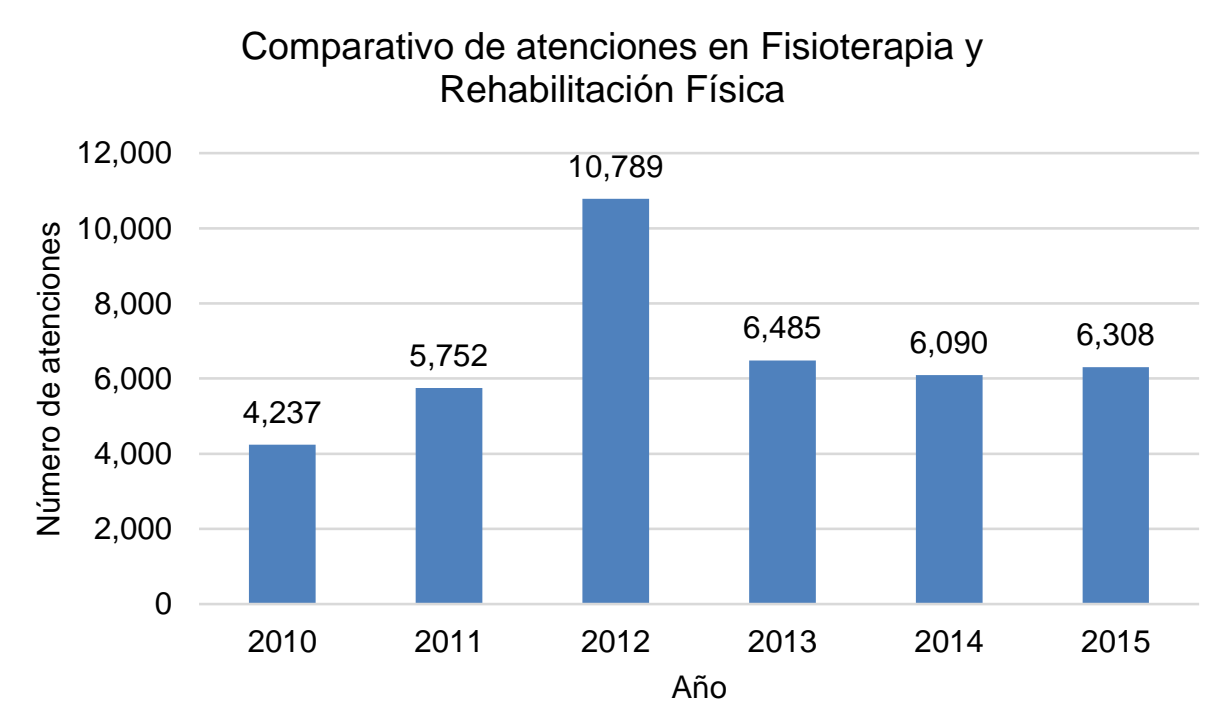

Fuente: IPD, (2016).

Social

El proyecto logrará la generación de empleos a especialistas en fisioterapia que actualmente laboran en clínicas u hospitales, que quieran desarrollarse en la rama de fisioterapia deportiva. Por otro lado, el proyecto brindará un servicio que mejore las 
condiciones físicas y de vida de las personas, particularmente en los deportistas al recuperar y alcanzar su máximo nivel de rendimiento.

\subsection{Hipótesis de trabajo}

La creación de un centro de terapia física y rehabilitación deportiva es factible, debido a que existe un mercado dispuesto a aceptar los servicios planteados, además de ser técnica, económica, financiera, social y medioambientalmente viable.

\subsection{Marco referencial de la investigación}

- "Estudio de pre factibilidad para la puesta en marcha de un centro de gimnasia y terapia geriátrica." - Costa López, Leonardo Martín

Ambas investigaciones plantean un centro de fisioterapia para mejorar la calidad de vida y rendimiento físico de las personas. Sin embargo, difieren en su público objetivo, pues el presente proyecto es exclusivamente para deportistas, mientras que la mencionada es hacia el adulto mayor.

- "Estudio de pre factibilidad para la instalación de una clínica médica en la ciudad de Trujillo.” - Iyo Valdivia, José Antonio

Ambos estudios se enfocan en el ámbito de la salud. Sin embargo, a diferencia de la investigación planteada, se pretende instalar una clínica médica orientándose a la atención materno-infantil y situándose en la ciudad de Trujillo.

- "Estudio de pre factibilidad para la implementación de centro de bienestar que brinda atención integral a pacientes con diabetes mellitus en Lima Metropolitana." - Santos Trinidad, Maricela Yanneth; Alocen Oblitas, Pablo Christian

A diferencia del presente estudio, el público objetivo son pacientes con diabetes. No obstante, ambos estudios se enfocan en el ámbito de la salud ofreciendo una atención integral a pacientes de Lima Metropolitana que pertenezcan al NSE A y B, con servicios especializados, buscando la máxima calidad.

- "Plan de negocios para el establecimiento de una clínica gíneco obstétrica de Lima Norte" - Huaraz Zuloaga, Eliana Melisa 
A diferencia del estudio propuesto, el centro tiene como principal objetivo el tratamiento gíneco obstétrico y el público objetivo son pacientes de Lima Norte específicamente. No obstante, ambos estudios se enfocan en el ámbito de la salud con servicios personalizados y de alta calidad.

- "Plan de negocios centro de salud especializado en enfermedades urológicas "Berdejo Hurtado, Romy Sandra; López Concha, Patricia Pilar

A diferencia del presente estudio, el centro tiene como principal objetivo el tratamiento de enfermedades urológicas para el NSE C y D en Lima Norte. Sin embargo, ambos estudios evalúan la viabilidad de un proyecto enfocado en el ámbito de la salud y del tratamiento médico con personal médico calificado y equipamiento y infraestructura de alto nivel.

\subsection{Marco conceptual}

- Actividad física: Conjunto de movimientos corporales que se realizan con determinado fin. La práctica de la actividad física en forma sistemática y regular debe tomarse como un elemento significativo en la prevención, desarrollo y la rehabilitación de la salud.

- Deporte: Actividad física que se promueve para la recreación, mejora de la salud, renovación y desarrollo de las potencialidades físicas y mentales del ser humano, mediante la participación y sana competencia en todas sus disciplinas deportivas, recreativas y de educación física, premiando a los que triunfan en una contienda leal de acuerdo con sus aptitudes y esfuerzos.

- Deportista aficionado o amateur: Personas que se dedican a la práctica del deporte por ocio o entretenimiento, incluso si lo hacen dentro de un club deportivo. El deporte por afición se realiza para mejorar la salud, hacer ejercicio o socializar.

- Deportista de alto rendimiento: Personas con talento deportivo, con dedicación diaria a la práctica deportiva, siendo su principal actividad representar al país como seleccionado en competencias internacionales; y obtener resultados deportivos a nivel nacional y/o internacional. 
- Distensión muscular: Se presenta cuando un músculo es sometido a un estiramiento exagerado y hay desgarro, la cual puede ser causada por un accidente, uso inadecuado de un músculo o sobrecarga muscular.

- Esguince: También llamado torcedura, es una lesión del ligamento (tejido que conecta dos o más huesos en una articulación) que resulta cuando éste se distiende o se rompe.

- Espasticidad: Músculos tensos y rígidos.

- Fisioterapeuta: Profesional de la salud que interviene en la prevención, diagnóstico, tratamiento y recuperación de las alteraciones del movimiento corporal en personas con discapacidad. Encargado de aplicar distintas técnicas con el fin de brindar una mejoría al estado físico y reincorporar al paciente a sus actividades de vida diaria.

- Medicina del deporte: Especialidad médica que estudia los efectos del ejercicio del deporte y, en general, de la actividad física, desde el punto de vista de la prevención y tratamiento de las enfermedades y lesiones.

- Rehabilitación física: Cuando se habla de Rehabilitación se habla de un nivel de atención médica que se encuentra en el tercer nivel de atención de la enfermedad, el primer nivel es la Prevención, el segundo es el Diagnóstico y Tratamiento, y el tercero es la Rehabilitación. Esta última, está encargada de recuperar al máximo las capacidades del individuo que ha sufrido alguna lesión o enfermedad y reincorporar al paciente a sus actividades de la vida diaria.

- Tejidos blandos: Los tejidos blandos conectan, apoyan o rodean a otros tejidos. Algunos ejemplos incluyen músculos, tendones, grasa y vasos sanguíneos.

- Terapia física o físioterapia deportiva: Tratamiento médico que consiste en rehabilitar completamente al deportista después de la lesión o después de una operación, para evitar una lesión mayor y permitirle volver al deporte en el menor tiempo posible. 


\section{CAPÍTULO II. ESTUDIO DE MERCADO}

\subsection{Aspectos generales del estudio de mercado}

\subsubsection{Definición del servicio}

El centro presentado en el proyecto ofrecerá los servicios de terapia física y rehabilitación física con un enfoque especializado y con prioridad en la atención al deportista, usando tecnología de punta y un capital humano profesional y correctamente capacitado. De esta forma se busca asegurar la calidad de servicio y efectividad en la cura y rehabilitación de los deportistas ante sus molestias y lesiones, lo cual será la principal carta de presentación de la empresa. Además, brindar una experiencia diferenciada basada en los resultados obtenidos.

El principal servicio consiste en la terapia física y rehabilitación del deportista, empleando un conjunto de técnicas médico deportivas, con el objetivo de recuperar y mejorar la condición física del deportista para que pueda reanudar sus entrenamientos.

Asimismo, se emplearán equipos especializados y un personal altamente capacitado en lesiones deportivas para lograr óptimos resultados. El local estará estratégicamente ubicado en una zona de fácil acceso para los posibles deportistas, de igual manera, contará con una infraestructura adecuada, amplia y cómoda para el desenvolvimiento del negocio.

Para aumentar la satisfacción del deportista, se contará con equipos de última tecnología en el mercado, una atención totalmente personalizada, los tratamientos para las lesiones y los deportistas pueden variar, y se ofrecerán distintos medios para reservar una cita, tanto vía telefónica, presencial e incluso a través de Internet. Además, si el deportista se ausenta a una sesión, el centro le brindará la facilidad de recuperar la sesión con indicaciones específicas por parte del equipo.

En la siguiente tabla, se detallan los servicios que el centro va a ofrecer. Cabe resaltar que dependerá del deportista y del tipo de lesión que presente, para elaborar la mejor combinación en técnica y tiempo para el tratamiento. El fisioterapeuta será el responsable de armar el mejor plan de recuperación para el deportista, en base a su conocimiento y experiencia. 
Tabla 2.1

\section{Servicios ofrecidos por el CTFR}

\begin{tabular}{|c|c|c|}
\hline \multirow[t]{2}{*}{$\begin{array}{l}\text { Terapia } \\
\text { Física }\end{array}$} & $\begin{array}{l}\text { Agentes } \\
\text { Físicos }\end{array}$ & $\begin{array}{l}\text { Parte inicial del tratamiento de lesiones, tiene efectos sobre la inflamación y la } \\
\text { curación de tejidos y el dolor. } \\
\text { A continuación, se detallarán los agentes físicos a considerarse para el centro. Las } \\
\text { dos primeras, son medios que ayudan a poner en aviso las estructuras que van a ser } \\
\text { trabajadas posteriormente. Las siguientes tres, medios que disminuyen el proceso de } \\
\text { inflamación y estimula para que las estructuras dañadas se regeneren. Y, el último } \\
\text { agente físico se emplea para la recuperación de lesiones crónicas. } \\
\text { - Agentes térmicos: Aplicación de compresas de frío o calor. La primera de ellas } \\
\text { permite controlar la inflamación y el dolor para acelerar la recuperación después de } \\
\text { un golpe o lesión. Las compresas de calor aumentan la predisposición a la elasticidad } \\
\text { y facilita el trabajo posterior. Tiempo recomendado } 10 \text { a } 15 \text { minutos por sesión. } \\
\text { - Electroterapia: Estimulación eléctrica para producir una analgesia superficial para } \\
\text { acelerar y mejorar la rehabilitación del paciente. Tiempo recomendado de } 10 \text { a } 20 \\
\text { minutos. } \\
\text { - Ultrasonido terapéutico: Aplicación del dispositivo de ultrasonido que permite la } \\
\text { emisión de ondas de sonido para generar calor en las zonas profundas de los tejidos, } \\
\text { disminuyendo el proceso inflamatorio. Tiempo recomendado de } 5 \text { a } 10 \text { minutos. } \\
\text { - Láser terapéutico: Aplicación de láser en zonas muy puntuales para regenerar los } \\
\text { tejidos dañados. Tiempo recomendado de } 5 \text { a } 10 \text { minutos. } \\
\text { - Magnetoterapia: Tratamiento mediante campos magnéticos para la recuperación de } \\
\text { tejidos y regeneración de zonas afectadas. Tiempo recomendado de } 30 \text { minutos. } \\
\text { - Ondas de choque: Tratamiento no invasivo que favorece a la regeneración de } \\
\text { tejidos a través de una inflamación saludable, es decir, reagudizan lesiones crónicas } \\
\text { (aquellas que persisten más allá del tiempo normal para la recuperación de un tejido.) } \\
\text { para buscar solución mediante la estimulación. Tiempo recomendado de } 5 \text { a } 10 \\
\text { minutos. }\end{array}$ \\
\hline & $\begin{array}{l}\text { Terapia } \\
\text { Manual }\end{array}$ & $\begin{array}{l}\text { Técnicas manuales orientadas a la solución de disfunciones y/o alteraciones } \\
\text { biomédicas del movimiento normal humano. Pueden ser de dos tipos: } \\
\text { - Intrusivo: el método "punción seca" consiste en la aplicación de una aguja para } \\
\text { liberar el dolor en los puntos activadores del dolor en el músculo. } \\
\text { - No intrusivo: los masajes terapéuticos son técnicas y manipulaciones para devolver } \\
\text { la mecánica normal al cuerpo. } \\
\text { El tiempo adecuado para esta etapa del tratamiento es de } 20 \text { a } 30 \text { minutos. }\end{array}$ \\
\hline \multicolumn{2}{|c|}{ Rehabilitación Física } & $\begin{array}{l}\text { Considerado la esencia del tratamiento, pues se requiere de una adecuada } \\
\text { rehabilitación física para permitirle al deportista reanudar sus actividades y prevenir } \\
\text { lesiones futuras. } \\
\text { Consiste en una serie de ejercicios en busca de la recuperación de las capacidades } \\
\text { del paciente que ha sufrido alguna lesión y reincorporarlo a sus actividades de la } \\
\text { vida diaria. } \\
\text { Estos ejercicios se enfocan en la recuperación y fortalecimiento de músculos y } \\
\text { articulaciones. } \\
\text { El tiempo adecuado para esta tercera etapa del tratamiento es de } 30 \text { minutos. }\end{array}$ \\
\hline
\end{tabular}

Fuente: Hüter-Becker, (2005)

Las atenciones tendrán un horario accesible, es decir en las mañanas, de 6 am a 10 am, y un segundo horario en las noches, de 5 pm a 9 pm. Esto debido a que, durante 
la semana, el negocio debe estar acorde a las actividades de los deportistas y su disponibilidad para ser atendidos en horarios cómodos para ellos y que no interfieran con su cronograma diario. También, se atenderán los días sábados, de 6 am a 2 pm, para aquellas personas que no puedan asistir en día de semana. Cada sesión tendrá una duración aproximada de una hora, en la cual se tratarán las lesiones combinando las diferentes técnicas de terapia.

El público objetivo del proyecto, serán deportistas entre 15-59 años que requieran atención de fisioterapia y rehabilitación, a partir de lesiones ocasionadas por actividades deportivas y relacionadas. Se centrará el negocio, a las personas pertenecientes al nivel socioeconómico A y B, ya que son los mismos los que cuentan con la disposición y acceso directo a pagar este servicio especializado, el cual está caracterizado por su alto costo de consulta y atención.

\subsubsection{Principales características del servicio}

\subsubsection{Usos y propiedades}

El centro de terapia física y rehabilitación, estará orientado a deportistas aficionados y de alto rendimiento. Se atenderá a todos aquellos deportistas que presenten lesiones que requieran de un tratamiento fisioterapéutico para reanudar sus actividades y entrenamientos. A continuación, se presenta una lista con las lesiones más frecuentes en algunos deportes indicada por el Director de Servicios Biomédicos del Instituto Peruano del Deporte.

- Artes marciales: lesión de rodilla, esguince de tobillo/muñeca, desgarros, tendinitis en articulaciones, contusiones.

- Atletismo: lesión de rodilla, esguince de robillo, contracturas, distensiones, desgarros.

- Futbol: esguince de tobillo, contracturas, desgarros.

- Gimnasio: lesiones en articulaciones, desgarros, tendinitis.

- Vóley: lesión de rodilla, esguince de tobillo, inflamación en articulaciones, contracturas. 
El deportista será atendido por un médico especializado en deportes para evaluar su condición y a partir de ello, derivarlo a terapia física y/o rehabilitación física de ser necesario. Ambos, médico y fisioterapeuta, trabajarán en conjunto para tener un seguimiento del deportista y así garantizar una recuperación adecuada.

El tiempo de recuperación de cada deportista dependerá de muchos factores, tales como grado de lesión, continuidad en las sesiones de terapia programada y descanso del deportista de sus actividades deportivas. Una lesión leve podría recuperarse en 1 semana, mientras que una lesión grave, como un desgarro o rotura de ligamento podría necesitar hasta 6 meses de rehabilitación física.

El centro contará con una serie de máquinas especializadas para tratar directamente el dolor a través de la terapia de agentes físicos. Asimismo, para el servicio de terapia manual y rehabilitación física, que consiste en la recuperación hacia las máximas capacidades de los miembros afectos, se contará con equipamiento adicional.

El centro dispondrá de muletas y sillas de ruedas para facilitar el movimiento y traslado de los deportistas, así como también, contará con los accesos necesarios y adecuados para aquellos que requieran el uso de los mismos.

Por otro lado, se tendrán en cuenta las normas de defensa civil y se cumplirán todas las normas de seguridad. También, se contará con certificación que refiere a la salud y seguridad ocupacional desde el inicio de los servicios.

\subsubsection{Servicios sustitutos y complementarios}

Servicios sustitutos

El Instituto Peruano del Deporte (IPD) ofrece el servicio de terapia física y rehabilitación en el Centro Médico de La Videna, a través de la Dirección Nacional de Servicios Biomédicos (DINASEB), el cual consiste en un servicio gratuito para los deportistas calificados de alto nivel que pertenecen a las selecciones de los deportes afiliados.

Servicios complementarios

Como servicios complementarios a los ofrecidos en el centro de terapia física y rehabilitación, están los comerciantes de accesorios ortopédicos, los servicios de psicología y nutrición. 
Luego de sufrir una lesión deportiva, el deportista en algunos casos requiere de accesorios ortopédicos como rodilleras, tobilleras, musleras, entre otros, ya sea para disminuir el dolor mientras se continúa con la práctica o para inmovilizar el miembro afectado. Por otro lado, los servicios de psicología también son un aspecto importante, ya que la parte psicológica también trabaja en la recuperación del deportista. Esta se encarga de facilitar la reincorporación y el no abandono de la actividad física y el deporte.

Finalmente, el servicio de nutrición es un elemento complementario, enfocándose en el estado y las necesidades de los deportistas para su óptimo rendimiento. Esto se logra con 4 procesos fundamentales:

- Conocer los hábitos y frecuencia del consumo de alimentos para conocer el aporte nutricional de los alimentos ingeridos por los deportistas.

- Evaluación de los datos antropométricos necesarios para elaborar una dieta balanceada.

- Seguimiento durante el tratamiento para conocer la evolución de cada uno de los deportistas.

- Asesoramiento de los deportistas en cada evaluación para logar los objetivos.

\subsubsection{Determinación del área de influencia del servicio}

El servicio del presente proyecto, al ser un centro médico especializado en terapia física para deportistas, no tiene un radio de influencia determinado. Debido a que es un servicio escaso, las personas estarán dispuestas a ir a otro distrito distinto de donde residen o trabajan.

El área geográfica del proyecto será en Lima Metropolitana, ya que el centro será para personas deportistas de Lima Metropolitana. Todo deportista de provincia que desee solicitar los servicios tendrá que viajar a Lima, pues el estudio está enfocado a la población de Lima Metropolitana.

En la tabla 2.2 se muestra la distribución de distritos por zonas según la Asociación Peruana de Empresas de Investigación de Mercados (APEIM), que se basa en criterios de proximidad geográfica, características socioculturales, económicas y de estilo de vida similares. 
Tabla 2.2

Distribución de distritos por zonas

\begin{tabular}{|l|l|}
\hline Zona & Distritos \\
\hline Zona 1 & Ventanilla, Puente Piedra, Comas, Carabayllo \\
\hline Zona 2 & Independencia, Los Olivos, San Martín de Porras \\
\hline Zona 3 & San Juan de Lurigancho \\
\hline Zona 4 & Cercado, Rímac, Breña, La Victoria \\
\hline Zona 5 & Ate, Chaclacayo, Lurigancho, Santa Anita, San Luis, El Agustino \\
\hline Zona 6 & Jesús María, Lince, Pueblo Libre, Magdalena, San Miguel \\
\hline Zona 7 & Miraflores, San Isidro, San Borja, Santiago de Surco, La Molina \\
\hline Zona 8 & Surquillo, Barranco, Chorrillos, San Juan de Miraflores \\
\hline Zona 9 & Villa El Salvador, Villa maría del Triunfo, Lurín, Pachacamac \\
\hline Zona 10 & Callao, Bellavista, La Perla, La Punta, Carmen de la Legua \\
\hline
\end{tabular}

Fuente: APEIM, (2015)

Como ya se mencionó el proyecto no tiene un radio de influencia directo; sin embargo, el proyecto se enfocará en la zona 7 (definido en la tabla 2.2) debido a que es donde se concentra la mayor parte de la población con el poder adquisitivo requerido para asistir a los servicios planteados. Por lo tanto, se buscará localizar el centro cerca o en uno de los distritos que pertenecen a la zona mencionada.

\subsubsection{Análisis del sector}

Rivalidad entre las firmas establecidas en el sector: El Centro Médico Especializado OSI es una institución médica especializada en medicina física y rehabilitación, que entre sus servicios cuenta con terapia física deportiva. PhysioMove, centro de fisioterapia y rehabilitación, entre sus servicios brinda el de fisioterapia para deportistas. Asimismo, en el año 2013 se inauguró la Clínica Chacarilla del Complejo Hospitalario San Pablo destinada a la medicina física y rehabilitación, donde cuentan con el servicio de medicina deportiva. Las clínicas privadas también cuentan con sus respectivos departamentos de medicina física y rehabilitación como lo son la Clínica Anglo Americana (sede La Molina) y la Clínica Ricardo Palma (sede San Isidro). Se puede concluir que hay una rivalidad alta entre las firmas establecidas en el sector, pues el mercado peruano ya cuenta con centros especializados en los servicios que se desean implementar; sin embargo, la 
oferta aún no llega a abastecer la demanda de deportistas que requieren de los servicios médicos.

Poder de negociación de proveedores: Se requieren equipos fisioterapéuticos tecnológicos de alto precio, y actualmente el Perú cuenta con un limitado número de proveedores, como Phymed y J.P. Rehab S.R.L. Se puede indicar que el poder de negociación de los proveedores es alto debido al restringido número de proveedores actuales en el Perú, y al ser una nueva empresa aún no reconocida en el mercado no se podrá negociar de manera significativa la compra de los productos e instrumentos.

Riesgo de ingreso de competidores potenciales: Por un lado, la magnitud de la inversión no es significativamente elevada y es accesible a obtener préstamos para su desarrollo. Paralelamente, el servicio del proyecto requiere profesionales capacitados en medicina deportiva, la cual aún no está consolidada en el país. A partir de ello, se puede concluir que el riesgo de ingreso de competidores potenciales es medio, si bien el financiamiento es accesible, la especialización de fisioterapia deportiva aún no se ha desarrollado en el país en grandes proporciones.

Amenaza de productos sustitutos: Actualmente, el Instituto Peruano del Deporte ofrece el servicio de terapia física y rehabilitación en el Centro Médico de La Videna, el cual consiste en un servicio gratuito para los deportistas calificados de alto nivel que pertenecen a las selecciones de los deportes afiliados. Por otro lado, algunos gimnasios de Lima han implementado los programas de terapia física, como es el Wellness Centro Fitness y Terapia ubicado en La Molina; sin embargo, estos centros no cuentan con personal capacitado ni equipos para deportistas de alto rendimiento, siendo su público objetivo los miembros del gimnasio que en su mayoría son deportistas aficionados. Además, la acupuntura es una forma de medicina alternativa que se utiliza para aliviar dolores. Por lo tanto, la amenaza de productos sustitutos es media debido a que los deportistas calificados cuentan con un servicio de atención médica gratuito, y los gimnasios han empezado a ampliar su portafolio de servicios brindando programas de terapia física orientada a un segmento de deportistas.

Poder de negociación de los compradores: Los deportistas que acudan a los servicios de terapia física, buscan mejorar su condición física, ya sea por dolores existentes e incluso para prevenirlos, o desean rehabilitarse de alguna lesión deportiva. Actualmente, el mercado ofrece sólo 3 centros que atiendan las necesidades específicas 
de los deportistas de manera especializada y enfocada en la satisfacción del cliente, con infraestructura y personal del más alto nivel. Por este motivo, se puede expresar que el poder de negociación de los compradores es bajo, debido a que se trata de un tema de salud y buscarán la mejor manera de aliviar las molestias, por lo que estarán dispuestos a adquirir servicios médicos que garanticen buenos resultados.

\subsubsection{Determinación de la metodología que se empleará en la investigación}

\section{de mercado}

Se empleará una investigación de mercado para determinar la demanda del proyecto. Para ello, se analizará la demanda a través de los patrones de consumo actuales del servicio. Una vez demostrada la relevancia del tema, se determinará la demanda potencial con la información demográfica proporcionada por fuentes como IPSOS y APEIM. Dicha demanda, será expresada en número de sesiones por año para tener un mejor alcance para los temas posteriores. Luego, se empleará una adecuada segmentación del mercado, la cual nos mostrará un mercado meta y junto con los resultados de las encuestas realizadas al público objetivo, se tendrá una demanda proyectada para los cinco años del proyecto

\subsection{Análisis de la demanda}

\subsubsection{Cuantificación de los posibles mercados objetivos}

Para la cuantificación del posible mercado objetivo, se analizarán los patrones de consumo para determinar la relevancia del tema. Luego, se aplicará una encuesta apropiadamente segmentada, orientada a deportistas entre 15-59 años, que vivan en los distritos de Miraflores, San Isidro, San Borja, Santiago de Surco y La Molina. Una vez obtenidos los resultados, se realizarán los cálculos correspondientes para determinar y cuantificar los posibles mercados objetivos.

\subsubsection{Demanda potencial}

\subsubsection{Patrones de consumo del servicio}

El interés de las personas por realizar actividades físicas y deportivas está aumentando, y esto gracias a los distintos programas que vienen desarrollando entidades como el Instituto Peruano del Deporte (IPD), el Ministerio de Salud (MINSA) y las 
Municipalidades Distritales. La búsqueda del bienestar y salud es un factor importante hacia la práctica del deporte.

Año a año, ha ido aumentando la cantidad de participantes en actividades físicas, hacia el año 2015 el total era casi el doble de personas que en el 2012. Como se observa en la figura 2.1, hay una tendencia positiva en el número de participantes en actividades físicas, deportivas y recreativas en Lima Metropolitana entre el 2010 y 2015.

\section{Figura 2.1}

Evolución anual de deportistas (2010-2015)

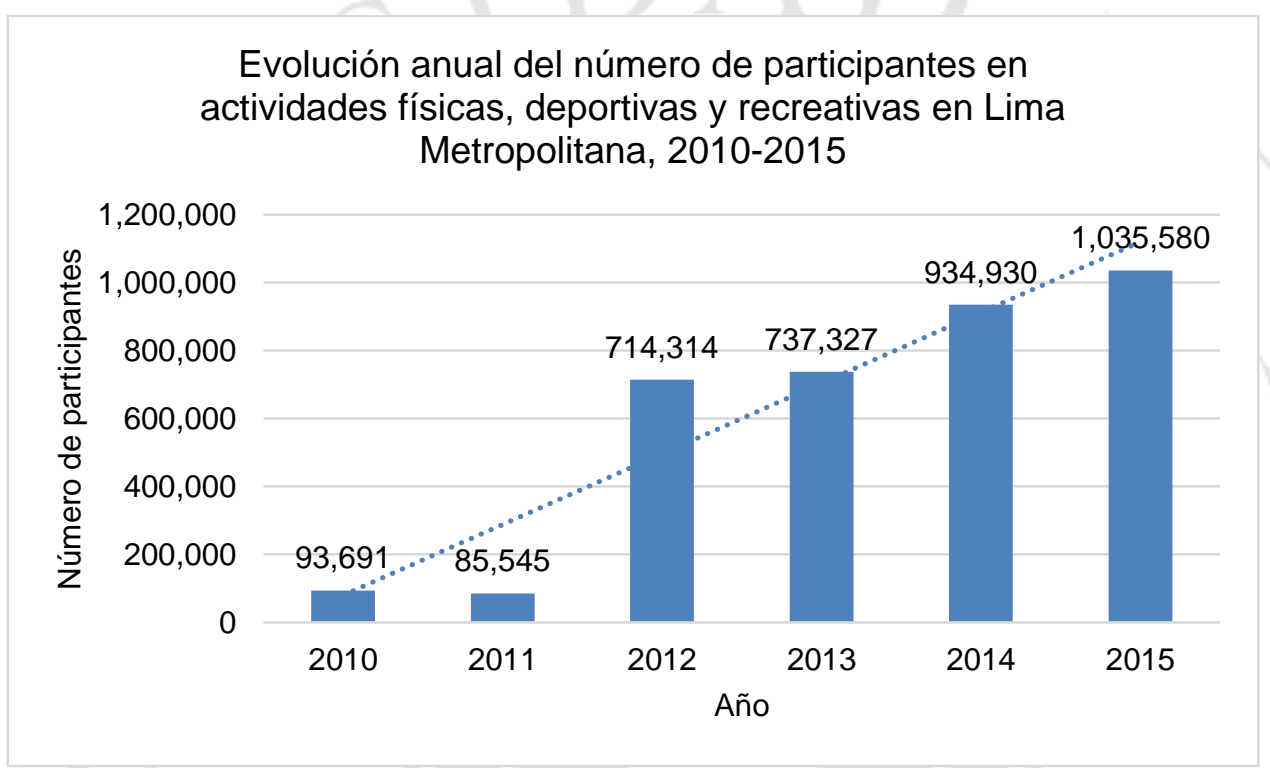

Fuente: IPD, (2016)

Un aspecto importante dentro de la práctica de actividades físicas es que ejercitarse de manera constante puede provocar dolores o lesiones que disminuyen el rendimiento e incluso puede limitar la actividad física. Es por ello, que se debe dar gran importancia al tratamiento temprano de dolores o lesiones, para continuar en el óptimo rendimiento de la actividad física.

En la figura 2.2 se observa una tendencia positiva en las atenciones por servicio médico que brinda la Dirección Nacional de Servicios Biomédicos (DINASEB) del IPD, mostrando un fenómeno aleatorio en el 2012. 
Figura 2.2

Evolución de atenciones por servicio médico (2010-2015)

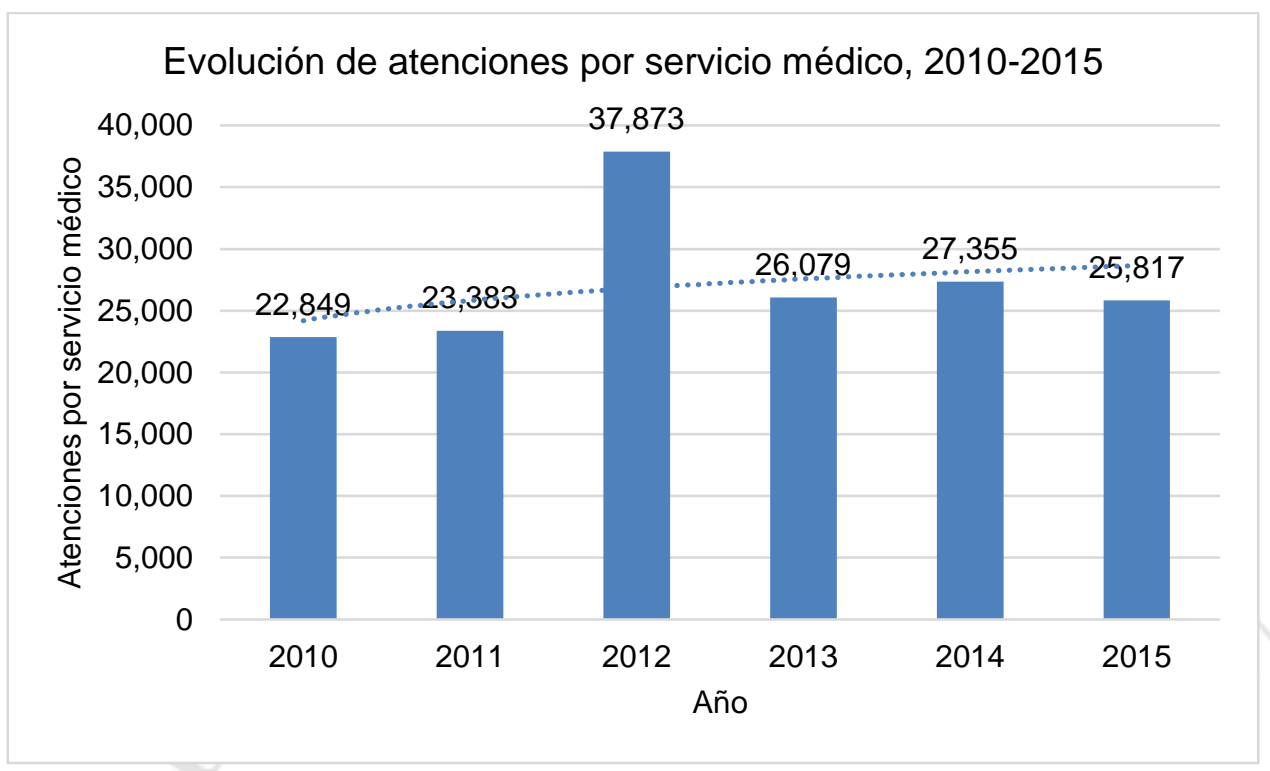

Fuente: IPD, (2016)

Adicionalmente, en la figura 2.3 se muestra que casi el $25 \%$ de las atenciones médicas realizadas en DINASEB son de Fisioterapia y Rehabilitación Física.

Figura 2.3

Distribución de atenciones médicas (2015)

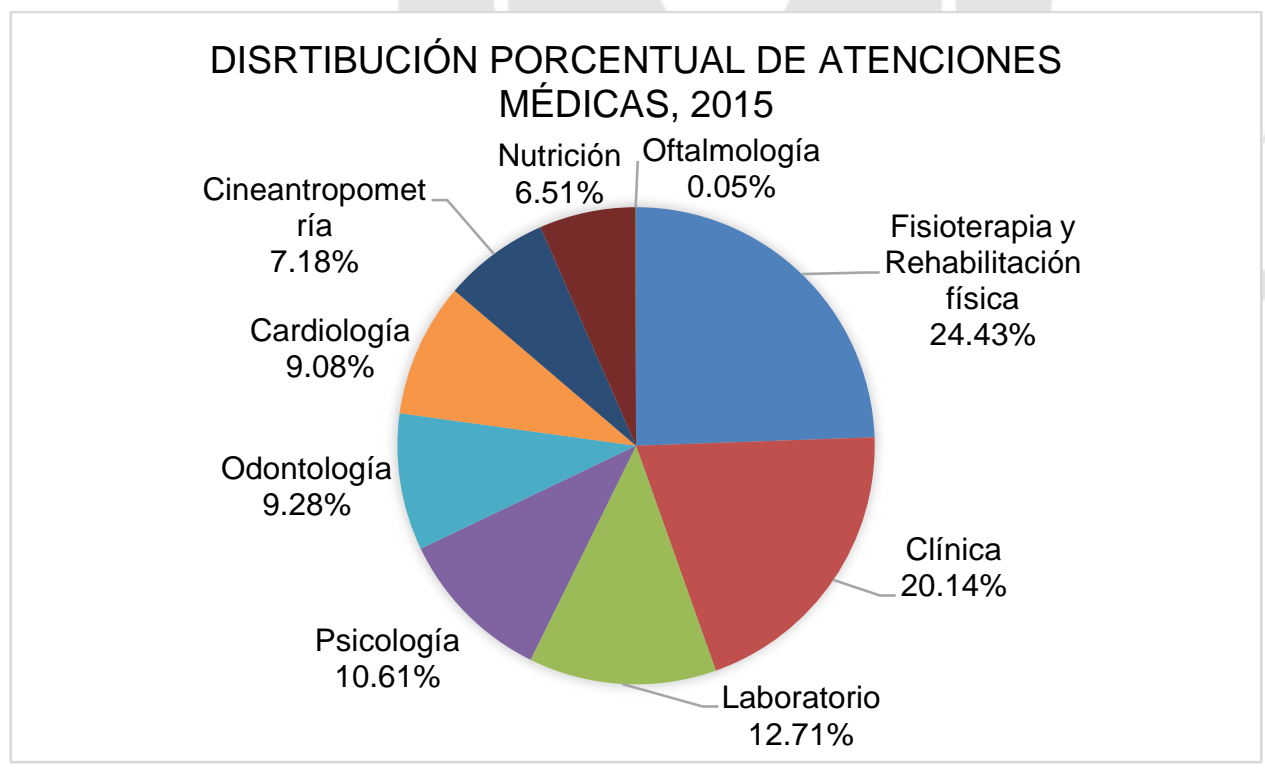

Fuente: IPD, (2016)

Así, se demuestra la relevancia del tema en cuestión, y el posible éxito del mismo como servicio exclusivo para deportistas aficionados y calificados de alto nivel, los 
mismos que mostrarán mayor interés en la práctica del mismo y la búsqueda de un mayor bienestar.

\subsubsection{Determinación de la demanda potencial}

Primero se presentará la población entre 15 y 59 años en los distritos de Miraflores, San Isidro, San Borja, Santiago de Surco y La Molina. En el informe "Perú: Población total al 30 de junio, por grupos quinquenales de edad, según departamento, provincia y distrito", publicado por el INEI, se obtiene información hasta el 2015. Para el presente trabajo, se proyectó la población en cada distrito, en base a los 10 últimos años, para calcular un estimado hacia el 2016.

Tabla 2.3

Población entre 15 y 59 años en los distritos de la zona 7 (2016)

\begin{tabular}{|l|l|}
\hline Distrito & Población entre 15-59 años \\
\hline Miraflores & 51.881 \\
\hline San Isidro & 33.052 \\
\hline San Borja & 72.021 \\
\hline Santiago de Surco & 229.067 \\
\hline La Molina & 117.771 \\
\hline Total & $\mathbf{5 0 3 . 7 9 2}$ \\
\hline
\end{tabular}

Fuente: INEI, (2016)

Según APEIM, los distritos mencionados pertenecen a la Zona 7. A continuación, se muestra la distribución de niveles socioeconómicos A y B en dicha zona. Se proyectó la población en cada distrito, en base a los 10 últimos años, para calcular un estimado hacia el 2016.

Tabla 2.4

Distribución NSE A y B en la zona 7 (\% personas)

\begin{tabular}{|l|l|l|}
\hline Zona & NSE A & NSE B \\
\hline Zona 7 (Miraflores, San Isidro, San Borja, Santiago de Surco, La Molina) & $\mathbf{3 0 , 4}$ & $\mathbf{5 0 , 8}$ \\
\hline
\end{tabular}

Fuente: APEIM, (2015)

De esta manera, considerando el total de personas entre 15 y 59 años que viven en la Zona 7 y la distribución de niveles, se calcula el número de personas pertenecientes a los NSE A y B en la zona mencionada. 


$$
503.792 \text { personas } \times\left(\frac{30,4+50,8}{100}\right)=409.173 \text { personas }
$$

Según el Ministerio de Salud, el 90\% de peruanos no practica ningún deporte. Esta situación se observa en las zonas urbanas, personas que trabajan no encuentran un tiempo en su agenda para practicar algún deporte. (Euromonitor, 2016)

Para la presente investigación se considerará el mismo porcentaje de personas que realiza deporte para determinar la demanda potencial. Es decir, se asumirá que el 10\% de la población sí practica deporte, están entre los rangos de edad establecidos y viven en los distritos del sector 7, con lo cual se obtiene la siguiente demanda potencial:

$$
\text { Demanda potencial }=409.173 \text { personas } \times \frac{10}{100}=\mathbf{4 0 . 9 1 7} \text { deportistas }
$$

\subsection{Análisis de la oferta}

\subsubsection{Análisis de la competencia. Número de operadores y ubicaciones}

Actualmente, Lima cuenta con centros médicos especializados en fisioterapia y rehabilitación física. En la siguiente tabla se muestra el número de establecimientos formales en los distritos de la Zona 7 mencionada anteriormente. 
Tabla 2.5

Número de operadores y ubicaciones

\begin{tabular}{|c|c|c|}
\hline Ubicación & Total operadores & Operadores \\
\hline Miraflores & 8 & $\begin{array}{l}\text { Centro Médico Especializado OSI } \\
\text { Clínica Delgado } \\
\text { Columna Center } \\
\text { Fisiosalud } \\
\text { Fisioterapia TMO } \\
\text { Kinesia - Fisioterapia y Rehabilitación } \\
\text { Medisport } \\
\text { Nopain }\end{array}$ \\
\hline San Isidro & & $\begin{array}{l}\text { Clínica Anglo Americana } \\
\text { Clínica Javier Prado } \\
\text { Clínica Ricardo Palma } \\
\text { Spine Center Peru } \\
\text { Trausa }\end{array}$ \\
\hline San Bc & 7 & $\begin{array}{l}\text { CEM Vital Center } \\
\text { Clínica Internacional } \\
\text { Consultorio Lic. Rocio Lavado Salazar } \\
\text { Crymef } \\
\text { Nopain } \\
\text { Physiomed } \\
\text { Sanna - Clínica San Borja }\end{array}$ \\
\hline Santiago de Surco & 4 & $\begin{array}{l}\text { Centro Médico Especializado OSI } \\
\text { Centro Osteopático Vida } \\
\text { Cerfid S.A.C. Jockey Salud } \\
\text { Clínica Chacarilla }\end{array}$ \\
\hline La Molina & 7 & $\begin{array}{l}\text { CEMDER } \\
\text { Clínica San Felipe } \\
\text { Corpus Et Vita } \\
\text { Fisio Life } \\
\text { Fisioterapia TMO } \\
\text { Medifas } \\
\text { Physiomove }\end{array}$ \\
\hline Total & 31 & \\
\hline
\end{tabular}

Fuente: Páginas Amarillas/Consulta a Especialista, (2016)

\subsubsection{Características del servicio ofertado por los principales competidores}

Como principales competidores, se tomarán aquellos centros que ofrezcan los servicios de terapia física deportiva como un programa determinado, así como aquellos que tengan mayor participación en los sectores al que pertenece el público objetivo. Entre los principales competidores está el Centro Médico Especializado OSI, institución médica especializada en medicina física y rehabilitación, que entre sus servicios cuenta con terapia física deportiva. PhysioMove, centro de fisioterapia y rehabilitación, entre sus servicios brinda el de fisioterapia para deportistas. Asimismo, en el año 2013 se inauguró 
la Clínica Chacarilla del Complejo Hospitalario San Pablo destinada a la medicina física y rehabilitación, donde cuentan, entre la gran variedad de servicios, con el servicio de medicina deportiva. Las clínicas privadas también cuentan con sus respectivos departamentos de medicina física y rehabilitación como lo son la Clínica Anglo Americana (sede La Molina) y la Clínica Ricardo Palma (sede San Isidro).

En la tabla 2.6, se muestra el número de atenciones por año de los principales competidores. Cabe mencionar que, entre los tres competidores, sólo el IPD ofrece exclusivamente el servicio de terapia física para deportistas de alto rendimiento pertenecientes a las distintas federaciones. En el caso del C.M.E. OSI y la clínica Chacarilla, el servicio de terapia deportiva está dentro del portafolio de servicios que se ofrecen.

Tabla 2.6

Número de atenciones de principales competidores

\begin{tabular}{|c|c|c|c|c|c|c|c|}
\hline Competidor & $\begin{array}{l}\text { Tiempo } \\
\text { promedio } \\
\text { por sesión }\end{array}$ & $\begin{array}{l}\text { Personal } \\
\text { disponible } \\
\text { (en } \\
\text { personas) }\end{array}$ & $\begin{array}{l}\text { Horas } \\
\text { disponibles } \\
\text { al día }\end{array}$ & $\begin{array}{l}\mathrm{N}^{\circ} \\
\text { sesiones } \\
\text { al día }\end{array}$ & $\begin{array}{l}\text { Días/ } \\
\text { semana }\end{array}$ & $\begin{array}{l}\text { Semanas/ } \\
\text { año }\end{array}$ & $\begin{array}{l}\mathrm{N}^{\circ} \\
\text { sesiones } \\
\text { al año }\end{array}$ \\
\hline \multirow{2}{*}{ C.M.E. OSI } & \multirow{2}{*}{1 hora } & \multirow[t]{2}{*}{7} & $\begin{array}{ll}\text { L-V: } & 14 \\
\text { horas } & \end{array}$ & 98 & \multirow[t]{2}{*}{$6(\mathrm{~L}-\mathrm{S})$} & \multirow[t]{2}{*}{52} & \multirow{2}{*}{26.936} \\
\hline & & & S: 4horas & 28 & & & \\
\hline IPD & 1 hora & 3 & 9 horas & 27 & 5 & 52 & 7.020 \\
\hline $\begin{array}{l}\text { Clínica } \\
\text { Chacarilla }\end{array}$ & 1 hora & 10 & 17 horas & 170 & 6 & 52 & 53.040 \\
\hline
\end{tabular}

Elaboración propia

\subsubsection{Planes de ampliación existentes}

Hasta la fecha no se conoce de algún plan exacto de ampliación; sin embargo, como se mencionó anteriormente, algunos gimnasios en Lima han estado optando por un nuevo servicio adicional que es el de terapia física y rehabilitación.

\subsection{Determinación Demanda para el proyecto}

\subsubsection{Segmentación del mercado}

Para poder llegar de manera más eficiente y eficaz a los deportistas, se ha realizado una segmentación del mercado demográfica, geográfica y psicográfica. 
Demográficamente, el proyecto se enfocará en personas, tanto hombres como mujeres, entre 15 y 59 años, debido a que es el rango de edad que mayor deporte practica y están más propensos a lesionarse por la intensidad de la actividad. Asimismo, se considerará el nivel socioeconómico de las personas que viven en los distritos elegidos, los cuales serán A y B, ya que cuentan con la disposición y acceso directo a pagar este servicio especializado de alto costo de atención.

En cuanto a la segmentación geográfica, se seleccionó la zona 7 (Miraflores, San Isidro, San Borja, Santiago de Surco y La Molina) debido a que la mayoría de personas que viven en esos distritos cuentan con el poder adquisitivo necesario para cubrir los gastos del servicio.

Finalmente se realizó una segmentación psicográfica por estilo de vida, esto es, las personas que practican deporte, debido a que el servicio será orientado a deportistas aficionados y calificados de alto nivel.

\subsubsection{Selección de mercado meta}

\subsubsection{Diseño y Aplicación de Encuestas}

Para determinar la viabilidad del mercado se formuló una encuesta (Anexo 1) que luego fue respondida por 100 personas. La encuesta se realizó considerando los límites establecidos según el público objetivo. A continuación, se muestran los resultados obtenidos.

Figura 2.4

Resultados de las encuestas

1.- ¿En cuál de los siguientes rangos de edad, se encuentra usted?

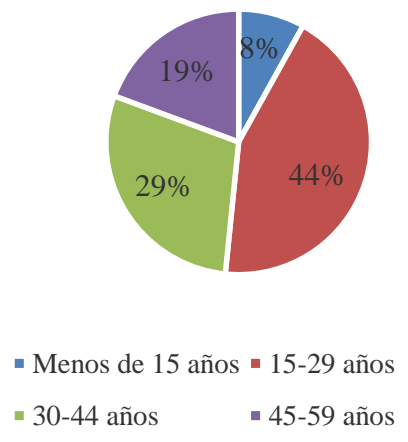

2.- ¿En qué distrito vive?

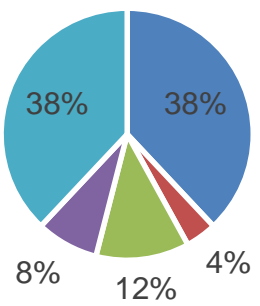

- La Molina - Miraflores

- San Borja - San Isidro

- Santiago de Surco 
3.- Indique el deporte que practica

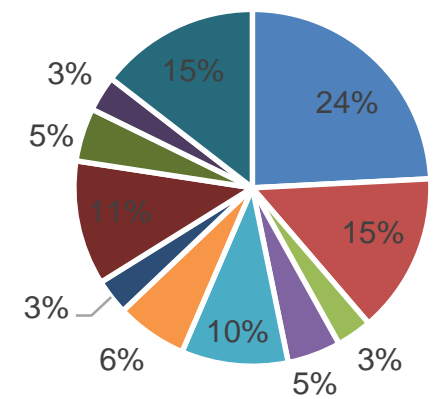

- Artes Marciales

- Atletismo / Correr - Bmx

- Bowling

- Futbol

- Gimnasio

- Natación

- Otros

- Surf

- Tenis de Mesa

- Voley

4-. ¿Cuántas veces a la semana practica deporte?

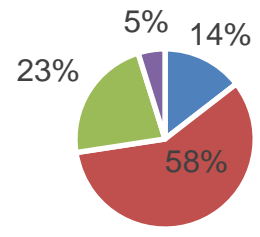

- 1-2 veces por semana

- 3-4 veces por semana

- 5-6 veces por semana

- Todos los días de la semana

6.- ¿Durante la práctica deportiva, ha sufrido alguna lesión?

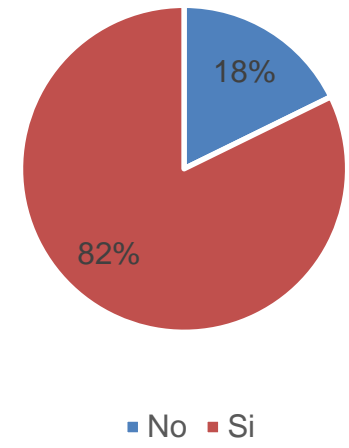

5.- ¿Cuántas horas a la semana practica deporte aproximadamente?

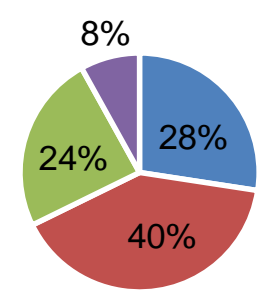

- Menos de 6 horas - De 6 a 20 horas

- De 20 a 30 horas - Más de 30 horas

7.- ¿Recurrió a algún servicio de terapia física y/o rehabilitación física?

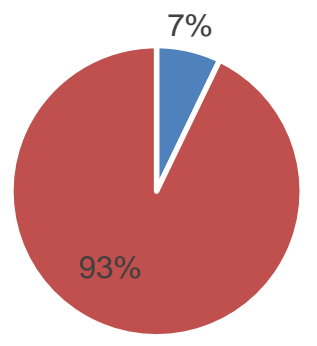

- No - Si 


\section{1.- Especificar lesión}

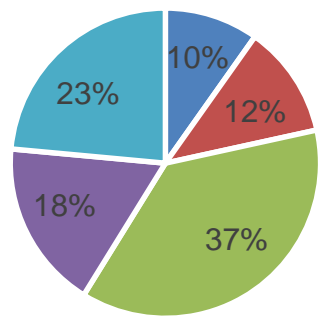

- Contractura muscular - Desgarro muscular - Esguince - Tendinitis = Otros

8.- ¿En dónde tomo dicho servicio?

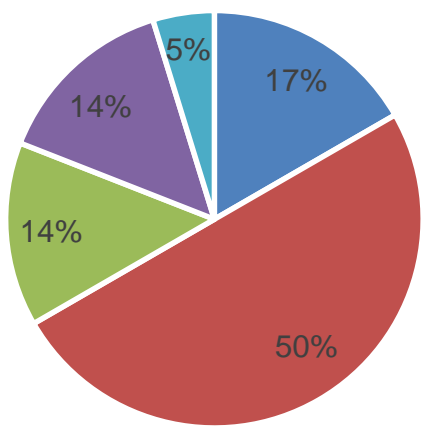

- Centro médico especializado - Clinica particular - Doctor particular - Videna - Otros

10.- ¿Cómo se enteró de ese lugar?

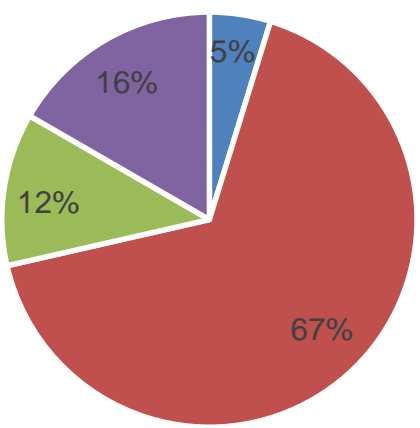

- Internet (redes sociales) - Recomendación de algún conocido - Seguro médico - Otros 
11.- Si sufriera alguna lesión durante la práctica deportiva, ¿estaría dispuesto a ir a un centro de terapia física con un servicio personalizado orientado al paciente y que cuente con equipos de última tecnología?

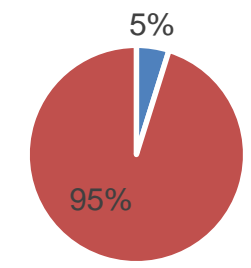

$-\mathrm{No} \cdot \mathrm{Si}$

12.- ¿Cuánto estaría dispuesto usted a pagar por una sesión de 1 hora de terapia física y/o rehabilitación física?

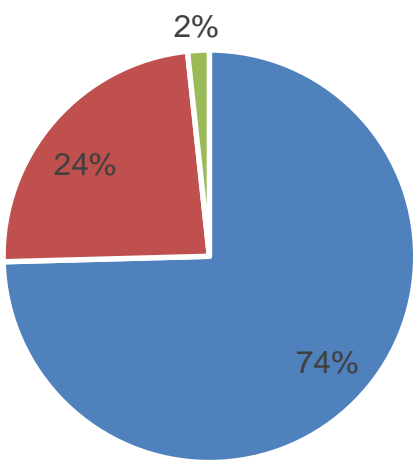

- Menos de 100 soles - Entre 100 y 150 soles "Más de 150 soles

Elaboración propia

Se calculará el mercado meta del proyecto del año 0 (2016), utilizando el porcentaje de deportistas que practican entre 5 a 7 días y más de 20 horas semanales, así como aquellos deportistas que han sufrido lesiones durante la práctica.

$$
\text { Mercado } \text { meta }_{2016}=40.917 \text { deportistas } \times \frac{17}{100} \times \frac{82}{100}=5.703 \text { deportistas lesionados }
$$

\subsubsection{Proyección de la demanda}

Para la proyección de la demanda se tomará en cuenta el porcentaje de crecimiento de la población y de la distribución por niveles socioeconómicos A y B en los distritos antes mencionados, a través de los censos realizados años atrás, recopilados por INEI. De esta manera, se obtiene el número de habitantes en los NSE A y B proyectado y, se asumirá 
que el porcentaje de las personas que practican deporte. El procedimiento será el mismo que el presentado en la determinación de la demanda potencial.

Primero, se calculará la proyección del crecimiento de la población de la zona 7 , entre los 15 y 59 años, hacia el 2021. Para determinar el tipo de distribución estadística a utilizar para la proyección, se evaluó la varianza $\left(\mathrm{R}^{2}\right)$ para determinar cuál modelo se ajusta más a los datos.
Linear
$\mathrm{y}=5213.2 \mathrm{x}+472515$
$\mathrm{R}^{2}=\underline{99.98 \%}$
Exponencial
$\mathrm{y}=472704 \mathrm{e}^{0.0107 \mathrm{x}}$
$\mathrm{R}^{2}=99.96 \%$
Logarítmica
$y=12663 \ln (x)+476030$
$\mathrm{R}^{2}=95.29 \%$
Potencia
$480101 x^{0.026}$
$\mathrm{R}^{2}=94.06 \%$

Se utilizará la distribución lineal debido a que tiene una varianza más cerca al $100 \%$.

Tabla 2.7

Población histórica entre 15 y 59 años en los distritos de la zona 7

\begin{tabular}{|l|l|}
\hline Año & Población \\
\hline 2011 & 477.614 \\
\hline 2012 & 482.990 \\
\hline 2013 & 488.274 \\
\hline 2014 & 493.440 \\
\hline 2015 & 498.455 \\
\hline
\end{tabular}

Fuente: INEI, (2016)

Tabla 2.8

Población proyectada entre 15 y 59 años en los distritos de la zona 7

\begin{tabular}{|l|l|}
\hline Año & Población \\
\hline 2016 & 503.792 \\
\hline 2017 & 509.006 \\
\hline 2018 & 514.219 \\
\hline 2019 & 519.432 \\
\hline 2020 & 524.647 \\
\hline 2021 & 529.858 \\
\hline
\end{tabular}

Elaboración propia

Luego, con los datos históricos de la distribución de NSE A y B en la zona 7, se proyectará el crecimiento de las personas pertenecientes a dichos niveles. Para determinar el tipo de distribución estadística a utilizar para la proyección, se evaluó la varianza $\left(\mathrm{R}^{2}\right)$. 
NSE A

Linear

$$
\mathrm{y}=-0.0043 \mathrm{x}+0.3225 \quad \mathrm{R}^{2}=88.26 \%
$$

Exponencial

$\mathrm{y}=0.3226 \mathrm{e}^{-0.014 \mathrm{x}}$

$\mathrm{R}^{2}=88.57 \%$

Logarítmica

$\mathrm{y}=-0.01 \ln (\mathrm{x})+0.3194$

$\mathrm{R}^{2}=95.49 \%$

Potencia

$\mathrm{y}=0.3194 \mathrm{x}^{-0.031}$

$\mathrm{R}^{2}=\underline{95.56 \%}$

Para el NSE A. se utilizará la distribución potencia debido a que tiene una varianza más cerca al $100 \%$.

NSE B

Linear

$$
\mathrm{y}=0.0515 \mathrm{x}+0.287
$$$$
\mathrm{R}^{2}=94.30 \%
$$

Exponencial

$$
\mathrm{y}=0.298 \mathrm{e}^{0.1289 \mathrm{x}}
$$$$
\mathrm{R}^{2}=91.48 \%
$$

Logarítmica$$
\mathrm{R}^{2}=\underline{99.50 \%}
$$

Potencia

$$
\mathrm{y}=0.1136 \ln (\mathrm{x})+0.3255
$$$$
\mathrm{R}^{2}=98.77 \%
$$

Para el NSE B. se utilizará la distribución logarítmica debido a que tiene una varianza más cerca al $100 \%$.

Tabla 2.9

Distribución histórica de niveles en la zona 7 (\% personas)

\begin{tabular}{|l|l|l|l|}
\hline Año & NSE A & NSE B & Total \\
\hline 2011 & 32,0 & 32,3 & 64,3 \\
\hline 2012 & 32,0 & 32,3 & 64,3 \\
\hline 2013 & 31,1 & 41,1 & 72,2 \\
\hline 2014 & 31,0 & 44,6 & 75,6 \\
\hline 2015 & 30,6 & 48,3 & 78,9 \\
\hline
\end{tabular}

Fuente: APEIM, (2015)

Tabla 2.10

Distribución proyectada de niveles en la zona 7 (\% personas)

\begin{tabular}{|l|l|l|l|}
\hline Año & NSE A & NSE B & Total \\
\hline 2016 & 30,4 & 50,8 & 81,2 \\
\hline 2017 & 30,2 & 52,9 & 83,1 \\
\hline 2018 & 30,1 & 54,7 & 84,7 \\
\hline 2019 & 29,9 & 56,2 & 86,1 \\
\hline 2020 & 29,8 & 57,5 & 87,3 \\
\hline 2021 & 29,7 & 58,7 & 88,4 \\
\hline
\end{tabular}

Elaboración propia 
Se considerará al año 2016 como el año 0, 2017 como año 1 y así sucesivamente hasta llegar al quinto año del proyecto que será el 2021. Con las proyecciones de la población y distribución de NSE en los distritos de la zona 7, se proyecta el mercado meta la cual muestra el número de deportistas que podrían asistir al centro planteado, aquellos que sufren lesiones y requieren de atención de fisioterapia y/o rehabilitación:

Tabla 2.11

Mercado meta, 2016-2021 ( $\mathrm{N}^{\circ}$ deportistas)

\begin{tabular}{|l|l|l|l|l|l|l|}
\hline Año & 2016 & 2017 & 2018 & 2019 & 2020 & 2021 \\
\hline Mercado meta & 5.703 & 5.897 & 6.072 & 6.235 & 6.387 & 6.532 \\
\hline
\end{tabular}

Elaboración propia

\subsubsection{Determinación de la demanda del proyecto}

Para determinar la demanda del proyecto, se tomarán en cuenta la intención e intensidad de asistencia al centro propuesto.

Según las encuestas realizadas, el $95 \%$ está dispuesto a invertir en su pronta recuperación ante una lesión, asistiendo a un centro de terapia física con un servicio personalizado orientado al deportista y que cuenta con equipos de última tecnología, características de diferenciación del centro. Este valor es elevado, ya que los deportistas necesitan recuperar sus dolencias y lesiones en corto plazo para retomar sus actividades físicas.

En cuanto a la intensidad de asistencia, esta será de $100 \%$ debido a que el deportista irá el total de número de sesiones que el fisioterapeuta indique para recuperar su condición física. El fisioterapeuta a través del diagnóstico y en base a su conocimiento y experiencia, calculará un número ideal de sesiones para que el deportista regrese a sus niveles óptimos de rendimiento.

Demanda para el proyecto ${ }_{2016}=5.703$ deportistas $\times \frac{95}{100} \times \frac{100}{100}=\mathbf{5 . 4 1 7}$ deportistas

Para hallar la demanda del proyecto, se considerará una participación del mercado del $10 \%$ de la población de deportistas que estén dispuestos a asistir al centro de terapia y rehabilitación física en cuestión.

$$
\text { Demanda para el proyecto }{ }_{2016}=5.417 \text { deportistas } \times \frac{10}{100}=\mathbf{5 4 1} \text { deportistas }
$$


Finalmente, para hallar la demanda del proyecto en número de sesiones, se considerará un promedio de 20 sesiones por deportista, valor obtenido a través de la consulta a especialista en base a su experiencia en terapia física y rehabilitación a deportistas. Asimismo, se puede observar que en promedio los deportistas encuestados asistieron a 20 sesiones de terapia física (pregunta 7), corroborando así, el valor indicado previamente.

$$
\text { Demanda para el proyecto }{ }_{2016}=541 \text { deportistas } \times 20 \frac{\text { sesiones }}{\text { deportista }}=\mathbf{1 0 . 8 2 0} \text { sesiones }
$$

Utilizando la misma fórmula para los siguientes cinco años, se obtiene la demanda proyectada, tanto en número de deportistas como número de sesiones:

\section{Tabla 2.12}

Demanda proyectada

\begin{tabular}{|l|l|l|l|l|l|l|}
\hline Año & 2016 & 2017 & 2018 & 2019 & 2020 & 2021 \\
\hline $\mathrm{N}^{\circ}$ deportistas & 541 & 560 & 576 & 592 & 606 & 620 \\
\hline $\mathrm{N}^{\circ}$ sesiones & 10.820 & 11.200 & 11.520 & 11.840 & 12.120 & 12.400 \\
\hline
\end{tabular}

Elaboración propia

\subsection{Definición de la Estrategia de Comercialización}

\subsubsection{Políticas de plaza}

La plaza incluye actividades de la empresa orientadas a que el servicio esté disponible para el público objetivo. En cuanto a la ubicación, no es indispensable que el centro propuesto esté en una avenida a la vista del público, pues al ser un servicio médico y escaso es recomendable situarse en un ambiente sin contaminación auditiva. También se debe tener en cuenta el fácil acceso de los deportistas; por ejemplo, en caso que un deportista requiera el uso de silla de ruedas u otra ayuda técnica. Asimismo, dado que el principal medio de publicidad es el sistema "boca a boca" (a detallar en el siguiente punto) no se requiere de anuncios visuales fuera del local.

\subsubsection{Publicidad y promoción}

Así como se observó en los resultados de la encuesta, el $67 \%$ de los encuestados respondieron que se enteraron de los centros a los que asistieron mediante la recomendación de algún conocido. Esto quiere decir que el principal canal de publicidad 
del tipo de negocio es a través del sistema conocido como "boca en boca". Y hoy en día, gracias al gran alcance de los medios sociales, la difusión de un tema puede llegar más lejos del simple círculo de amigos que lo rodea, siendo el márketing viral uno de los autores de la publicidad. El márketing viral es la versión en Internet del márketing de boca en boca. Así, nuestro CTRF contará con presencia en Facebook y con su propia página web en la cual se detallarán los servicios que brindamos, horarios, contactos, entre otros.

El principal elemento para lograr una adecuada publicidad es el resultado obtenido. Es por ello, que se enfocará en brindar un servicio con la máxima calidad y tecnología para la total satisfacción del deportista. Y si a ello, se agrega referencias, se podría percibir un mayor éxito en la difusión del centro en el mercado. Con referencias, quiere decir a tener deportistas que sean íconos o imagen del público objetivo, en este caso, deportistas de alto rendimiento que son reconocidos a nivel nacional.

Por lo tanto, si se tiene como imagen a deportistas destacados que han recibido un buen servicio en el centro propuesto y con resultados positivo, se logrará que las personas recomienden a sus conocidos el servicio que se está ofreciendo.

\subsubsection{Análisis de precios}

\subsubsection{Precios actuales}

El centro de terapia física y rehabilitación contará con dos niveles de precios. El primero será para la cita con el fisioterapeuta quien hará el diagnóstico y asignará el tratamiento correspondiente. El segundo, es el precio de la cita para la terapia en sí, es decir una vez que ya inició el tratamiento. Este segundo pago, se efectuará cada vez que el deportista asista al centro para continuar con su tratamiento.

Para determinar el precio, a través de la encuesta se determinó cuánto estaría dispuesto el deportista a pagar por una sesión de terapia. El 74\% respondió menos de 100 soles, mientras que al 24\% le pareció adecuado pagar entre 100 y 150 soles. Adicionalmente, se tomará como referencia el precio de los principales competidores. 
Tabla 2.13

Precio promedio por cita de las principales competencias

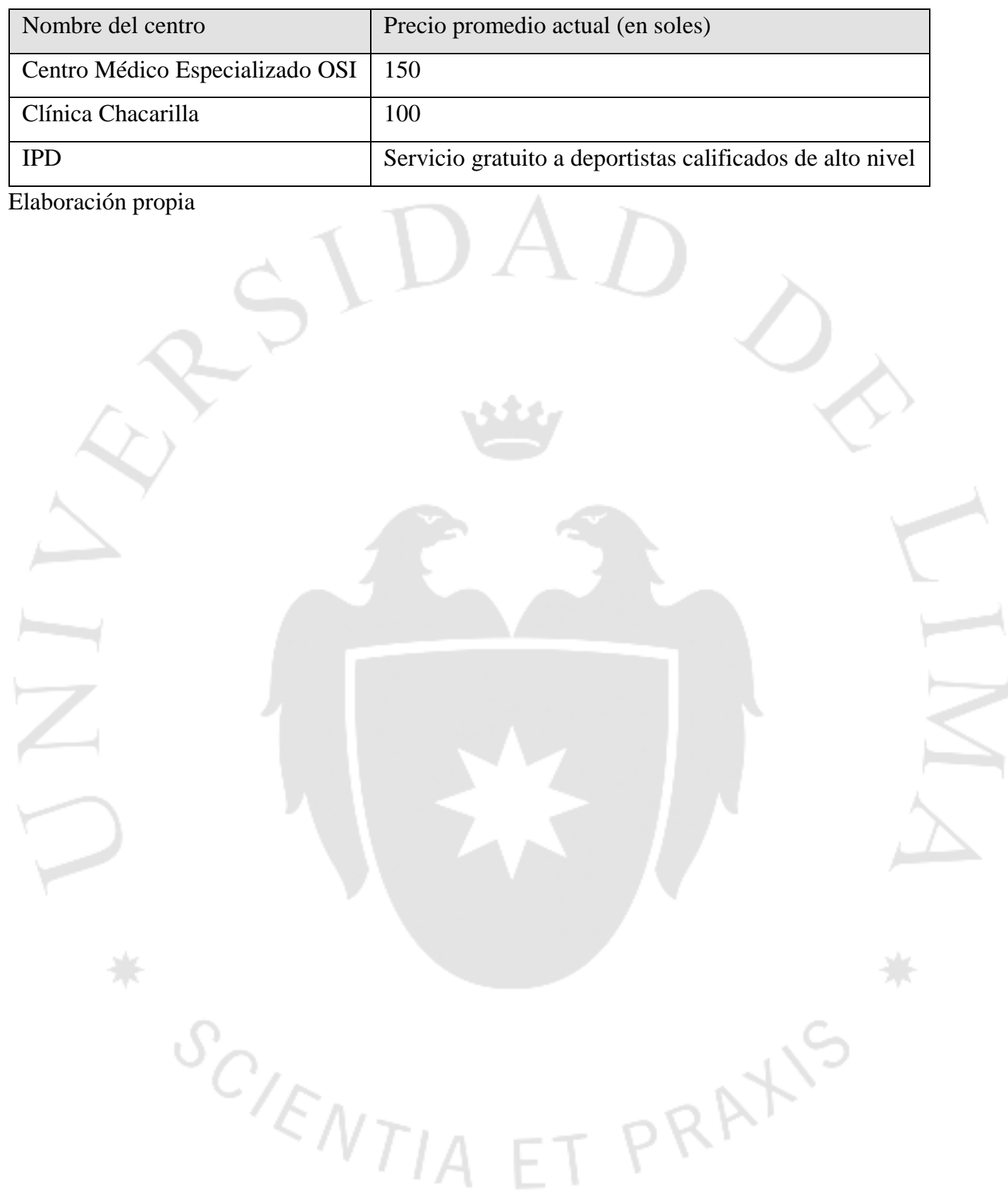




\section{CAPÍTULO III. LOCALIZACIÓN DEL SERVICIO}

En cuanto a la macro localización, se determinó a través del factor preferente y el estudio de mercado, que el CTRF se ubicará en Lima Metropolitana. A continuación, se realizará el análisis de micro localización.

\subsection{Identificación y análisis detallado de los factores de localización}

Para determinar la ubicación del centro de rehabilitación y terapia física se considerarán 5 factores, cuyo detalle se presenta a continuación:

a) Ubicación de la competencia (UC): la ubicación de la competencia es un factor importante para determinar la localización del centro ya que influye en la participación del mercado. Se considerará el número de operadores en cada distrito.

b) Disponibilidad de locales $(D L)$ : la disponibilidad de terrenos en cada distrito mostrará la facilidad o dificultad de encontrar una ubicación óptima del servicio según las políticas de plaza.

c) Costo del local (CL): para el costo de alquiler del local se considerará el promedio del precio de soles por $\mathrm{m}^{2}$ del precio de locales en cada distrito.

d) Facilidades municipales (FM): en cuanto a las facilidades municipales, se considerarán los costos de las licencias de edificación y funcionamiento.

e) Seguridad ciudadana (SC): la seguridad ciudadana es un factor importante en la elección de la localización, al elegir un distrito seguro se evitarán robos o delitos tanto al centro como a los pacientes. La seguridad ciudadana se puede medir en términos de percepción de inseguridad de parte de los habitantes del distrito, victimización (personas que han sido víctimas de un delito en los últimos 6 meses) y nivel de satisfacción con el serenazgo respectivo de cada distrito. 


\subsection{Identificación y descripción de las alternativas de localización}

Como ha sido mencionado en el Capítulo II, el área geográfica del proyecto será en Lima

Metropolitana. Si bien el proyecto no tiene un radio de influencia directo, este se enfocará en la zona 7, por lo tanto, se buscará localizar el centro en uno de los distritos pertenecientes a la zona mencionada. A continuación, se describirán los distritos señalados con respecto a los factores de localización establecidos:

Tabla 3.1

Descripción de alternativas

\begin{tabular}{|c|c|c|c|c|c|}
\hline Distrito & $\begin{array}{l}\text { Ubicación de la } \\
\text { competencia (Páginas } \\
\text { Amarillas, 2016) }\end{array}$ & $\begin{array}{c}\text { Costo } \\
\text { promedio } \\
\text { alquiler del } \\
\text { local } \\
\text { (Urbania, } \\
\text { 2016) }\end{array}$ & $\begin{array}{l}\text { Disponibilidad } \\
\text { de locales } \\
\text { (Urbania, } \\
\text { 2016) }\end{array}$ & $\begin{array}{l}\text { Facilidades } \\
\text { Municipales }\end{array}$ & $\begin{array}{c}\text { Seguridad Ciudadana } \\
\text { (Lima Como Vamos, } \\
\text { 2015) }\end{array}$ \\
\hline Miraflores & $\begin{array}{l}\text { - Centro Médico } \\
\text { Especializado OSI } \\
\text { - Clínica Delgado } \\
\text { - Columna Center } \\
\text { - Fisiosalud } \\
\text { - Fisioterapia TMO } \\
\text { - Kinesia } \\
\text { - Medisport } \\
\text { - Nopain }\end{array}$ & $34,1 \mathrm{~S} / . / \mathrm{m} 2$ & $\begin{array}{l}200 \text { locales } \\
\text { aprox. }\end{array}$ & $\begin{array}{l}\text { Costo de } \\
\text { licencia de } \\
\text { funcionamiento } \\
\text { : S/. 411,63 } \\
\text { Tiempo de } \\
\text { demora: } 15 \text { días } \\
\text { hábiles }\end{array}$ & $\begin{array}{l}\text { Percepción inseguridad } \\
\text { ciudadana: } 34,0 \% \\
\text { Índice de victimización: } \\
29,8 \% \\
\text { Nivel de satisfacción } \\
\text { con su serenazgo: } \\
81,6 \% \text {. }\end{array}$ \\
\hline San Isidro & $\begin{array}{l}\text { - Clínica Anglo } \\
\text { Americana } \\
\text { - Clínica Javier Prado } \\
\text { - Clínica Ricardo } \\
\text { Palma } \\
\text { - Spine Center Peru } \\
\text { - Trausa }\end{array}$ & $\begin{array}{l}35,6 \mathrm{~S} / \\
/ \mathrm{m} 2\end{array}$ & $\begin{array}{l}130 \text { locales } \\
\text { aprox. }\end{array}$ & $\begin{array}{l}\text { Costo de } \\
\text { licencia de } \\
\text { funcionamiento } \\
\text { : S/. 391,00 } \\
\text { Tiempo de } \\
\text { demora: } 15 \text { días } \\
\text { hábiles }\end{array}$ & $\begin{array}{l}\text { Percepción inseguridad } \\
\text { ciudadana: } 21,4 \% \\
\text { Índice de victimización: } \\
30,1 \% \\
\text { Nivel de satisfacción } \\
\text { con su serenazgo: } 88,3 \%\end{array}$ \\
\hline San Borja & $\begin{array}{l}\text { - CEM Vital Center } \\
\text { - Clínica Internacional } \\
\text { - Consultorio Lic. } \\
\text { Rocio Lavado Salazar } \\
\text { - Crymef } \\
\text { - Nopain } \\
\text { - Physiomed } \\
\text { - Sanna - Clínica San } \\
\text { Borja }\end{array}$ & $\begin{array}{l}26,97 \\
\text { S/./m2 }\end{array}$ & $\begin{array}{l}50 \text { locales } \\
\text { aprox. }\end{array}$ & $\begin{array}{l}\text { Costo de } \\
\text { licencia de } \\
\text { funcionamiento } \\
\text { : S/. } 693,51 \\
\text { Tiempo de } \\
\text { demora: } 15 \text { días } \\
\text { calendario }\end{array}$ & $\begin{array}{l}\text { Percepción inseguridad } \\
\text { ciudadana: } 32,3 \% \\
\text { Índice de } \\
\text { victimización: } 28,3 \% \text {. } \\
\text { Nivel de satisfacción } \\
\text { con su serenazgo: } 77 \% \text {. }\end{array}$ \\
\hline $\begin{array}{l}\text { Santiago } \\
\text { de Surco }\end{array}$ & $\begin{array}{l}\text { - Centro Médico } \\
\text { Especializado OSI } \\
\text { - Centro Osteopático } \\
\text { Vida } \\
\text { - Cerfid S.A.C. Jockey } \\
\text { Salud } \\
\text { - Clínica Chacarilla } \\
\end{array}$ & $\begin{array}{l}22,94 \\
\text { S/./m2 }\end{array}$ & $\begin{array}{l}130 \text { locales } \\
\text { aprox. }\end{array}$ & $\begin{array}{l}\text { Costo de } \\
\text { licencia de } \\
\text { funcionamiento } \\
\text { : S/. } 279,00 \\
\text { Tiempo de } \\
\text { demora: } 15 \text { días } \\
\text { hábiles }\end{array}$ & $\begin{array}{l}\text { Percepción inseguridad } \\
\text { ciudadana: } 43,5 \% \\
\text { Índice de victimización: } \\
35 \% \text {. } \\
\text { Nivel de satisfacción } \\
\text { con su serenazgo: } 75 \% \text {. }\end{array}$ \\
\hline La Molina & $\begin{array}{l}\text { - CEMDER } \\
\text { - Clínica San Felipe } \\
\text { - Corpus Et Vita } \\
\text { - Fisio Life } \\
\text { - Fisioterapia TMO } \\
\text { - Medifas } \\
\text { - Physiomove }\end{array}$ & $24,8 \mathrm{~S} / . / \mathrm{m} 2$ & $\begin{array}{l}50 \text { locales } \\
\text { aprox. }\end{array}$ & $\begin{array}{l}\text { Costo de } \\
\text { licencia de } \\
\text { funcionamiento } \\
: \text { S/. 391,00 } \\
\text { Tiempo de } \\
\text { demora: } 10 \text { días } \\
\text { hábiles } \\
\end{array}$ & $\begin{array}{l}\text { Percepción inseguridad } \\
\text { ciudadana: } 34,6 \% \\
\text { Índice de victimización: } \\
35 \% \text {. } \\
\text { Nivel de satisfacción } \\
\text { con su serenazgo: } \\
64.3 \% \text {. }\end{array}$ \\
\hline
\end{tabular}

Fuente: Municipalidades de Lima, Página Amarillas, Urbania, (2016) 


\subsection{Evaluación y selección de localización}

Para evaluar y seleccionar la localización de la planta se utilizará el método de Ranking de Factores. En primer lugar, se analizará el nivel de importancia relativa de cada factor para asignarle una ponderación relativa:

Tabla 3.2

Importancia relativa de factores

\begin{tabular}{|c|c|c|c|c|c|c|c|}
\hline & UC & CL & DL & FM & SC & Conteo & Ponderación \\
\hline UC & & 0 & 0 & 1 & 0 & 1 & $9 \%$ \\
\hline CL & 1 & & 1 & 1 & 1 & 4 & $36 \%$ \\
\hline DL & 1 & 0 & & 1 & 1 & 3 & $27 \%$ \\
\hline FM & 0 & 0 & 1 & & 0 & 1 & $9 \%$ \\
\hline SC & 1 & 0 & 0 & 1 & & 2 & $18 \%$ \\
\hline & & & & & Total & $\mathbf{1 1}$ & $\mathbf{1 0 0 \%}$ \\
\hline
\end{tabular}

Elaboración propia

Para evaluar el nivel de desarrollo de cada alternativa de localización, se asignará la calificación de cada factor en cada localidad alternativa de acuerdo a la siguiente puntuación:

Tabla 3.3

Puntuación

\begin{tabular}{|l|l|}
\hline Excelente & 10 \\
\hline Muy bueno & 8 \\
\hline Bueno & 6 \\
\hline Regular & 4 \\
\hline Deficiente & 2 \\
\hline
\end{tabular}

Elaboración propia

A continuación, se realizará el ranking de factores para determinar la localización más adecuada: 
Tabla 3.4

Ránking de factores

\begin{tabular}{|l|l|l|l|l|l|l|l|l|l|l|l|l|}
\hline \multirow{2}{*}{ Factores } & \multirow{2}{*}{ Ponderación } & \multicolumn{2}{l|}{ Miraflores } & \multicolumn{2}{l|}{ San Isidro } & \multicolumn{2}{l|}{ San Borja } & \multicolumn{2}{l|}{ Surco } & \multicolumn{2}{l|}{ La Molina } \\
\cline { 3 - 13 } & & Calif. & Punt. & Calif. & Punt. & Calif. & Punt. & Calif. & Punt. & Calif. & Punt. \\
\hline UC & $9 \%$ & 6 & 0,54 & 4 & 0,36 & 6 & 0,55 & 4 & 0,36 & 6 & 0,55 \\
\hline CL & $36 \%$ & 4 & 1,44 & 4 & 1,45 & 8 & 2,91 & 6 & 2,18 & 8 & 2,91 \\
\hline DL & $27 \%$ & 8 & 2,16 & 6 & 1,09 & 4 & 1,09 & 6 & 1,62 & 4 & 0,73 \\
\hline FM & $9 \%$ & 6 & 0,55 & 6 & 0,55 & 4 & 0,36 & 8 & 0,73 & 6 & 0,55 \\
\hline SC & $18 \%$ & 8 & 1,44 & 10 & 2,73 & 8 & 2,18 & 6 & 1,64 & 6 & 1,64 \\
\hline Total & $100 \%$ & & 6,18 & & 6,18 & & $\mathbf{7 , 0 9}$ & & 6,53 & & 6,36 \\
\hline
\end{tabular}

Elaboración propia

De acuerdo al resultado, se elegirá San Borja como el distrito más adecuado para la localización del local. 


\section{CAPÍTULO IV. DIMENSIONAMIENTO DEL SERVICIO}

\subsection{Relación tamaño-mercado}

El tamaño según el mercado será el que se calculó en el capítulo 2.4.4 Determinación de la demanda para el proyecto. Se seleccionará la demanda del último año del proyecto como tamaño del servicio; por lo tanto, el tamaño según el mercado es de 12.400 sesiones.

Tabla 4.1

Demanda del proyecto

\begin{tabular}{|l|l|l|l|l|l|l|}
\hline Año & 2016 & 2017 & 2018 & 2019 & 2020 & 2021 \\
\hline $\mathrm{N}^{\circ}$ deportistas & 541 & 560 & 576 & 592 & 606 & 620 \\
\hline $\mathrm{N}^{\circ}$ sesiones & 10.820 & 11.200 & 11.520 & 11.840 & 12.120 & 12.400 \\
\hline
\end{tabular}

Elaboración propia

\subsection{Relación tamaño-recursos}

El principal recurso productivo es la mano de obra para los servicios, es decir los médicos, fisioterapeutas y personal de atención al cliente. Al estar ubicado el local en Lima, no habrá inconvenientes en contar con el personal requerido ya que existen personas altamente calificadas disponibles. Así, los recursos productivos no serán una restricción para el tamaño de planta.

\subsection{Relación tamaño-tecnología}

El tamaño del CTRF en relación a la tecnología se determinó con la teoría de un sistema de producción intermitente en el capítulo 5.4.1. Cálculo de la capacidad instalada. Así, el cuello de botella se encuentra en la estación de magneto que da una relación tamañotecnología de 11.981 sesiones/año. 


\subsection{Relación tamaño-inversión}

Para el proyecto, la inversión será para la compra del terreno, la construcción del local, la adquisición de máquinas requeridas para brindar los servicios y los gastos preoperativos. La sumatoria de la inversión fija tangible e intangible será de S/. 244.264,89 para poder satisfacer la demanda de 12.400 sesiones en un año. Los detalles del cálculo de este indicador se muestran en el capítulo 7.1. Inversiones.

\subsection{Relación tamaño-punto de equilibrio}

Como se trata de un proyecto con más de un servicio, para el cálculo del punto de equilibrio se ponderará el precio variable unitario de una sesión, el costo variable unitario (materiales) y costos fijos de la terapia física. El resultado será la capacidad mínima por servicio a ofrecer en el Centro de Rehabilitación y Terapia Física. A continuación, se muestra el cálculo:

$$
P E=\frac{C F}{P v u-C v i}=\frac{763.913}{72.88-1.34}=10.678 \text { sesiones }
$$

\subsection{Selección de la dimensión del servicio}

Finalmente, el tamaño óptimo de planta es el de tecnología, limitando así el servicio a 11.981 sesiones por año. Además, se observa que se encuentra por encima del punto de equilibro, por debajo del tamaño de mercado y que existen los recursos suficientes para abastecer este tamaño de planta. 


\section{CAPÍTULO V. INGENIERÍA DEL PROYECTO}

\subsection{Definición del servicio basada en sus características de operación}

\subsubsection{Especificaciones técnicas del servicio}

El Centro de Terapia Física y Rehabilitación (CTFR) para deportistas será completamente personalizado, pues los principales objetivos del centro son ofrecer un servicio de recuperación y además, brindar una experiencia gratificante donde el paciente sienta la satisfacción y un completo recupero en su condición física. Por tal motivo, se contará con especialistas en el rubro de medicina deportiva.

Todos los procedimientos involucrados serán dispuestos por especificaciones médicas, pues es prioridad garantizar el progreso y recupero en la situación del paciente de manera responsable.

Se tomará en cuenta los protocolos de tratamiento según tipo de lesión, elaborados por técnicos e investigadores miembros de Confederación Mundial de Terapia Física (WCPT). Se han ido descubriendo y estableciendo dichos protocolos, junto con estudios que determinan su efectividad. Sin embargo, no se puede tratar a todos los pacientes de una manera general o estandarizada, pues cada paciente y lesión es diferente. En el Perú, la secuencia del tratamiento y los procedimientos dependen del criterio y experiencia del fisioterapeuta.

En cuanto a la infraestructura y distribución del local, se tomará en cuenta las normas y especificaciones de las municipalidades pertinentes, defensa civil, y sobre todo, garantizar seguridad y comodidad en los pacientes y trabajadores.

A continuación, se detallarán los tres tipos de servicios a ofrecer.

Terapia con Agentes Físicos

Los agentes físicos son parte del tratamiento de lesiones gracias a sus efectos sobre la inflamación y la curación de los tejidos, el dolor, el tono muscular o las restricciones de la movilidad. (Cameron, 2009)

En caso el paciente presente más de un problema, es necesario establecer un número limitado de objetivos. Es recomendable que se atiendan primero los problemas 
más importantes y aquellos que sea más probable que respondan a las intervenciones disponibles.

Entre los tratamientos con agentes físicos se encuentran:

\section{- Crioterapia}

- Termoterapia

- Electroterapia

- Ultrasonido

- Láser

- Magnetoterapia

- Ondas de choque

En el punto 5.3 se detallará cada una de los equipos mencionados.

Terapia Manual

Los agentes físicos son componentes de un programa completo de rehabilitación que no se deberían utilizar como una única intervención. Es por ello, que también se contará con la terapia manual, la cual consiste en técnicas manuales orientadas a la solución de disfunciones y/o alteraciones biomédicas del movimiento normal humano.

Los objetivos de la terapia manual son recuperar el movimiento cuando las articulaciones presentan una restricción en el mismo, aliviar el dolor articular y muscular, y mejorar la funcionalidad del paciente. (Bienfait, 2001)

Se realizó una consulta a un fisioterapeuta especializado en deporte, para conocer los tipos de terapia manual que aplican para el tratamiento de lesiones deportivas. La terapia manual se puede clasificar en dos tipos:

- Intrusivo: método de Punción Seca, el cual consiste en la aplicación de una aguja para liberar dolor en los puntos gatillos; es decir, puntos activadores del dolor en el músculo.

- No intrusivo: métodos manuales o también conocidos como masajes terapéuticos, es la aplicación de técnicas, manipulaciones, movilizaciones de segmentos corporales para devolverle la mecánica normal al cuerpo. 
El tiempo promedio ideal para la terapia manual es de 30 minutos, para que la parte del cuerpo lesionada haya sido trabajada sin causar molestias o dolores adicionales.

Rehabilitación Física

Luego de haber tratado la lesión en sí, se inicia con la rehabilitación física del paciente. Este último paso es considerado la esencia del tratamiento, el cual consiste en la aplicación de ejercicios terapéuticos que buscan la recuperación de las capacidades del individuo que ha sufrido alguna lesión y lograr el principal objetivo: reincorporar al paciente a sus actividades diarias. (Horn, 2005)

Una duración aproximada de los ejercicios como parte de la rehabilitación física es de 30 minutos, según menciona el fisioterapeuta mencionado anteriormente.

\subsection{Proceso para la realización del servicio}

\subsubsection{Descripción del proceso del servicio}

El proceso del servicio del CTFR inicia cuando el paciente solicita una primera cita a través de la página web, llamada telefónica o incluso de manera presencial. La persona encargada de atención al cliente, una asistente, confirmará la fecha y hora de la cita.

El día programado de la cita, el paciente ingresa al local siendo recibido cordialmente por el personal de atención al cliente. Enseguida, la asistente registrará los datos del paciente en una base de datos donde se ingresarán los datos personales y posteriormente se llevará el control de asistencia. La misma asistente, realiza el cobro de la primera cita al paciente.

Mientras el paciente espera a ser atendido, se elabora un reporte manual a nombre del paciente donde se tomarán las notas respectivas del diagnóstico tanto del médico como del fisioterapeuta. Luego, este reporte es entregado al médico y el paciente ingresa a la consulta. Mediante chequeo y evaluación física, el médico determina la condición del paciente, la cual informa al paciente y la redacta en el reporte. Una vez que el reporte tenga el diagnóstico respectivo lo recibe el fisioterapeuta. El paciente, pasa a una atención con el fisioterapeuta quien también realiza una evaluación física al paciente y determina las especificaciones que requiere. A continuación, establece una rutina y establece el número de sesiones necesarias; información que también será escrita en el reporte. 
Con el diagnóstico y las especificaciones del tratamiento, el reporte es entregado a atención al cliente, donde en coordinación con el paciente se evaluará la disponibilidad de horarios. Llegado un acuerdo, se confirma y programan las sesiones necesarias.

Cuando el paciente regrese al centro para iniciar las sesiones de tratamiento, éste tendrá un proceso diferente el cual se explicará en un segundo diagrama de flujo. Una vez que el paciente ingresa al local, se confirma si es el horario de la sesión programada. Si es correcto, la asistente procede al cobro de la sesión, cabe mencionar que el cobro de la sesión de terapia será el mismo día programado. Si el paciente se encuentra en las instalaciones del centro sin una sesión programada, la asistente buscará disponibilidad en el horario. Si hay disponibilidad, se procede con la cobranza de la sesión; en caso contrario, se reprograma la sesión.

Mientras el paciente espera a ser atendido, la asistente busca el reporte del paciente para entregarlo al fisioterapeuta. Una vez que el fisioterapeuta recibe el reporte, llama al paciente e inicia la sesión correspondiente. Al terminar, actualiza el reporte con lo realizado durante la sesión, el progreso y las observaciones pertinentes.

A partir de este punto pueden presentarse dos situaciones, puede ser que al paciente aún le queden sesiones de terapia programadas o en caso contrario, culmine su última sesión. De ser el primer caso, el paciente se retira del local y vuelve para su siguiente cita. En caso contrario, se entrega el reporte al médico y el paciente pasa a atenderse con este, para evaluar el progreso y recupero del mismo. Tras la evaluación, el médico determinará si el paciente requiere más sesiones de terapia física y/o rehabilitación, o si el paciente ya está en condiciones de culminar su tratamiento; es decir, recuperado de la lesión con la que ingresó al centro. Si requiere de más sesiones, el paciente reprograma nuevas citas en atención al cliente. Pero, si el paciente ya finalizó su tratamiento, se retira. Finalmente, el médico actualiza el reporte final y lo entrega a atención al cliente para que esa almacenado. 


\subsubsection{Diagrama de flujo del servicio}

Figura 5.1

Diagrama de flujo para el proceso de inscripción y primera cita del paciente

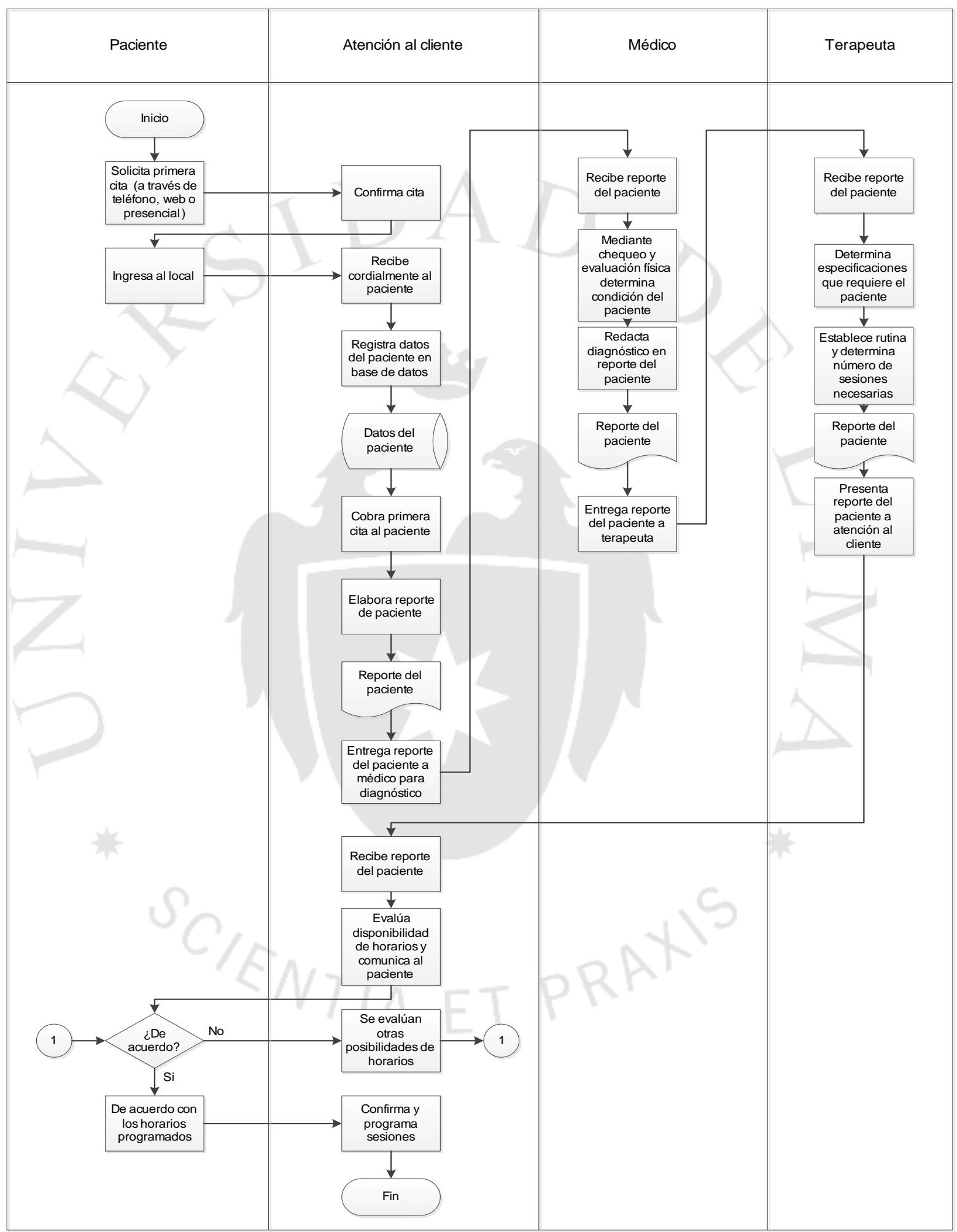

Elaboración propia 
Figura 5.2

Diagrama de flujo para el proceso de sesión de terapia del paciente

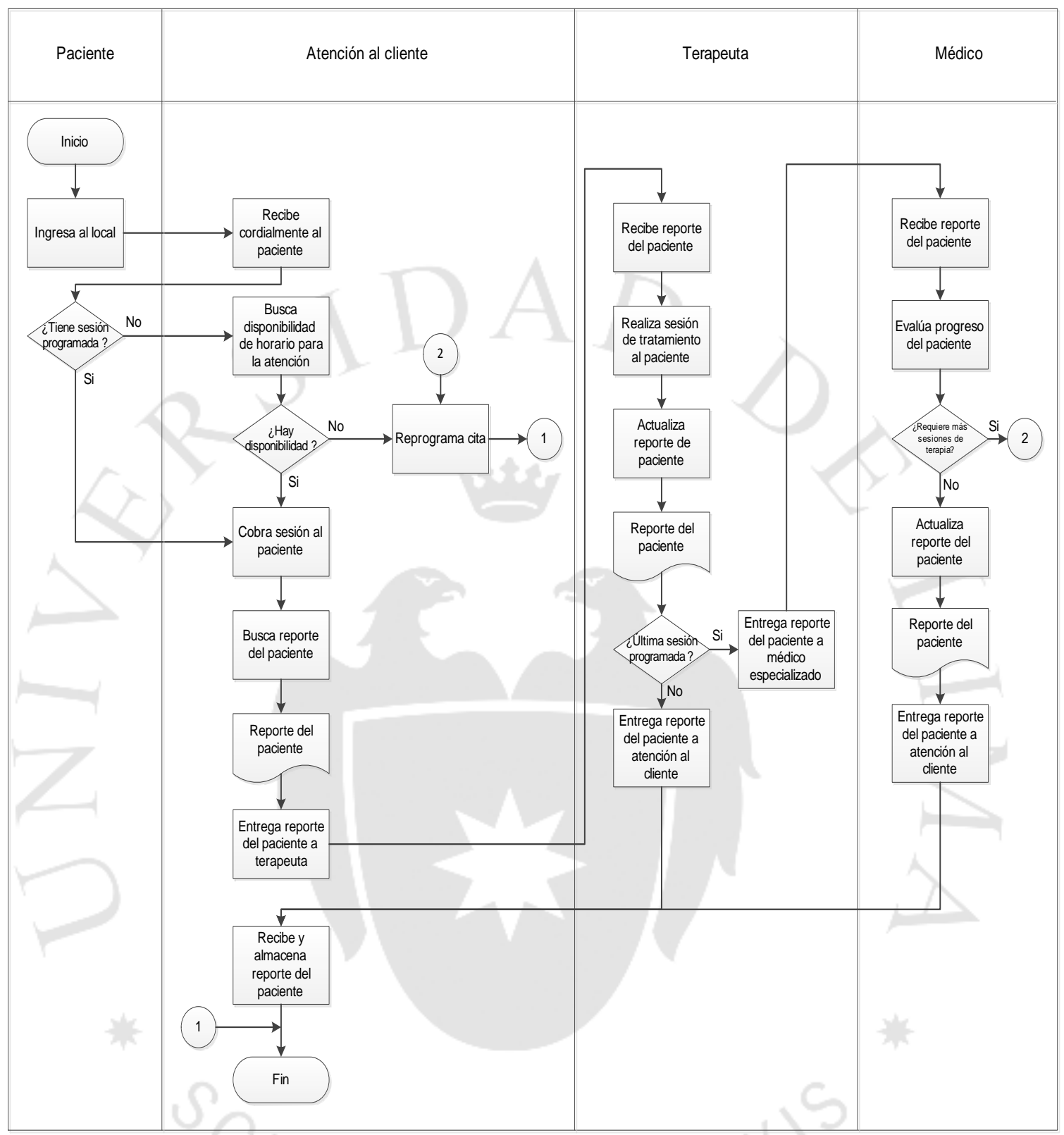

Elaboración propia

\subsection{Tecnología, equipo, mobiliario e instalaciones}

\subsubsection{Selección de la tecnología, equipo, mobiliario e instalaciones}

La capacidad instalada depende directamente de la infraestructura del local. En el presente proyecto, la naturaleza de los equipos está enfocada en incrementar la calidad en la atención al paciente. Por tal motivo, se seleccionarán los equipos y la tecnología que permita garantizar seguridad, comodidad y satisfacción al paciente. 
Como se mencionó anteriormente, en el proyecto se aplicarán las técnicas de terapia manual, terapia con agentes físicos y rehabilitación física. Esto debido a la eficiencia de las tres técnicas en conjunto para la recuperación de las lesiones deportivas, la cual ha sido sustentada por un especialista en el rubro de medicina deportiva.

A continuación, se detallará la tecnología existente para el tratamiento de lesiones. Los equipos se seleccionarán a través de dos aspectos: benchmarking y consulta a profesionales. Se tomará en cuenta los equipos y sus respectivas marcas que la principal competencia utiliza y adicionalmente, se realizará consultas a profesionales fisioterapeutas. Con este último punto se buscará una recomendación de las marcas que están en el mercado, considerando la experiencia del fisioterapeuta de haber trabajado con dichas marcas y garantizar la calidad de la misma. Asimismo, para los tiempos promedios del uso de cada agente físico se utilizaron datos en base de la experiencia de un fisioterapeuta especializado en lesiones deportivas.

Agentes térmicos

Se clasifican en dos tipos: crioterapia y termoterapia. Para ambos casos, el tiempo recomendado de exposición al paciente es de 10 a 15 minutos por sesión.

La crioterapia es la transferencia de calor del paciente mediante la utilización de un agente de enfriamiento. Ésta se utiliza para controlar la inflamación, el dolor, la hinchazón y el espasmo muscular, y para acelerar la recuperación después de una lesión o un golpe.

Por otro lado, la termoterapia es la transferencia de calor al paciente con un agente de calentamiento. La termoterapia se utiliza para controlar el dolor, aumentar la predisposición a la elasticidad y lograr que las zonas elásticas de los tejidos blandos se lubriquen y queden predispuestas a ser trabajadas. Asimismo, se considera una experiencia psicológica del calor como algo reconfortante y relajante que puede influir también en la percepción del dolor por parte del paciente.

\section{Electroterapia}

La electroterapia consiste en la estimulación eléctrica que produce contracciones musculares, provocando una analgesia superficial para acelerar y mejorar la rehabilitación de pacientes. La electroterapia aumenta la fuerza y la resistencia muscular, reduce la espasticidad, aumenta la circulación y controla el dolor. (Cameron, 2009) 
De 10 a 20 minutos de aplicación es lo recomendado para una sesión.

\section{Ultrasonido}

El ultrasonido permite la emisión de ondas de sonido de entre 1 y $3 \mathrm{MHz}$, produciendo efectos térmicos. Estos efectos se utilizan para la reducción del dolor y tratar ciertos problemas que impiden el funcionamiento correcto de los músculos y los huesos. El ultrasonido emite calor profundo para lograr el aumento de la vascularización y disminuir el proceso inflamatorio de las zonas más profundas. (Cameron, 2009)

El tiempo de aplicación es directamente proporcional al área de tratamiento, a mayor área de tratamiento más tiempo. Por ejemplo, para áreas pequeñas o focalizadas se emplea por 5 minutos y 10 minutos para lesiones en la espalda.

\section{Láser terapéutico}

La luz láser es un haz de luz ultravioleta con propiedades regenerativas de tejidos. Una de sus principales propiedades la concentración de luz en superficies muy pequeñas, es decir, en zonas muy puntuales. Para la terapia física se recomienda el uso de rayos láser de baja intensidad, ya que la profundidad de penetración queda limitada a las capas epidérmicas superiores. (Cameron, 2009)

Estudios han observado que la terapia láser y la fototerapia pueden reducir el dolor y la discapacidad asociados a una amplia variedad de malestares tanto a nivel muscular como de nervio y hueso. Los efectos de la luz láser han sido estudiados y recomendados porque hay indicios firmes que este tipo de energía electromagnética facilita la cicatrización. (Cameron, 2009)

Entre 5 y 10 minutos de aplicación de láser terapéutico es una duración adecuada por sesión.

\section{Magnetoterapia}

La magnetoterapia utiliza la energía electromagnética, siendo un tratamiento eficaz, seguro y no invasivo. Los campos magnéticos interactúan con las células favoreciendo la recuperación de tejidos y regeneración de zonas afectadas. Este tipo de terapia tiene un efecto antiinflamatorio, analgésico, descontracturante, antiespasmódico y favorece a la consolidación del hueso. (Cameron, 2009)

Para el caso del ultrasonido, se recomienda una duración de 30 minutos. 
Ondas de choque

La terapia de ondas de choque es un tratamiento no invasivo que favorece a la regeneración de tejidos. Durante la terapia de ondas de choque, una onda de sonido de gran intensidad interactúa con los tejidos corporales. Entre los efectos de esta interacción está la inversión de inflamaciones crónicas. A medida que el área lesionada se va tratando, se restaura la funcionalidad y se alivia el dolor. (Hüter-Becker, 2005)

La terapia de ondas de choque se aplica a menudo en medicina deportiva por su curación de los tejidos blandos y su efecto regenerador. Kijewski (s.f.) afirma:

La terapia de ondas de choque es un método novedoso para el tratamiento del sistema músculo-esquelético en fisioterapia del deporte. Se trata de un método no invasivo, seguro y muy eficaz. En aproximadamente 10 días, los tratamientos de terapia de ondas de choque pueden reducir el dolor en el $84 \%$ de los casos. Estas conclusiones se basan en dos años de observación, con aproximadamente 5.000 tratamientos separados de ondas de choque.

La aplicación de las ondas de choque se limita a una duración de 5 a 10 minutos.

Finalmente, para determinar los equipos y mobiliario a emplear en el servicio, se contactó a un especialista en fisioterapia deportiva.

\section{Tabla 5.1}

Equipo y mobiliario seleccionado

\begin{tabular}{|l|l|l|}
\hline \multirow{4}{*}{ Uso } & \multicolumn{2}{|l|}{ Tecnología, instalaciones y equipo } \\
\hline \multirow{4}{*}{ Terapia Física (Agentes Físicos) } & Tanque para compresas frías & Máquina de láser terapéutico \\
\cline { 2 - 3 } & Tanque para compresas calientes & Máquina para magnetoterapia \\
\cline { 2 - 3 } & Máquinas para electroterapia & Máquina de ondas de choque \\
\cline { 2 - 3 } & Máquina de ultrasonido & Taburete \\
\hline \multirow{5}{*}{ Terapia Física } & Camillas de tratamiento & Biombo \\
\hline & Mesa auxiliar & Colchoneta para ejercicio \\
\hline \multirow{5}{*}{ Rehabilitación Física } & Tubos y ligas elásticas & Espaldera de madera \\
\cline { 2 - 3 } & Plataformas de equilibrio & Espejos \\
\cline { 2 - 3 } & Pelotas de ejercicio & Banda sin fin \\
\cline { 2 - 3 } & Pesas y mancuernas & \\
\cline { 2 - 3 } & Barras paralelas & \\
\cline { 2 - 3 } & Bicicleta fija & \\
\hline
\end{tabular}

Fuente: Consulta a Especialista 


\section{Instalaciones}

Para el presente proyecto se emplearán servicios estándar de agua, desagüe y eléctricas, debido a que los equipos seleccionados no requieren de instalaciones mayores ni especiales para su uso.

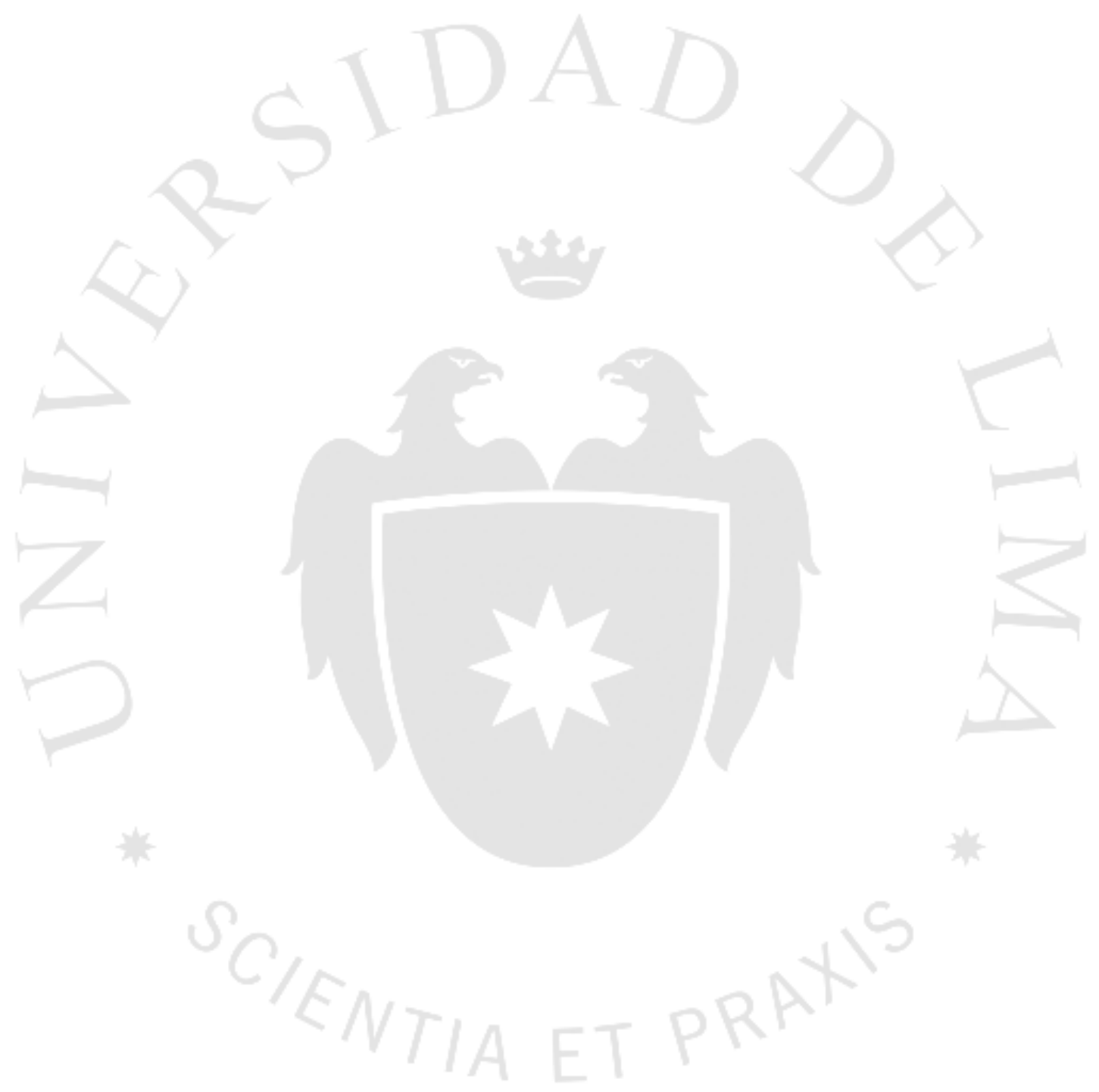




\subsubsection{Descripción de la tecnología}

Tabla 5.2

Tanque para compresas frías

\begin{tabular}{|c|c|}
\hline Marca & DJO - Chattanooga \\
\hline Modelo & $\mathrm{C}-5$ \\
\hline País de procedencia & Estados Unidos \\
\hline Dimensiones & $70 \times 40 \times 85 \mathrm{~cm}$ \\
\hline Peso & 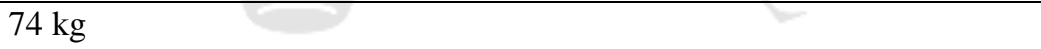 \\
\hline Tensión de red & $220-240 \mathrm{~V}$ \\
\hline Frecuencia de red & 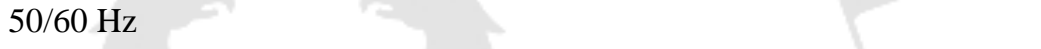 \\
\hline Características & $\begin{array}{l}\text { Fabricado en acero inoxidable } \\
\text { Capacidad para } 12 \text { compresas frías } \\
\text { Celdas cerradas con aislamiento de espuma para mejor rendimiento } \\
\text { Compresor de trabajo pesado } \\
\text { Bobinas de refrigeración } \\
\text { Ruedas giratorias silenciosas de } 7.5 \mathrm{~cm} \text { de goma para movimiento sin } \\
\text { fricción } \\
\text { Válvula de desagüe de fácil limpieza y descongelación } \\
\text { Clase de seguridad eléctrica Tipo B } \\
\text { Pruebas de seguridad: EN } 60601-1\end{array}$ \\
\hline Accesorios & 12 Coolpac estándar \\
\hline
\end{tabular}

Fuente: J.P. Rehab S.R.L., (2016) 
Tabla 5.3

Tanque para compresas calientes

\begin{tabular}{|c|c|}
\hline Marca & DJO - Chattanooga \\
\hline Modelo & $\mathrm{M}-2$ \\
\hline País de procedencia & México \\
\hline Dimensiones & $70 \times 40 \times 85 \mathrm{~cm}$ \\
\hline Peso & $37 \mathrm{~kg}$ \\
\hline Tensión de red & $110-240 \mathrm{~V}$ \\
\hline Frecuencia de red & $50 / 60 \mathrm{~Hz}$ \\
\hline Características & $\begin{array}{l}\text { Temperatura regulada con termostato } \\
\text { Depósito aislado } \\
\text { Capacidad del tanque: } 68,81 \text { litros } \\
\text { Temp. Normal de operación } 71^{\circ} \mathrm{C}-74^{\circ} \mathrm{C} \\
\text { Límite de seguridad: } 82^{\circ} \mathrm{C}-85^{\circ} \mathrm{C} \\
\text { Tiempo de calefacción: Llega a } 70^{\circ} \mathrm{C} \text { en } 6 \text { horas. } \\
\text { Tiempo de enfriamiento } 3 \text { horas a partir de } 70^{\circ} \mathrm{Cs} \\
\text { Clase de seguridad Tipo B } \\
\text { Ensayos de seguridad UL, cUL.CE }\end{array}$ \\
\hline Accesorios & 12 compresas medianas tamaño estándar 25 x $30 \mathrm{~cm}$ \\
\hline
\end{tabular}

Fuente: J.P. Rehab S.R.L., (2016) 
Tabla 5.4

Máquina de electroterapia

\begin{tabular}{|c|c|}
\hline Marca & DJO - Chattanooga \\
\hline Modelo & Intelect Mobile Stim \\
\hline País de procedencia & Estados Unidos \\
\hline Dimensiones & $33 \times 29 \times 16.3 \mathrm{~cm}$ \\
\hline Peso & $2.3 \mathrm{~kg}$ \\
\hline Tensión de red & $120-240 \mathrm{~V}$ \\
\hline Frecuencia de red & $50 / 60 \mathrm{~Hz}$ \\
\hline Características & $\begin{array}{l}02 \text { canales de salida } \\
\text { Pantalla digital } \\
\text { Intensidad y controles de parámetros independientes para cada canal } \\
\text { Corrientes estándares (IFC } 2 \text { polos, IFC } 4 \text { polos, galvánica, alto voltaje, } \\
\text { microcorriente, VMS ( vms burst), Tens (bifásico asimétrico, bifásico } \\
\text { simétrico), rusa, trabert, monofásica rectangular y diadinámicas) } \\
15 \text { posiciones de memoria definidas por el usuario } \\
\text { Unidad para uso encima de la mesa, montada en la pared o uso móvil } \\
\text { Su ligero diseño junto con la opción de batería y bolsa de transporte a } \\
\text { medida, hacen que sea fácil de transportar }\end{array}$ \\
\hline Accesorios & $\begin{array}{l}04 \text { esponjas } \\
04 \text { electrodos de carbono } 6 * 8 \\
01 \text { manual cd } \\
01 \text { juego de cables } \\
02 \text { velcros }\end{array}$ \\
\hline
\end{tabular}

Fuente: Phymed S.R.L., (2016) 
Tabla 5.5

Máquina de ultrasonido

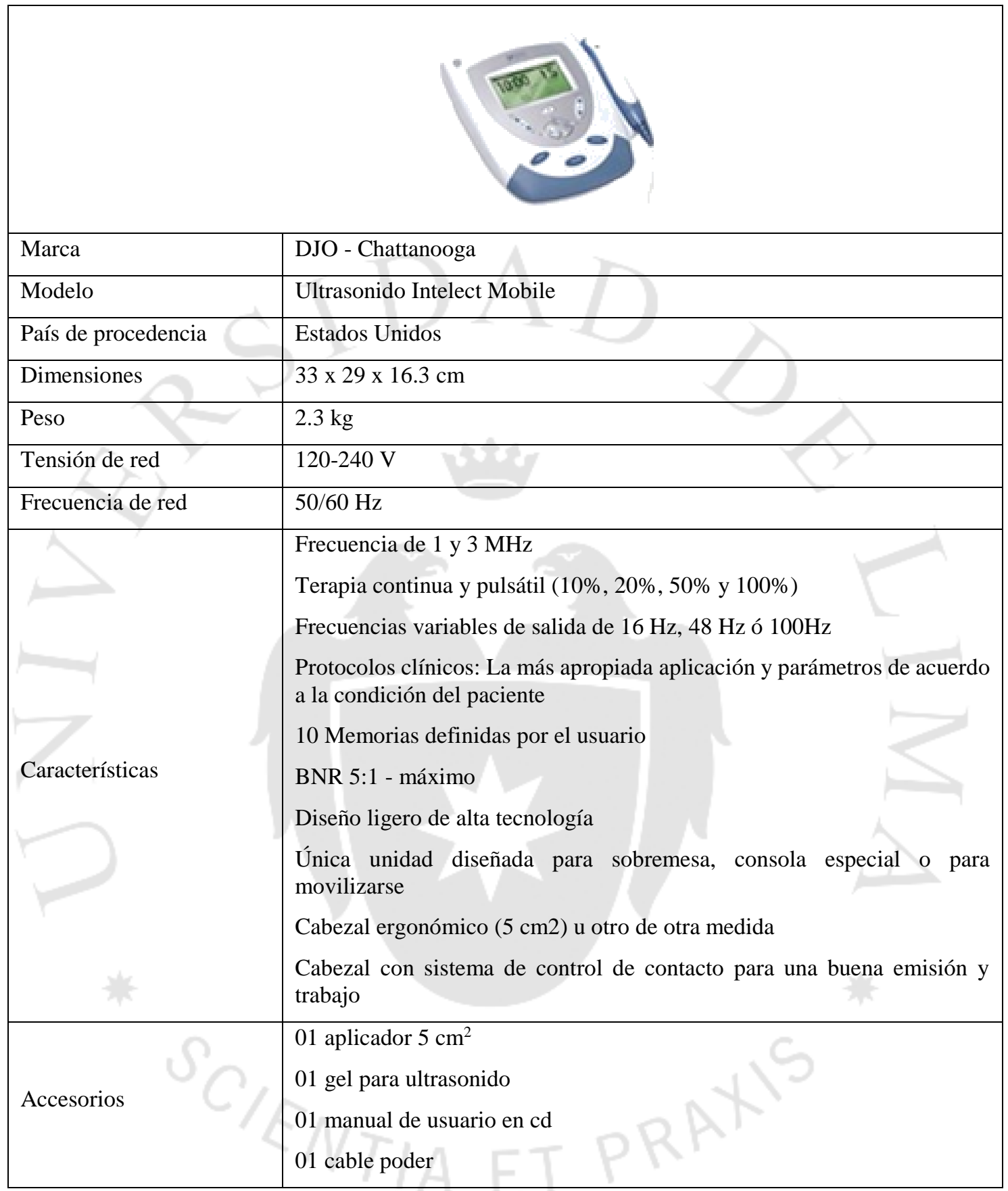

Fuente: Phymed S.R.L., (2016) 
Tabla 5.6

Máquina de láser terapéutico

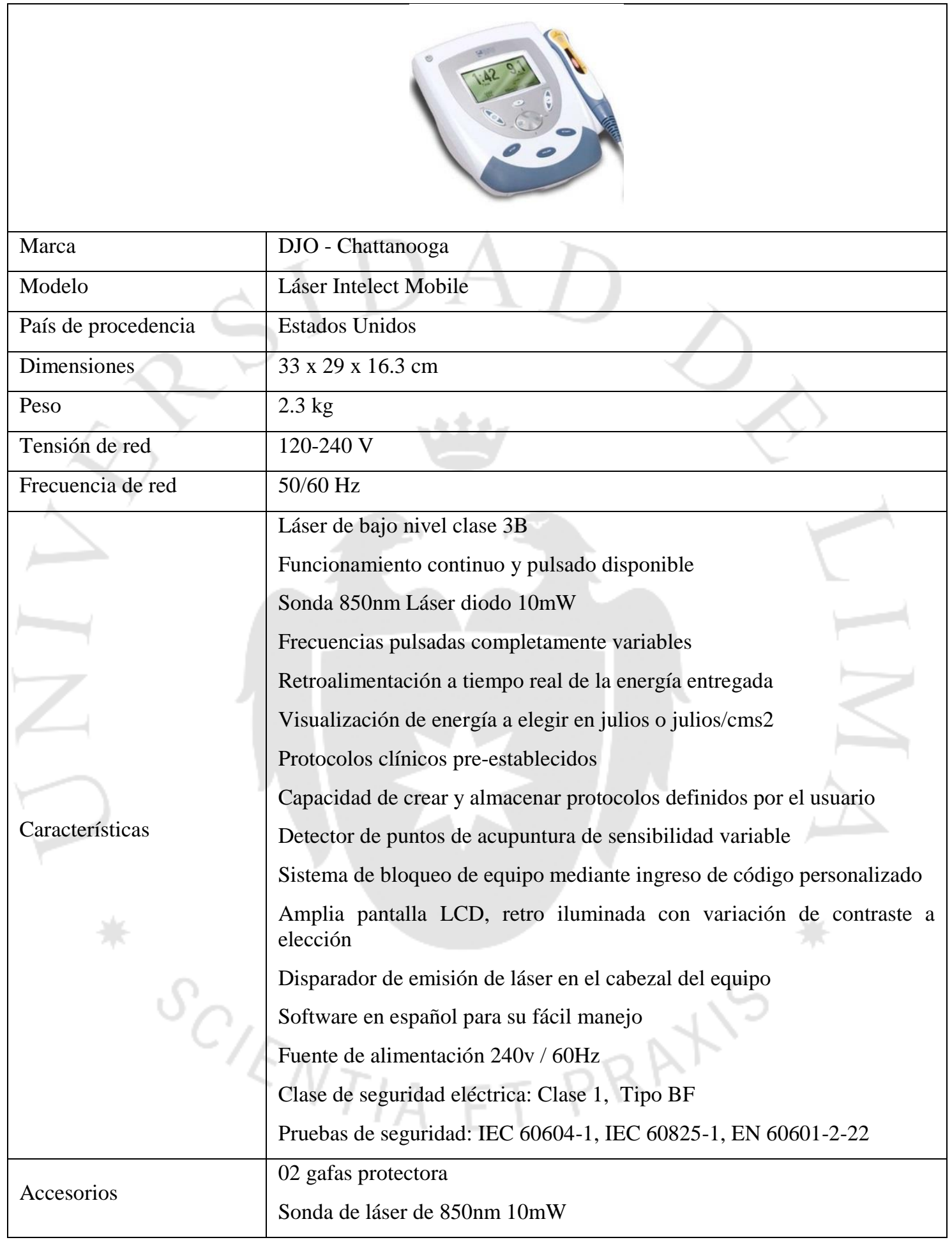

Fuente: J.P. Rehab S.R.L., (2016) 
Tabla 5.7

Máquina de magnetoterapia

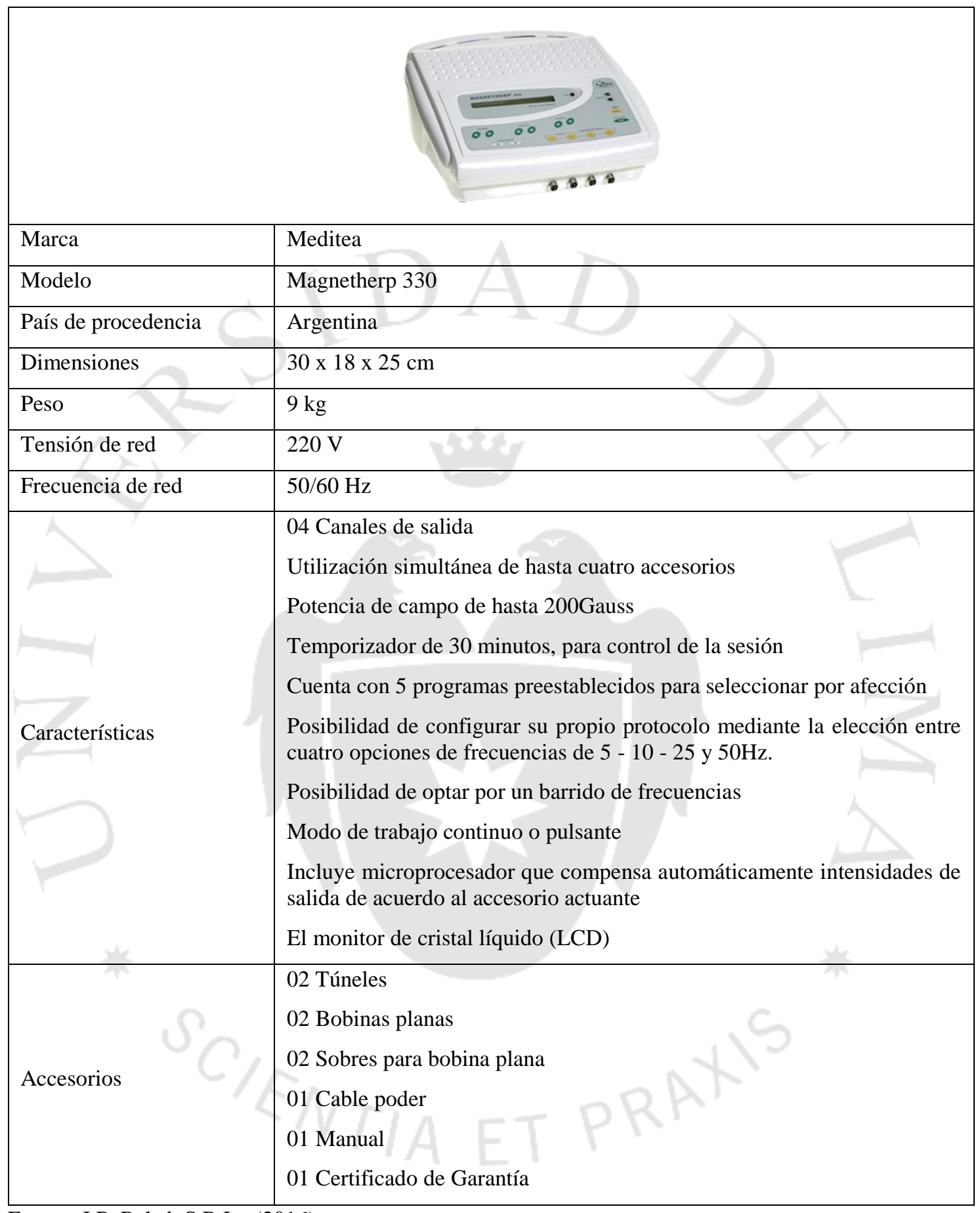

Fuente: J.P. Rehab S.R.L., (2016) 
Tabla 5.8

Máquina de ondas de choque

\begin{tabular}{|c|c|}
\hline Marca & Storz Medical \\
\hline Modelo & DUOLITH SD1 ULTRA MÓDULO R-SW + MONITOR \\
\hline País de procedencia & Suiza \\
\hline Dimensiones & $60 \times 50 \times 150 \mathrm{~cm}$ \\
\hline Peso & $\sqrt{2}+2$ \\
\hline Tensión de red & 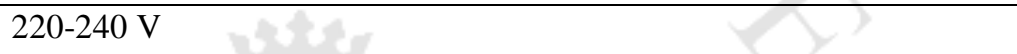 \\
\hline Frecuencia de red & $50 / 60 \mathrm{~Hz}$ \\
\hline Características & $\begin{array}{l}\text { Sistema de Ondas de Choque Radiales (RSWT) } \\
\text { Dos conectores para aplicadores radiales } \\
\text { Presión: } 1 \text { - } 5 \text { bar } \\
\text { Frecuencia de choque: } 1 \text { - } 21 \mathrm{~Hz} \\
\text { Máxima densidad de energía: } 0.28 \mathrm{~mJ} / \mathrm{mm} 2 \\
\text { Profundidad de penetración radial: } 50 \mathrm{~mm} \\
\text { Tecnología de oscilación D-Actor® } \\
\text { Puerto LAN y USB para transferencia de datos } \\
\text { Diseño de actualización modular } \\
\text { Capacidad de acoplamiento a onda de choque focal } \\
\text { Capacidad de acoplamiento a ultrasonografía Doppler o monocromático } \\
\text { Selector de presión y frecuencia integrado en el aplicador } \\
\text { Sistema de disparo por contacto con la piel "Skin Touch" } \\
\text { Aplicador con absorción de ruido (opcional) "Noise Absorption" }\end{array}$ \\
\hline Accesorios & $\begin{array}{l}01 \text { Carrito } \\
01 \text { Modulo R-SW } \\
01 \text { Modulo de Control (Pantalla) } \\
01 \text { Aplicador Radial } \\
02 \text { Proyectiles } \\
02 \text { Tubo guía } \\
01 \text { Transmisor de } 15 \mathrm{~mm} \\
01 \text { Transmisor de } 20 \mathrm{~mm} \\
01 \text { Manual de Operación } \\
01 \text { Cable Pode }\end{array}$ \\
\hline
\end{tabular}

Fuente: Phymed S.R.L., (2016) 


\subsection{Capacidad Instalada}

La capacidad instalada es la disponibilidad de infraestructura necesaria en función a la definición del tamaño de planta, que se basa en el diseño del proceso y está limitada por el tamaño tecnología. En el presente proyecto la capacidad instalada se expresa en número de sesiones al año, considerando el personal y los horarios disponibles.

\subsubsection{Cálculo de la capacidad instalada del servicio}

El CTFR atenderá 8 horas efectivas al día, 6 días a la semana y 52 semanas al año. En la figura 5.3 se muestra el horario tentativo de la semana.

\section{Figura 5.3}

Horario tentativo para el CTFR

\begin{tabular}{|l|l|l|l|l|l|l|}
\hline Hora & Lunes & Martes & Miércoles & Jueves & Viernes & Sábado \\
\hline $06: 00-07: 00$ & & & & & & \\
\hline $07: 00-08: 00$ & & & & & & \\
\hline $08: 00-09: 00$ & & & & & & \\
\hline $09: 00-10: 00$ & & & & & & \\
\hline $10: 00-11: 00$ & & & & & & \\
\hline $11: 00-12: 00$ & & & & & & \\
\hline $12: 00-13: 00$ & & & & & & \\
\hline $13: 00-14: 00$ & & & & & & \\
\hline $14: 00-17: 00$ & & & & & & \\
\hline $17: 00-18: 00$ & & & & & & \\
\hline $18: 00-19: 00$ & & & & & & \\
\hline $19: 00-20: 00$ & & & & & & \\
\hline $20: 00-21: 00$ & & & & & & \\
\hline
\end{tabular}

Elaboración propia

Adicionalmente, se utilizará un factor de utilidad de 1, debido a que las máquinas serán programadas por el tiempo necesario, según requiera el paciente, y no parará de funcionar hasta que se cumpla el ciclo.

$$
U=\frac{T_{\text {real }}}{T_{\text {teórico }}}=\frac{30 \text { minutos }}{30 \text { minutos }}=1
$$

En cuanto al factor de eficiencia, se determinó un valor de 0.83 , a través de un estudio de tiempo realizado en el centro médico de la Videna, contando el tiempo real de 
atención de cada paciente, y este último valor, comparándolo contra el tiempo de estándar de cada sesión que debería ser de 60 minutos.

$$
E=\frac{T_{\text {real }}}{T_{\text {estándar }}}=\frac{50 \text { minutos }}{60 \text { minutos }}=0,83
$$

Considerando los datos mencionados anteriormente, para hallar la capacidad instalada del servicio, se aplicará la teoría de un sistema de producción intermitente, ya que el centro presenta diversos servicios poco estandarizados. Para ello, se emplearán estaciones de trabajo en las cuales se agrupan máquinas de similares características en términos funcionales. Se determinará la capacidad de atención de cada estación usando el criterio de servicios equivalentes, para luego determinar la capacidad de todo el sistema usando el concepto de cuello de botella entre las estaciones definidas. Los tipos de lesiones más frecuentes y su participación según la encuesta realizada se muestran en la tabla 5.10. Considerando que la demanda del proyecto es 12.400 sesiones al año, se calculó la cantidad de sesiones por tipo para satisfacer la demanda.

\section{Tabla 5.9}

Tipos de lesiones

\begin{tabular}{|l|l|l|}
\hline & Participación & Nro de sesiones \\
\hline S1: Contractura & $33 \%$ & 4.092 \\
\hline S2: Desgarro & $12 \%$ & 1.488 \\
\hline S3: Esguince & $37 \%$ & 4.588 \\
\hline S4: Tendinitis & $18 \%$ & 2.232 \\
\hline Total & $100 \%$ & 12.400 \\
\hline
\end{tabular}

Elaboración propia

En el CTRF se utilizarán 6 tipos de máquinas, agrupadas en 4 estaciones de acuerdo a su funcionalidad:

- E1: Magneto

- E2: Láser

- E3: Ultrasonido y electricidad

- E4: Compresas de frío y calor

Dentro de los servicios que ofrece el centro, la ruta de atención de cada paciente dependerá del tipo de lesión que presente. Cada servicio en particular requiere diferentes tiempos de atención. La determinación de la capacidad estará expresada en servicios 
equivalentes al tratamiento de un desgarro muscular. De acuerdo a la información brindada por el especialista, el tiempo que se toma en cada estación de acuerdo a la lesión es el siguiente:

Tabla 5.10

Tiempo por estación (minutos)

\begin{tabular}{|l|l|l|l|l|}
\hline & E1 & E2 & E3 & E4 \\
\hline S1 & 0 & 0 & 15 & 15 \\
\hline S2 & 30 & 10 & 8 & 30 \\
\hline S3 & 30 & 8 & 0 & 10 \\
\hline S4 & 30 & 0 & 10 & 15 \\
\hline
\end{tabular}

Elaboración propia

Se tomará como servicio equivalente el Desgarro (S2) porque utiliza las 4 estaciones. De tal manera, para la estación 1:

Tabla 5.11

Capacidad estación 1

\begin{tabular}{|l|l|l|l|}
\hline & Tiempo & Tiempo S2 & Nro de servicios equivalentes (SE) \\
\hline S1 & 0 & 30 & 0 \\
\hline S2 & 30 & 30 & 1 \\
\hline S3 & 30 & 30 & 1 \\
\hline S4 & 30 & 30 & 1 \\
\hline Total & $90^{\prime}=1,5$ horas & & 3 \\
\hline
\end{tabular}

Elaboración propia

Calculando la capacidad instalada de la estación, se obtiene:

Cap Inst $E 1=\frac{3 S E}{1,5 h r s} \times 3$ máqs $\times \frac{8 \text { hrs }}{\text { día }} \times \frac{6 \text { días }}{\text { sem }} \times \frac{52 \text { sem }}{a \tilde{n} o} \times 1 \times 0,83 \approx \frac{12.430 \text { sesiones }}{a \tilde{o} o}$

Así, la capacidad instalada de la estación 1 es 12.430 sesiones al año. De la misma manera se calculará la capacidad instalada de las estaciones 2,3 y 4. 
Tabla 5.12

Capacidad estación 2

\begin{tabular}{|l|l|l|l|}
\hline & Tiempo & Tiempo S2 & Nro de servicios equivalentes (SE) \\
\hline S1 & 0 & 10 & 0 \\
\hline S2 & 10 & 10 & 1 \\
\hline S3 & 8 & 10 & 0,8 \\
\hline S4 & 0 & 10 & 0 \\
\hline Total & 18 ' =0,3hora & & 1,8 \\
\hline
\end{tabular}

Elaboración propia

Calculando la capacidad instalada de la estación, se obtiene:

Cap Inst $E 2=\frac{1,8 S E}{0,3 \mathrm{hr}} \times 1$ máq $\times \frac{8 \mathrm{hrs}}{\text { día }} \times \frac{6 \text { días }}{\text { sem }} \times \frac{52 \mathrm{sem}}{a \tilde{\text { ño }}} \times 1 \times 0,83 \approx \frac{\mathbf{1 1 . 9 8 1} \text { sesiones }}{\text { año }}$

Tabla 5.13

Capacidad estación 3

\begin{tabular}{|l|l|l|l|}
\hline & Tiempo & Tiempo S2 & Nro de servicios equivalentes (SE) \\
\hline S1 & 15 & 8 & 1,88 \\
\hline S2 & 8 & 8 & 1 \\
\hline S3 & 0 & 8 & 0 \\
\hline S4 & 10 & 8 & 1,25 \\
\hline Total & $33^{\prime}=0,55$ hora & & 4,13 \\
\hline
\end{tabular}

Elaboración propia

Calculando la capacidad instalada de la estación, se obtiene:

Cap Inst $E 3=\frac{4,13 S E}{0,55 h r} \times 3$ máq $\times \frac{8 \text { hrs }}{\text { día }} \times \frac{6 \text { días }}{\text { sem }} \times \frac{52 \text { sem }}{a \tilde{n} o} \times 1 \times 0,83 \approx \frac{\mathbf{4 4 . 9 2 8 ~ s e s i o n e s}}{a \text { ño }}$

Tabla 5.14

Capacidad estación 4

\begin{tabular}{|l|l|l|l|}
\hline & Tiempo & Tiempo S2 & Nro de servicios equivalentes (SE) \\
\hline S1 & 15 & 30 & 0,5 \\
\hline S2 & 30 & 30 & 1 \\
\hline S3 & 10 & 30 & 0,3 \\
\hline S4 & 15 & 30 & 0,5 \\
\hline Total & $70 '=1,17$ hora & & 2,3 \\
\hline
\end{tabular}

Elaboración propia 
Calculando la capacidad instalada de la estación, se obtiene:

$$
\begin{aligned}
& \text { Cap Inst } E 4=\frac{2,3 S E}{1,17 h r s} \times 12 \text { compresas } \times \frac{8 \text { hrs }}{\text { día }} \times \frac{6 \text { días }}{\text { sem }} \times \frac{52 \text { sem }}{a \tilde{\text { no } o}} \times 1 \times 0,83 \\
& \approx \frac{47.923 \text { sesiones }}{a \tilde{\mathrm{n} o}}
\end{aligned}
$$

En el caso de la estación 4, se contará con una máquina para compresas frías y una máquina para compresas calientes, las cuales pueden almacenar hasta 12 compresas cada una. Para el cálculo de la capacidad instalada de dicha estación, se consideró que cada paciente requiere 2 compresas por sesión.

Por lo tanto, de acuerdo a lo calculado el cuello de botella se encuentra en la estación 2: 11.981 sesiones/año

\subsubsection{Cálculo detallado del número de recursos para el servicio}

Considerando que la capacidad instalada es de 11.981 sesiones, se va a disponer de 4 ambientes donde se atenderá simultáneamente. Cada ambiente contará con una camilla, una mesa, una silla y espacio suficiente para manipular las máquinas en cuestión. Para la adecuada atención de cada paciente, se requerirá el servicio de 2 fisioterapeutas y 2 técnicos especializados, además de un médico que atenderá al paciente antes y después de las sesiones de terapia física programadas.

Para determinar la cantidad específica de los equipos a utilizar, se realizó una consulta con un fisioterapeuta especializado en lesiones deportivas de acuerdo a su experiencia en otros centros de terapia física. 
Tabla 5.15

Número de recursos necesarios

\begin{tabular}{|c|c|c|}
\hline \multicolumn{2}{|l|}{ Recurso } & Cantidad \\
\hline \multirow{3}{*}{ Mobiliario } & Camillas & 5 \\
\hline & Mesas & 4 \\
\hline & Sillas & 6 \\
\hline \multirow{3}{*}{ Mano de obra } & Médico & 1 \\
\hline & Fisioterapeutas & 2 \\
\hline & Técnicos Especializados & 2 \\
\hline \multirow{7}{*}{ Equipo } & Tanque para compresas frías & 1 \\
\hline & Tanque para compresas calientes & 1 \\
\hline & Máquina para electroterapia & 2 \\
\hline & Máquina de ultrasonido & 1 \\
\hline & Máquina de láser terapéutico & 1 \\
\hline & Máquina para magnetoterapia & 3 \\
\hline & Máquina de ondas de choque & $1=$ \\
\hline
\end{tabular}

Elaboración propia

\subsection{Resguardo de la calidad}

\subsubsection{Calidad del proceso y del servicio}

Se tomará como base para el resguardo de la calidad del servicio la Política Nacional de Calidad en Salud RM N 727-2009/MINSA, cuya finalidad es contribuir a la mejora de la calidad de la atención de salud en las organizaciones proveedoras de servicios de salud mediante la implementación de directrices provenientes de la Autoridad Sanitaria Nacional.

Con respecto a las organizaciones proveedoras de atención de salud (MINSA, 2009):

- Garantizan la correcta implementación de las políticas nacionales de calidad.

- Mejoran la calidad de la atención de salud de manera sistemática y permanente.

- Reducen la ocurrencia de eventos adversos durante el proceso de atención de salud y atenúan sus efectos.

- Garantizan el pleno ejercicio del derecho a la salud de los usuarios con enfoque de interculturalidad y género. 
- Garantizan la competencia, seguridad y motivación del personal de salud.

- Aseguran los recursos necesarios para la gestión de la calidad de la atención en los establecimientos de salud.

\subsubsection{Niveles de satisfacción del cliente}

Para determinar el nivel de satisfacción del cliente, se considerarán los siguientes factores:

- Tiempo de atención

- Atención del personal: habilidades técnicas y sociales

- Disponibilidad de infraestructura y calidad de la tecnología

\subsubsection{Medidas de resguardo de calidad}

Para el resguardo de la calidad, se tomarán las siguientes consideraciones:

- Se implementará una política de calidad en la atención a los clientes

- Tener relaciones mutuamente beneficiosas con proveedores de las máquinas y de los materiales necesarios para la atención a los clientes.

- Capacitación al personal en atención al cliente

- Mejora continua en los servicios de la empresa

- Enfoque al cliente y detección de sus necesidades para brindar un servicio con un alto nivel de satisfacción del cliente mediante el establecimiento de estrategias.

\subsection{Impacto ambiental}

La contaminación ambiental es un factor que debe tomarse en cuenta para la instalación del servicio debido a que le brinda valor agregado a los stakeholders de la empresa y protege a la comunidad y al ecosistema que los rodea. A continuación, se muestra la matriz de Leopold para la implementación y operación de un Centro de Terapia y Rehabilitación Física. 
Figura 5.4

Matriz de Leopold

\begin{tabular}{|l|l|l|l|l|l|l|l|l|l|}
\hline Actividades & Elementos ambientales & Tierra & Agua & Aire & Estética & $\begin{array}{l}\text { Salud y } \\
\text { Seguridad }\end{array}$ & $\begin{array}{l}\text { Nivel de } \\
\text { empleo }\end{array}$ & Flora & Fauna \\
\hline Instalación & Acondicionamiento & & & & & & & & \\
\hline \multirow{2}{*}{ Operación } & $\begin{array}{l}\text { Terapia manual (algodón, } \\
\text { pomos de crema, otros } \\
\text { desechos) }\end{array}$ & & & & & & & & \\
\cline { 2 - 9 } & $\begin{array}{l}\text { Terapia con máquinas (ruido, } \\
\text { compresas) }\end{array}$ & & & & & & & & \\
\cline { 2 - 9 } & Rehabilitación & & & & & & & & \\
\hline
\end{tabular}

\begin{tabular}{|l|l|}
\hline & Impacto Positivo Alto \\
\hline & Impacto Positivo Moderado \\
\hline & Impacto Positivo Ligero \\
\hline & Impacto Negativo Ligero \\
\hline Impacto Negativo Moderado \\
\hline Impacto Negativo Alto \\
\hline
\end{tabular}

Elaboración propia

Instalación: durante la instalación del centro se van a realizar trabajos de acondicionamiento del local. Estos trabajos podrían tener un impacto negativo ligero en la tierra, agua y aire debido a que se producirán residuos sólidos, líquidos y gaseosos que pueden contaminar estos elementos. Además, existe un impacto negativo moderado a la salud y seguridad debido a que pueden existir riesgos de desplomes, caída de alturas, caída de objetos, golpes o cortes con las máquinas y herramientas. Por otro lado, habrá un impacto positivo tanto en el nivel de empleo como en la estética del local debido a que se necesitará subcontratar a mano de obra para realizar los trabajos y se arreglará la fachada y el interior del local.

Operación: durante la operación, las terapias y la rehabilitación tendrán un impacto positivo moderado en el nivel de empleo ya que se contratarán a fisioterapeutas y médicos con todos los beneficios laborales. Por otra parte, en la terapia con máquinas y en la rehabilitación puede existir un impacto negativo ligero en la salud y seguridad de los empleados debido a accidentes con las máquinas y herramientas. Además, en la terapia manual, con máquinas y rehabilitación, habrá un impacto negativo ligero por el uso de materiales como algodón. Asimismo, en la terapia con máquinas el agua y el aire tendrán un impacto negativo ligero debido al uso de compresas y al ruido que generan las 
máquinas. Para prevenir los accidentes se implementarán medidas de seguridad y salud ocupacional detalladas en el punto 5.7.

\subsection{Seguridad y salud ocupacional}

Tener una correcta planificación en cuanto a la seguridad y salud ocupacional permitirá prevenir accidentes y mejorar el clima laboral entre los empleados y pacientes del centro. Por tal motivo, se tomará en cuenta lo estipulado en la Ley № 29783, Ley de Seguridad y Salud en el Trabajo, el cual tiene como principal objetivo promover una cultura de prevención de riesgos laborales, mejorando las condiciones de seguridad, salud y medio ambiente, a fin de evitar y prevenir daños a la salud de los trabajadores, con la participación de los trabajadores empleadores. (Superintendencia Nacional de Fiscalización Laboral, 2014)

El sistema de gestión de seguridad y salud en el trabajo se rige por los siguientes principios, entre los más destacados:

- Asegurar un compromiso visible del empleador con la salud y seguridad de los trabajadores.

- Utilizar una metodología que asegure el mejoramiento continuo en seguridad y salud en el trabajo.

- Evaluar los principales riesgos que puedan ocasionar las mayores pérdidas a la salud y seguridad de los trabajadores, al empleador y otros.

La gestión de la seguridad y salud en el trabajo es responsabilidad del empleador, quien asume el liderazgo y compromiso de estas actividades. El empleador delegará las funciones y la autoridad necesaria al personal encargado del desarrollo, aplicación y resultados.

El centro, tendrá menos de 25 trabajadores y según se establece en el sistema, se deberá capacitar y nombrar, entre sus trabajadores, por lo menos un Supervisor de Seguridad y Salud en el Trabajo. Entre sus principales funciones están, hacer cumplir el presente reglamento, realizar inspecciones periódicas a las instalaciones de la empresa, y analizar las causas y las estadísticas de los incidentes, accidentes y de las enfermedades ocupacionales emitiendo las recomendaciones respectivas. 
El empleador, entre otras, tiene las siguientes obligaciones:

a) Garantizar la seguridad y la salud de los trabajadores en el desempeño de todos los aspectos relacionados con su labor, en el centro de trabajo.

b) Desarrollar acciones permanentes con el fin de perfeccionar los niveles de protección existentes.

c) Identificar las modificaciones que puedan darse en las condiciones de trabajo y disponer lo necesario para la adopción de medidas de prevención de los riesgos laborales.

d) Practicar exámenes médicos antes, durante y al término de la relación laboral a los trabajadores, acordes con los riesgos a que están expuestos en sus labores.

Por otra parte, los trabajadores tienen las siguientes obligaciones:

a) Cumplir con las normas, reglamentos e instrucciones de los programas de seguridad y salud en el trabajo que se apliquen en el lugar de trabajo.

b) Usar adecuadamente los instrumentos y materiales de trabajo, así como los equipos de protección personal y colectiva.

c) Comunicar al empleador todo evento o situación que ponga o pueda poner en riesgo su seguridad y salud y/o las instalaciones físicas; debiendo adoptar inmediatamente, de ser posible, las medidas correctivas del caso.

d) Asistencia obligatoria a la capacitación y entrenamiento sobre Seguridad y Salud en el Trabajo. 
A continuación, se presentan los principales riesgos dentro de la empresa.

Tabla 5.16

Riesgos

\begin{tabular}{|l|l|l|l|l|l|l|}
\hline $\begin{array}{l}\text { Fuente de } \\
\text { riesgo }\end{array}$ & Vulnerabilidad & Consecuencia & Causa & $\begin{array}{l}\text { Posibilidad } \\
\text { de } \\
\text { ocurrencia }\end{array}$ & $\begin{array}{l}\text { Intensidad } \\
\text { del daño }\end{array}$ & $\begin{array}{l}\text { Calificación } \\
\text { del riesgo }\end{array}$ \\
\hline Suelo & $\begin{array}{l}\text { Líquidos, } \\
\text { estorbos en el } \\
\text { piso }\end{array}$ & $\begin{array}{l}\text { Golpes y } \\
\text { contusiones }\end{array}$ & Caídas & $\begin{array}{l}\text { Ligeramente } \\
\text { dañino }\end{array}$ & Tolerable \\
\hline Máquinas & $\begin{array}{l}\text { Ruido por mal } \\
\text { funcionamiento }\end{array}$ & $\begin{array}{l}\text { Dolor de } \\
\text { cabeza }\end{array}$ & $\begin{array}{l}\text { Falta de } \\
\text { mantenimiento }\end{array}$ & Baja & $\begin{array}{l}\text { Altamente } \\
\text { dañino }\end{array}$ & Moderado \\
\hline $\begin{array}{l}\text { Toma- } \\
\text { corrientes }\end{array}$ & $\begin{array}{l}\text { Manipulación } \\
\text { con manos } \\
\text { mojadas }\end{array}$ & Quemaduras & Electrocución & Baja & $\begin{array}{l}\text { Altamente } \\
\text { dañino }\end{array}$ & Moderado \\
\hline $\begin{array}{l}\text { Equipos de } \\
\text { rehabilitación }\end{array}$ & $\begin{array}{l}\text { Personal } \\
\text { distraído }\end{array}$ & $\begin{array}{l}\text { Golpes y } \\
\text { contusiones }\end{array}$ & Caídas & Media & $\begin{array}{l}\text { Mediana- } \\
\text { mente } \\
\text { dañino }\end{array}$ & Moderado \\
\hline
\end{tabular}

\begin{tabular}{|c|c|c|c|c|}
\hline \multirow{2}{*}{\multicolumn{2}{|c|}{ Calificación }} & \multicolumn{3}{|c|}{ Probabilidad } \\
\hline & & Baja & Media & Alta \\
\hline \multirow{3}{*}{ Severidad } & Ligero & Trivial & Tolerable & Moderado \\
\hline & Medio & Tolerable & Moderado & Importante \\
\hline & Alto & Moderado & Importante & Intolerable \\
\hline
\end{tabular}

Elaboración propia

Otras consideraciones a tener en cuenta son:

- Protección contra incendios: se deberá tener el número adecuado de extintores para la infraestructura del local. Además, se deberá realizar simulacros para este tipo de eventos.

- Plan de evacuación en caso de sismo: Será necesario que se participe de los simulacros a nivel nacional y se programen simulacros dentro de la empresa. El local deberá contar con la señalización adecuada y con mapas de evacuación, zonas seguras, etc.

\subsection{Sistema de mantenimiento}

La gestión del mantenimiento es importante para un funcionamiento óptimo del Centro. Para el presente proyecto se contratará el servicio de terceros para el mantenimiento de 
los equipos. La empresa contratada para la limpieza del local se encargará también de la limpieza periódica de los equipos, mientras que para el mantenimiento preventivo y correctivo se contratará a una empresa especializada en este tipo de servicios.

Para manejar el sistema de mantenimiento se tomará en cuenta los siguientes tipos de actividades:

- Mantenimiento preventivo - tiene el objetivo de mantener los equipos en las condiciones de diseño sin permitir que se deterioren con el tiempo, provocando accidentes en los especialistas o pacientes.

- Mantenimiento correctivo - se realiza cuando se encuentra un defecto en el equipo. Debe corregirse antes de que se produzca una falla que pueda afectar los tratamientos a los clientes.

- Mantenimiento reactivo - se da cuando ocurre una falla en el equipo.

A continuación, se presenta el plan de mantenimiento preventivo para todos los equipos a ser utilizados. 
Tabla 5.17

Mantenimiento de equipos

\begin{tabular}{|c|c|c|}
\hline Trabajo de mantenimiento & Equipo & Periodicidad \\
\hline \multirow{5}{*}{ Limpieza profunda } & Tubos y ligas elásticas & Semanal \\
\hline & Plataformas de equilibrio & Semanal \\
\hline & Pelotas de ejercicio & Semanal \\
\hline & Pesas y mancuernas & Semanal \\
\hline & Barras paralelas & Semanal \\
\hline & Colchoneta para ejercicio & Semanal \\
\hline & Espaldera de madera & Semanal \\
\hline & Espejos & Semanal \\
\hline \multirow{2}{*}{ Limpieza profunda y revisión } & Tanque para compresas frías & Mensual \\
\hline & Tanque para compresas calientes & Mensual \\
\hline \multirow{5}{*}{ Limpieza profunda y calibración } & Máquinas para electroterapia & Bimestral \\
\hline & Máquina de ultrasonido & Bimestral \\
\hline & Máquina de láser terapéutico & Bimestral \\
\hline & Máquina de magnetoterapia & Bimestral \\
\hline & Máquina de ondas de choque & Bimestral \\
\hline \multirow{3}{*}{ Limpieza profunda, revisión y lubricación } & Banda sin fin & Trimestral \\
\hline & Escaladora & Trimestral \\
\hline & Bicicleta fija & Trimestral \\
\hline
\end{tabular}

Elaboración propia

\subsection{Programa de operaciones del servicio}

\subsubsection{Consideraciones sobre la vida útil del proyecto}

La vida útil del proyecto será de 5 años. Se han considerado los siguientes aspectos:

- Se trata de una pequeña empresa

- Se cubre el periodo de retorno de la inversión

- Se ha considerado el ciclo de vida de las empresas actuales del mismo rubro 


\subsubsection{Programa de operaciones del servicio durante la vida útil del proyecto}

A lo largo del ciclo de vida del proyecto no se producen variaciones significativas de la demanda que afecten el tamaño de la empresa y el número de trabajadores requerido.

Para análisis futuros, en caso surja la necesidad de crecimiento, se buscará contratar más especialistas y ampliar la capacidad del local. Dependiendo del crecimiento puede ser factible la creación de sucursales en otros distritos para aumentar la cantidad de pacientes atendidos.

\subsection{Requerimiento de materiales, personal y servicios}

\subsubsection{Materiales para el servicio}

Dado a que el proyecto es una empresa de servicio en donde el paciente deportista recuperado es el producto terminado, no existe una transformación de materia prima, y es por ello que no se requieren de insumos. En la siguiente tabla se muestran los materiales necesarios al año para el servicio.

Tabla 5.18

Requerimiento de materiales al año

\begin{tabular}{|l|l|l|}
\hline Material & Uso & Cantidad \\
\hline Papel para camillas (rollos 100m) & Camillas de tratamiento & 190 \\
\hline Sábanas (juego de dos) & Camillas de tratamiento & 5 \\
\hline Almohadas & Camillas de tratamiento & 10 \\
\hline Toallas & Envolver compresas frías y calientes & 24 \\
\hline Guantes (caja de 100 pares) & Higiene en terapia manual & 120 \\
\hline Alcohol & Limpiar antes de terapia con agentes físicos & 60 \\
\hline Algodón & Limpiar antes de terapia con agentes físicos & 120 \\
\hline Crema para masaje terapeútico & Facilitar terapia manual & 60 \\
\hline Papel toalla (200m) & Limpieza & 24 \\
\hline Papel higiénico (550m) & Servicios higiénicos & 18 \\
\hline Vendaje Neuromuscular & Terapia & 20 \\
\hline Vestimenta de personal & Vestimenta & 16 \\
\hline Artículos de oficina & Administración & 5 \\
\hline Fichas Médicas & Historias médicas & 11.980 \\
\hline
\end{tabular}

Elaboración propia 


\subsubsection{Determinación del requerimiento de personal de atención al cliente}

Para el presente proyecto, la mano de obra directa se considerará el personal médico, los fisioterapeutas y los técnicos respectivos que se encargarán del tratamiento de los pacientes en el CTFR.

En cuanto a los trabajadores indirectos, se encuentra el personal involucrado en la atención inicial y en la mejora de los servicios como en la calidad del servicio, para lograr el objetivo que es el paciente recuperado y apto para reanudar sus actividades físicas.

A continuación, se muestra la relación de puestos y el número de personas que el proyecto demandará como mano de obra directa e indirecta.

Tabla 5.19

Requerimiento de personal

\begin{tabular}{|l|l|l|}
\hline Clasificación & Cargo & $\mathrm{N}^{\circ}$ personas \\
\hline MOD & Médico & 1 \\
\hline MOD & Fisioterapeuta & 2 \\
\hline MOD & Técnico especializado & 2 \\
\hline MOI & Director general & 1 \\
\hline MOI & Asistente & 1 \\
\hline MOI & Jefe de operaciones & 1 \\
\hline MOI & Jefe comercial & 1 \\
\hline
\end{tabular}

Elaboración propia

\subsubsection{Servicios de terceros}

Los servicios de terceros son aquellos que no están relacionados con el principal giro del negocio, por eso se demandarán servicios externos que no se encontrarán dentro de la planilla, pero que es de vital importancia que la empresa incurra en esos gastos para aumentar la eficiencia del servicio.

En la siguiente tabla se muestran los servicios a tercerizar. 
Tabla 5.20

Servicios de terceros

\begin{tabular}{|l|l|}
\hline Servicio & Descripción \\
\hline Telefonía fija & Central telefónica con 3 anexos \\
\hline Internet & Servicio de Internet negocios de 4 Mbps \\
\hline Limpieza & Personas encargadas de la limpieza del local \\
\hline Vigilancia & 1 vigilante en la entrada del local en horario de atención \\
\hline $\begin{array}{l}\text { Mantenimiento y soporte técnico de } \\
\text { equipos }\end{array}$ & $\begin{array}{l}\text { Personal encargado de mantenimiento del local y de } \\
\text { equipos }\end{array}$ \\
\hline
\end{tabular}

Elaboración propia

\subsubsection{Otros: energía eléctrica, agua, transportes, etc.}

En cuanto a los requerimientos de otros servicios, se considerarán la energía eléctrica, el uso de agua potable y desagüe, y telefonía e Internet.

- Energía eléctrica: Se requiere para el funcionamiento de los equipos y las oficinas administrativas. Dado que la empresa estará ubicada en el distrito de San Borja, el proveedor de energía eléctrica es Luz del Sur

En la siguiente tabla se muestra el consumo de energía eléctrica producido en la iluminación del local y en las máquinas.

Tabla 5.21

Consumo de energía

\begin{tabular}{|l|l|l|l|l|}
\hline $\begin{array}{l}\text { Especificaciones } \\
\text { Consumo de Energía }\end{array}$ & Cantidad & $\begin{array}{l}\text { Consumo por hora } \\
\text { unitario }(\mathrm{kW} / \mathrm{h})\end{array}$ & $\begin{array}{l}\text { Utilización anual } \\
\text { unitario (h/año) }\end{array}$ & $\begin{array}{l}\text { Consumo anual } \\
(\mathrm{kW} / \mathrm{año})\end{array}$ \\
\hline $\begin{array}{l}\text { Iluminación (fluorescente, } \\
\left.1 \text { foco } \approx 8 \mathrm{~m}^{2}\right)\end{array}$ & 27 & 0,05 & 2.496 & 3.370 \\
\hline $\begin{array}{l}\text { Tanque para compresas } \\
\text { frías y calientes }\end{array}$ & 2 & 1,00 & 2.496 & 3.994 \\
\hline Máquina de electroterapia & 2 & 0,80 & 725 & 1.160 \\
\hline Máquina de ultrasonido & 1 & 0,80 & 470 & 376 \\
\hline $\begin{array}{l}\text { Máquina de láser } \\
\text { terapéutico }\end{array}$ & 1 & 0,80 & 980 & 768 \\
\hline $\begin{array}{l}\text { Máquina de } \\
\text { magnetoterapia }\end{array}$ & 3 & 0,80 & 2.165 & 5.196 \\
\hline $\begin{array}{l}\text { Máquina de ondas de } \\
\text { choque }\end{array}$ & 1 & 0,80 & 85 & 68 \\
\hline Banda sin fin & 1 & 1,40 & 1.000 & 1.400 \\
\hline
\end{tabular}

Elaboración propia 
- Agua potable y desagüe: El uso de agua se dará en los servicios higiénicos, de parte del personal y pacientes. El consumo de agua será de 20 litros por persona por día. La empresa proveedora de agua potable para la empresa es Sedapal.

Tabla 5.22

Consumo de agua

\begin{tabular}{|l|l|l|l|l|l|}
\hline & $\begin{array}{l}\text { Cantidad de personas por } \\
\text { día }\end{array}$ & $\begin{array}{l}\text { Consumo por día } \\
\text { (L/día) }\end{array}$ & $\begin{array}{l}\text { Consumo al } \\
\text { mes }\end{array}$ & Consumo al año \\
\hline Personal & 9 & 180 & $3.338,20$ & $28.058,40$ \\
\hline Clientes & 40 & 800 & $20.784,00$ & $249.408,00$ \\
\hline
\end{tabular}

Elaboración propia

- Telefonía e Internet: Necesario para mantener la comunicación entre los pacientes, secretaría, demás áreas de la empresa y servicios externos.

\subsection{Soporte físico del servicio}

\subsubsection{Factor edificio}

A continuación, se analizarán los principales factores para la construcción del centro.

- Número de pisos: El servicio contará con un piso para un tránsito más fluido y evitar largos recorridos, así como subir o bajar de pisos por parte de los pacientes.

- Material de los pisos: El piso de todo el centro será de porcelanato, ya que presenta una imagen pulcra al ambiente, refleja y proyecta una iluminación natural en el consultorio. Además, es un material durable, de alto tránsito, fácil de limpiar y mantener, lo cual lo hace ideal para consultorios médicos. Solamente en el área de rehabilitación física se contará con tapizón, para evitar deslizamientos.

- Accesos y vías de circulación: Es necesario tomar en cuenta las normas técnicas para el diseño de elementos de apoyo para personas con discapacidad en los establecimientos de salud regulado por el MINSA, ya que es probable que algunos pacientes requieran el uso de sillas de ruedas o algún otro accesorio ortopédico. 
Tabla 5.23

Criterios para accesos y circulaciones

\begin{tabular}{|l|l|l|}
\hline Vías de circulación & \multicolumn{2}{|l|}{ Características } \\
\hline Puertas exteriores & Ancho mínimo & $1 \mathrm{~m}$ \\
\hline \multirow{3}{*}{$\begin{array}{l}\text { Rampa de entrada (en caso } \\
\text { sea necesario) }\end{array}$} & Ancho mínimo & $1,2 \mathrm{~m}$ libre entre pasamanos \\
\cline { 2 - 3 } & Largo máximo & $6 \mathrm{~m}$ \\
\cline { 2 - 3 } & Pasamanos & $\begin{array}{l}\text { Altura }(2 \text { pasamanos): el primero a } 90 \mathrm{~cm} \text { y el segundo } \\
\text { a } 75 \mathrm{~cm} \text { del nivel del piso }\end{array}$ \\
\cline { 2 - 3 } & $\begin{array}{l}\text { Pendiente } \\
\text { máxima }\end{array}$ & $6 \%$ \\
\hline \multirow{2}{*}{ Puertas interiores } & \multirow{2}{*}{$\begin{array}{l}6 \% \\
\text { Ancho mínimo }\end{array}$} & Áreas de atención al paciente: $1 \mathrm{~m}$ \\
\cline { 2 - 3 } & Áreas administrativas: $90 \mathrm{~cm}$ \\
\hline Pasadizos & Ancho mínimo & $1,80 \mathrm{~m}$ \\
\hline
\end{tabular}

Fuente: MINSA, (2015)

- Techos: Se va a utilizar falso techo con material ligero, ya que tiene como ventajas el fácil montaje y practicidad para la instalación de iluminación y ductos. La altura mínima del piso terminado al falso techo será de $2,30 \mathrm{~m}$.

- Iluminación: Se instalarán lámparas de techo con luces fluorescentes empotradas en el falso techo para iluminar todos los espacios, de manera que se obtiene una luz blanca ideal para realizar las diferentes labores de oficina y de tratamiento respectivo. Asimismo, se considerarán las especificaciones establecidas por el Ministerio de Energía y Minas, en la norma EM. 010 - Instalaciones eléctricas interiores.

\subsubsection{El ambiente del servicio}

En cuanto a los ambientes con los que contará el servicio, se detallan a continuación.

- Estacionamiento: Se contará con cuatro estacionamientos, incluido un estacionamiento para discapacitados. Según la Municipalidad de San Borja, se requiere 1 estacionamiento por cada $40 \mathrm{~m}^{2}$ de área útil para los centros médicos. De acuerdo a lo establecido por la Municipalidad, el área útil no incluye baños, pasadizos, áreas destinadas a depósito y hall de acceso. Así, el área útil del CTRF es de $138 \mathrm{~m}^{2}$ y se requerirán 3.45, es decir 4, estacionamientos. Según el Ministerio de Vivienda, Construcción y Saneamiento, las dimensiones mínimas 
de los espacios de estacionamiento accesibles serán de 3,80m x 5,00m y los estacionamientos regulares deben ser mínimo de 2,50m x 5,00 m. Adicionalmente la Municipalidad de San Borja exige que se designe 1 estacionamiento de bicicletas por cada 5 estacionamientos vehiculares.

- Área administrativa: El personal administrativo estará formado por el director general, jefe de operaciones y jefe comercial. Se dispondrá de una sola oficina para todo el personal administrativo, el cual contará con un área aproximada de $15 \mathrm{~m}^{2}$.

- Área de consultorio: La sala de consultas médicas será un ambiente cerrado, ya que se utiliza principalmente para entrevistas y asesoramiento médico, así como para evaluaciones y elaboración de informes médicos. Lo recomendable es que el área de consultorio mida entre 12 a $16 \mathrm{~m}^{2}$, que cuente con un escritorio con computadora y dos sillas como mínimo.

- Área de tratamiento: Se dispondrá de un ambiente amplio y con divisiones para separar las camillas de atención para que el paciente reciba una atención privada. Cada sub-ambiente deberá contar con una silla, una camilla, y además de un tomacorriente para enchufar las máquinas.

- Área de rehabilitación física: Se diseñará un ambiente cuyas dimensiones estarán en relación a la cantidad de pacientes que se esperan tratar por turno, en este caso, hasta para 4 pacientes. Se dispondrá de todos los materiales, equipos e inmobiliarios necesarios, así como espejos en lugares convenientes para que los pacientes observen sus ejercicios.

- Área de espera: El tamaño depende del número y de la frecuencia de uso de las áreas de consultorio y tratamiento; sin embargo, al contar con el servicio de cita previa, se minimizará el tamaño de la sala de espera. Asimismo, en el área de espera se encontrará la recepción donde se programarán las citas y el registro de asistencia de los pacientes, y contará con un espacio para almacenar las actas de los pacientes (archivos). La conexión con la zona de funciones médicas será lo más corta posible. Según las normas técnicas para proyectos de arquitectura hospitalaria, elaborado por el MINSA, se considera $24 \mathrm{~m}^{2}$ por consultorio para el área de espera. 
- Almacén de materiales: El área destinada al almacén será reducido, ya que sólo se necesitará espacio para materiales de apoyo como sábanas, almohadas, papel toalla, algodón, entre otros.

- Servicios higiénicos: En el área administrativa se contará con un servicio higiénico mixto, tanto para damas como caballeros debido al bajo número de personal administrativo, el cual contará con un inodoro, un lavamanos y espacio suficiente para un vestuario.

- En el área común, para los pacientes, se contará con servicios separados uno para damas y otro para caballeros. Ambos servicios se diseñarán bajo las normas técnicas para el diseño de elementos de apoyo para personas con discapacidad en los establecimientos de salud, establecido por el MINSA:

- Circulaciones internas de $1,50 \mathrm{~m}$ de ancho.

- Puertas de cubículos con abatimiento hacia afuera.

- El inodoro debe estar colocado a $56 \mathrm{~cm}$ de su eje al muro más cercano y a 52 $\mathrm{cm}$ de altura.

○ Barras de apoyo de fierro galvanizado esmaltado de 1 1/2” de diámetro.

○ Las barras de apoyo horizontales de $90 \mathrm{~cm}$ de longitud colocadas a $50 \mathrm{~cm} \mathrm{y}$ $90 \mathrm{~cm}$ de altura del lado de la pared más cercana al inodoro y a $30 \mathrm{~cm}$ del muro posterior.

○ El lavabo estará colocado a $76 \mathrm{~cm}$ de altura libre.

○ Gancho para colgar muletas, colocado a 1,60 m de altura.

Tabla 5.24

Determinación de los servicios higiénicos

\begin{tabular}{|l|l|l|l|}
\hline Área & Cantidad & Área unitaria & Área total \\
\hline Área administrativa & 1 & $6 \mathrm{~m}^{2}$ & $6 \mathrm{~m}^{2}$ \\
\hline Área de atención & 2 & $6 \mathrm{~m}^{2}$ & $12 \mathrm{~m}^{2}$ \\
\hline
\end{tabular}

Elaboración propia 


\subsection{Disposición de la instalación del servicio}

\subsubsection{Disposición general}

Luego de haber calculado el número de recursos necesarios para el servicio, se determinará el área mínima para la zona de tratamiento físico, a través del método de Guerchet.

\section{Tabla 5.25}

Estimación del área teórica de terapia física, manual y rehabilitación.

\begin{tabular}{|c|c|c|c|c|c|c|c|c|c|c|c|}
\hline Elemento & 1 & a & $\mathrm{h}$ & $\mathrm{N}$ & $\mathrm{n}$ & Ss & $\mathrm{Sg}$ & Ss $\times n$ & Ss $\times n \times h$ & $\mathrm{Se}$ & ST \\
\hline \multicolumn{12}{|c|}{ Elementos estáticos } \\
\hline $\begin{array}{l}\text { Tanque para compresas } \\
\text { frías }\end{array}$ & 0,7 & 0,4 & 0,85 & 1 & 1 & 0,28 & 0,28 & 0,28 & 0,24 & 0,43 & 0,99 \\
\hline $\begin{array}{l}\text { Tanque para compresas } \\
\text { calientes }\end{array}$ & 0,7 & 0,4 & 0,85 & 1 & 1 & 0,28 & 0,28 & 0,28 & 0,24 & 0,43 & 0,99 \\
\hline $\begin{array}{l}\text { Máquina Electroterapia + } \\
\text { carro multifunción }\end{array}$ & 1,0 & 0,4 & 0,9 & 1 & 1 & 0,40 & 0,40 & 0,80 & 0,72 & 0,61 & 2,82 \\
\hline $\begin{array}{l}\text { Máquina Ultrasonido + } \\
\text { carro multifunción }\end{array}$ & 1,0 & 0,4 & 0,9 & 1 & 1 & 0,40 & 0,40 & 0,40 & 0,36 & 0,61 & 1,41 \\
\hline $\begin{array}{l}\text { Máquina Láser + carro } \\
\text { multifunción }\end{array}$ & 1,0 & 0,4 & 0,9 & 1 & 2 & 0,40 & 0,40 & 0,40 & 0,36 & 0,61 & 1,41 \\
\hline $\begin{array}{l}\text { Máquina Magnetoterapia } \\
\text { + carro multifunción }\end{array}$ & 1,0 & 0,4 & 0,9 & 1 & 3 & 0,40 & 0,40 & 1,20 & 1,08 & 0,61 & 2,82 \\
\hline Máquina ondas de choque & 1,5 & 0,6 & 0,5 & 1 & 1 & 0,90 & 0,90 & 0,90 & 0,45 & 1,37 & 3,17 \\
\hline Silla & 0,4 & 0,4 & 0,8 & 1 & 4 & 0,16 & 0,16 & 0,64 & 0,51 & 0,24 & 2,26 \\
\hline Camilla & 1,8 & 0,7 & 0,8 & 3 & 4 & 1,26 & 2,52 & 5,04 & 4,03 & 2,88 & 26,64 \\
\hline $\begin{array}{l}\text { Mueble para almacenar } \\
\text { accesorios }\end{array}$ & 1,5 & 0,70 & 1,80 & 1 & 2 & 1,05 & 1,05 & 2,10 & 3,78 & 1,60 & 7,40 \\
\hline Barras paralelas & 3,0 & 0,50 & 0,75 & 2 & 1 & 1,50 & 3,00 & 1,50 & 1,13 & 3,43 & 7,93 \\
\hline $\begin{array}{l}\text { Soporte para pesas y } \\
\text { mancuernas }\end{array}$ & 1,2 & 0,60 & 0,90 & 1 & 1 & 0,72 & 0,72 & 0,72 & 0,65 & 1,10 & 2,54 \\
\hline Espaldera de madera & 1,0 & 0,15 & 2,50 & 1 & 2 & 0,15 & 0,15 & 0,30 & 0,75 & 0,23 & 1,06 \\
\hline Banda sin fin & 1,6 & 0,70 & 1,30 & 2 & 1 & 1,12 & 2,24 & 1,12 & 1,46 & 2,56 & 5,92 \\
\hline Escaladora & 1,5 & 0,70 & 1,50 & 2 & 1 & 1,05 & 2,10 & 1,05 & 1,58 & 2,40 & 5,55 \\
\hline Bicicleta fija & 1,1 & 0,50 & 1,10 & 2 & 1 & 0,55 & 1,10 & 0,55 & 0,61 & 1,26 & 2,91 \\
\hline \multicolumn{3}{|l|}{ Elementos móviles } & $\not$ & 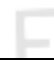 & & & & & & & \\
\hline Personal & & & 1,65 & - & 4 & 0,50 & & 2 & 3,30 & & \\
\hline Paciente & & & 1,65 & & 4 & 0,50 & & 2 & 3,30 & & \\
\hline \multicolumn{11}{|c|}{ Superficie total $\left(\mathrm{m}^{2}\right)$} & 75,80 \\
\hline
\end{tabular}

\begin{tabular}{|l|l|}
\hline hEM & 1,65 \\
\hline hEE & 1,08 \\
\hline $\mathrm{k}$ & 0,76 \\
\hline
\end{tabular}

Elaboración propia 
Según la superficie total determinada, el área de terapia física, manual y de rehabilitación física, teóricamente debe tener $75,80 \mathrm{~m}^{2}$. Adicionalmente, se está considerando espacios adicionales para que el tránsito sea cómodo.

El área que se considerará para la zona de terapia física y manual será:

- Largo: $9 \mathrm{~m}$

- Ancho: $6 \mathrm{~m}$

- Área total: $54 \mathrm{~m}^{2}$

En cuando el área teórica de rehabilitación, es de aproximadamente $30 \mathrm{~m}^{2}$, considerando los equipos y muebles necesarios. Se considerará un área total de $45 \mathrm{~m}^{2}$ debido a que los pacientes requieren de espacios amplios para ejecutar ciertos ejercicios y movimientos para la correcta rehabilitación física.

\subsubsection{Disposición de detalle}

- Diagrama relacional

Figura 5.5

Diagrama relacional

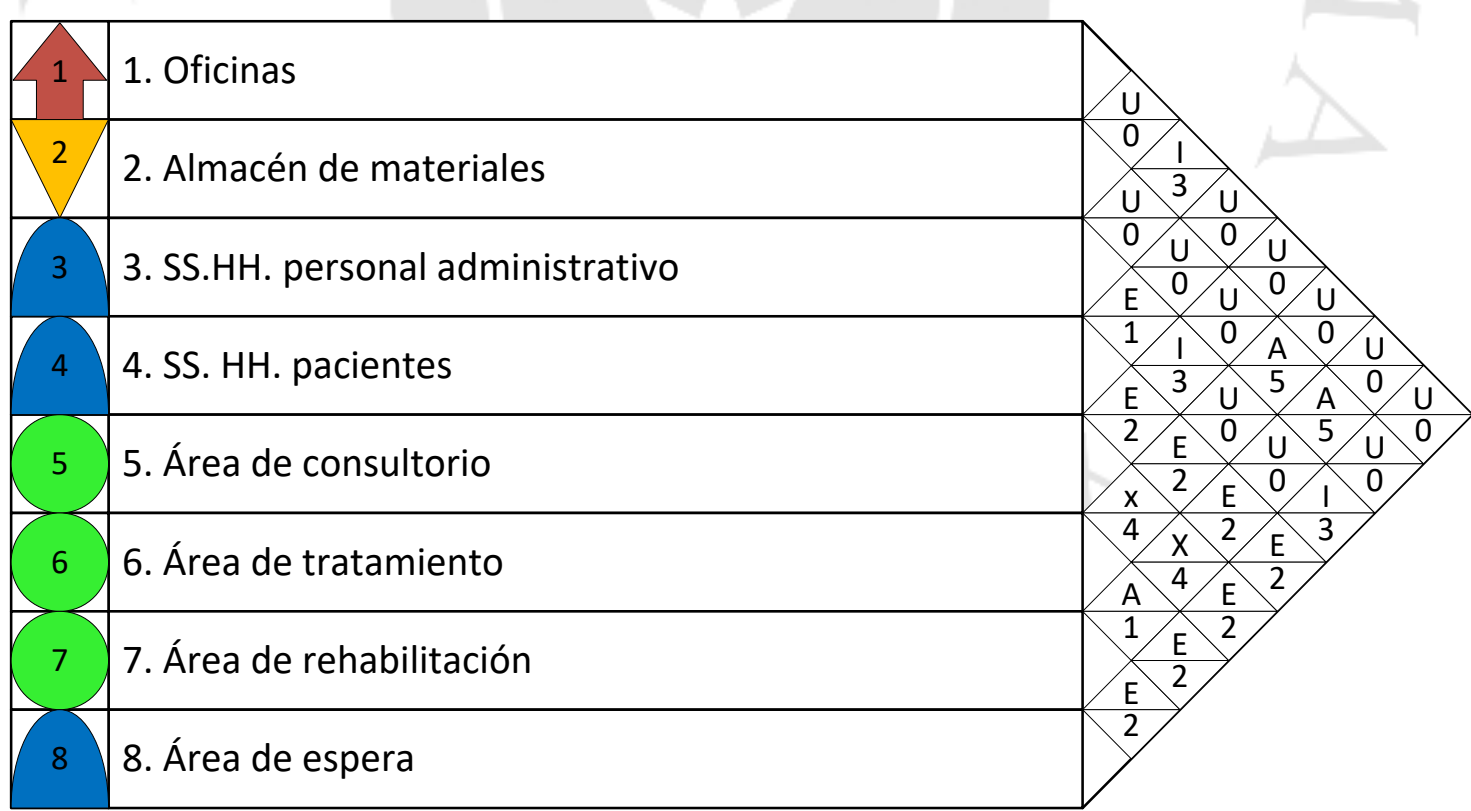

Elaboración propia 
- Diagrama relacional de actividades

Figura 5.6

Diagrama relacional de actividades

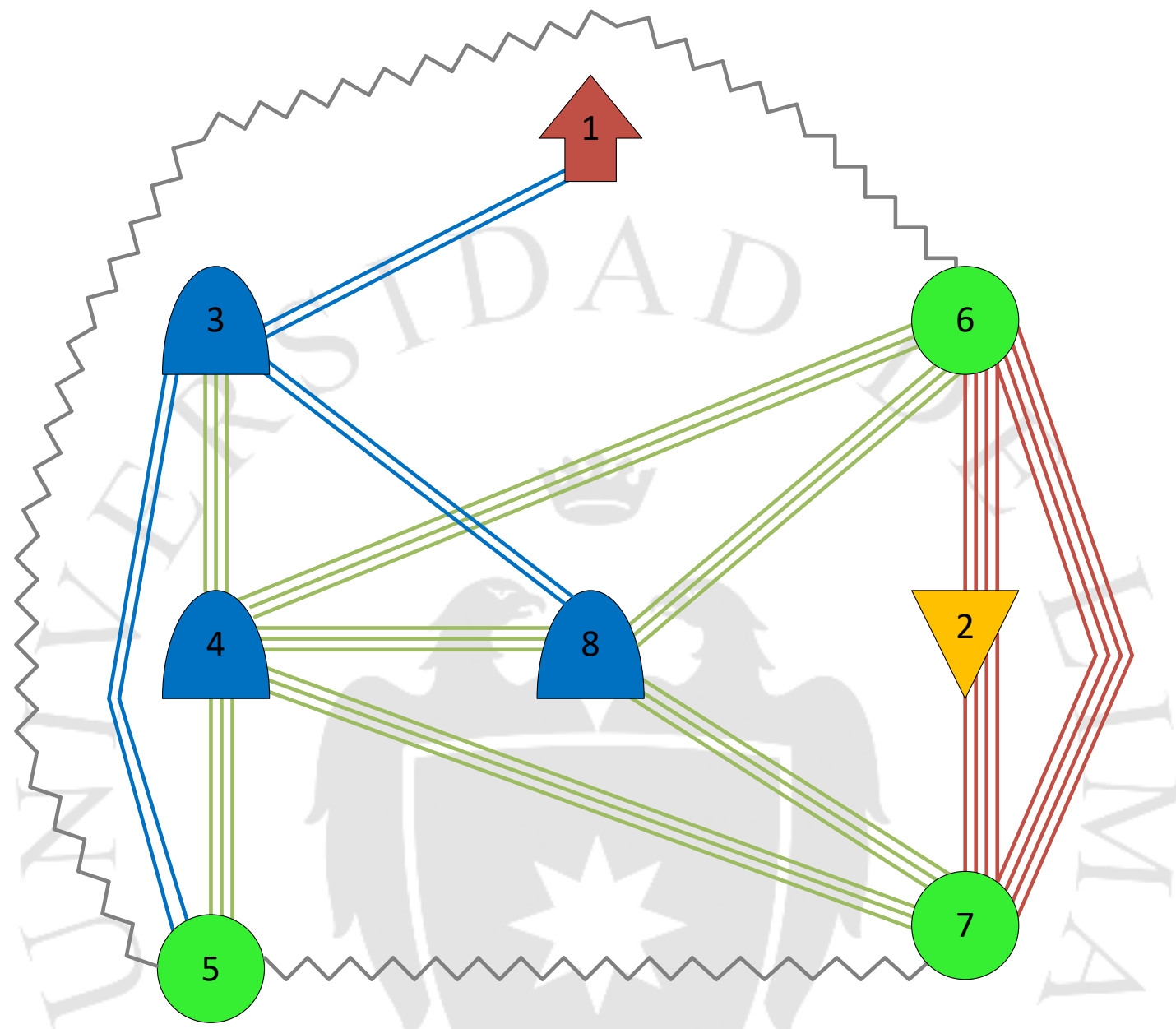

Elaboración propia 
- Diagrama relacional de espacios

Figura 5.7

Diagrama relacional de espacios

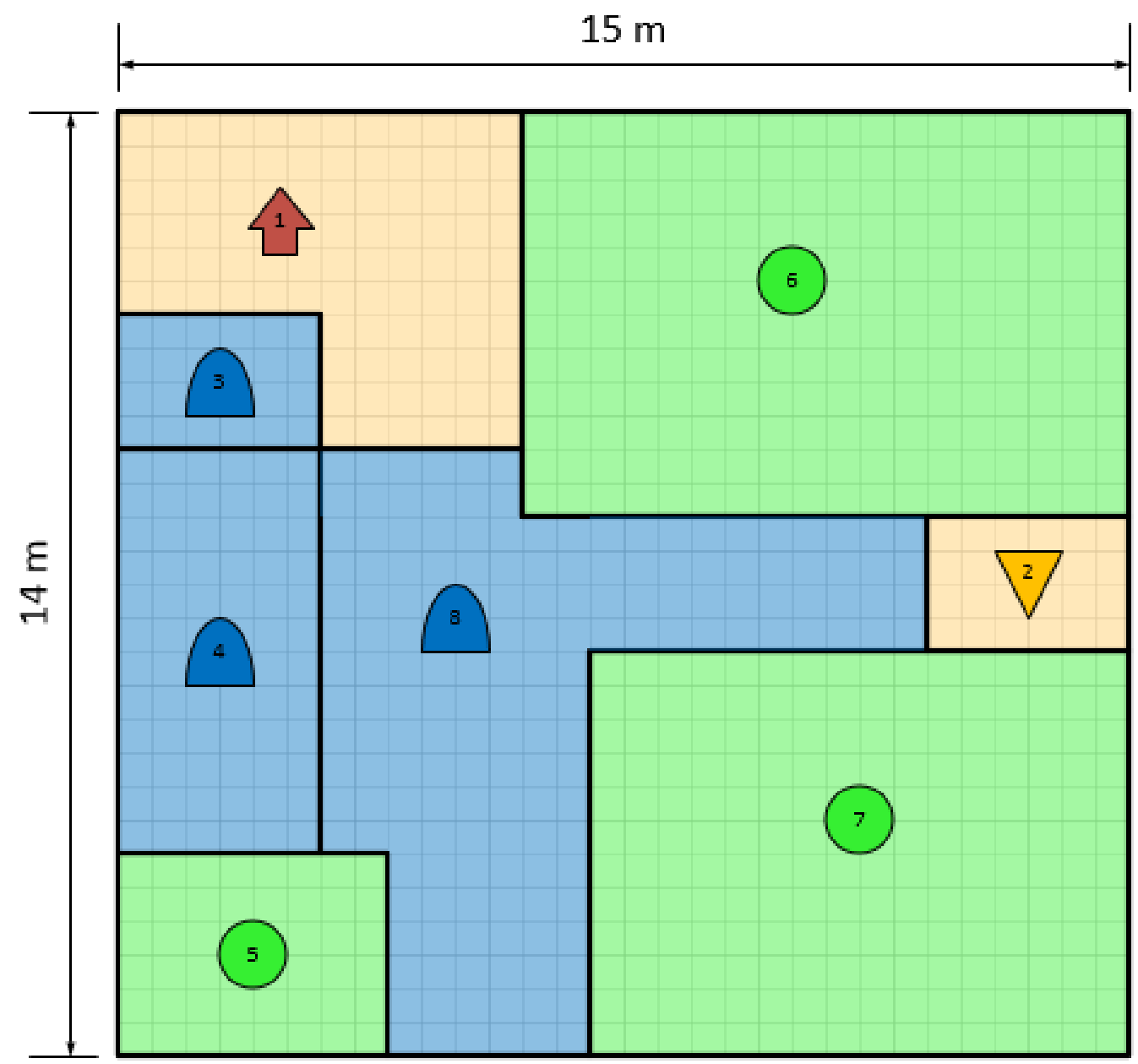

Elaboración propia 
- Diagrama detallado de planta

Figura 5.8

Plano del proyecto

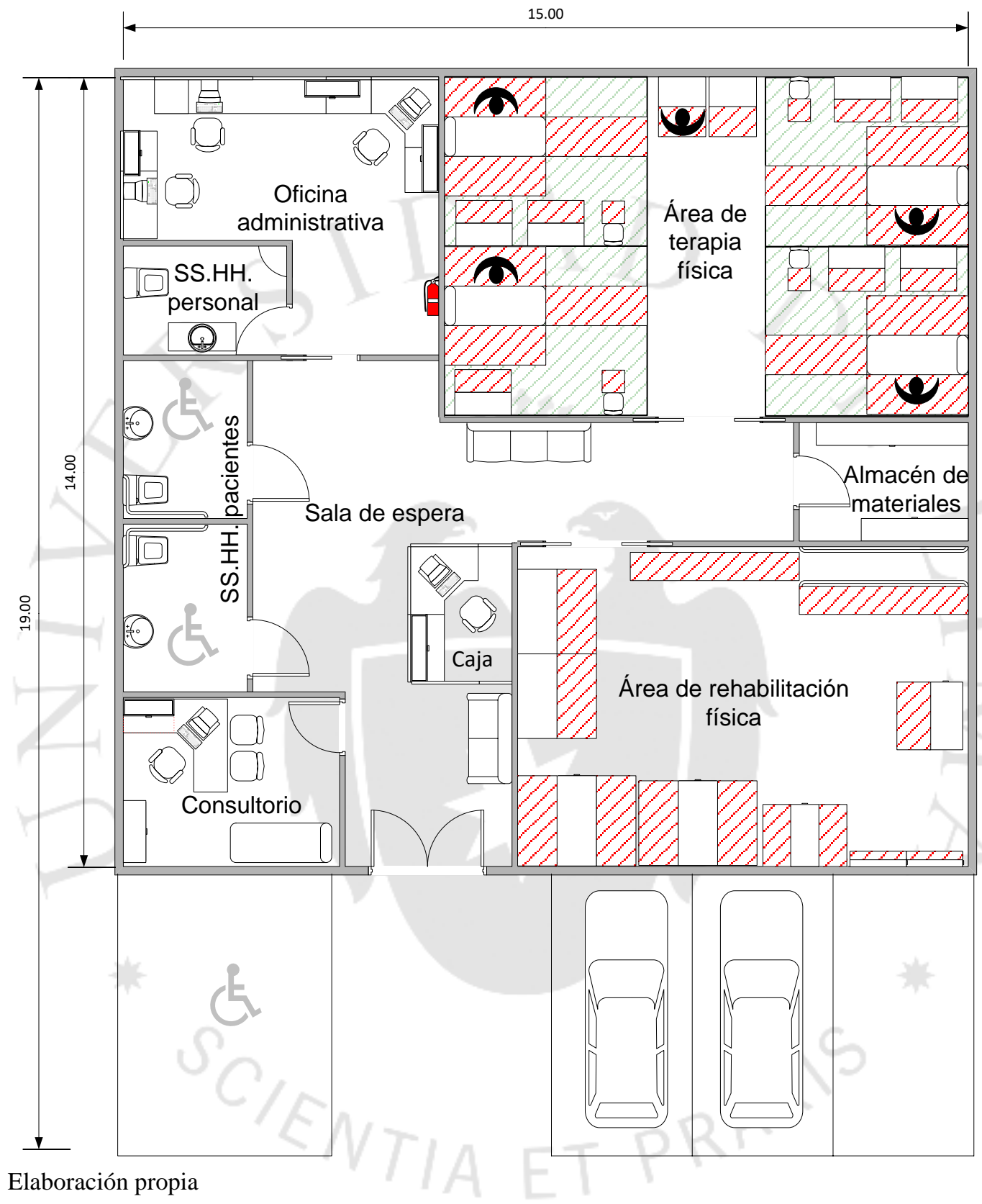

\begin{tabular}{|l|l|l|}
\hline \multicolumn{3}{|c|}{ Plano de distribución } \\
\hline Escala & Fecha & Área \\
\hline $1: 100$ & $19 / 10 / 2016$ & $285 \mathrm{~m}^{2}$ \\
\hline
\end{tabular}




\subsection{Cronograma de implementación del proyecto}

Para implementar el proyecto, se considerarán los siguientes pasos:

- Elaborar un estudio de pre-factibilidad donde se presentarán las necesidades de financiamiento y técnicas de producción necesarias. (22 semanas)

- Elaborar un estudio de factibilidad, donde se utilizarán antecedentes para poder analizarlos y con ayuda de información primaria se definirán variables de mercado, producción y financiamiento. (10 semanas)

- Ingeniería básica y de detalle, es donde se diseñan los planos de arquitectura, obras civiles, entre otros. (7 semanas)

- Constitución y organización, se selecciona al personal y se dan capacitaciones. (3 semanas)

- Contratos y adquisiciones, se realiza la compra de equipos, terreno, licencias, entre otros. (3 semanas)

- Gestión financiera, se buscará acreedores y se evalúan préstamos de un banco. (4 semanas)

- Instalación y montaje (se realizan las actividades de instalación, montajes, entre otros) (10 semanas)

- Pruebas (todos los equipos ya instaladas deben ser probadas y revisar su funcionamiento) (4 semanas)

- Puesta en marcha (4 semanas) 
Figura 5.9

Programa de implementación del proyecto

\begin{tabular}{|c|c|c|c|c|c|c|c|c|c|c|c|c|c|c|c|c|c|c|c|}
\hline \multirow{2}{*}{ Actividades } & \multirow{2}{*}{ Inicio } & \multirow{2}{*}{ Fin } & \multirow{2}{*}{$\begin{array}{l}\text { Duración } \\
\text { (semanas) }\end{array}$} & \multicolumn{9}{|c|}{2016} & \multicolumn{7}{|c|}{2017} \\
\hline & & & & abr & may & jun & jul & ago & sep & oct & nov & dic & ene & feb & mar & abr & may & jun & jul \\
\hline Estudio de Pre-Factibilidad & $01 / 04 / 2016$ & $31 / 10 / 2016$ & 30 & & & & & & & & & & & & & & & & \\
\hline Estudio de Factibilidad & $31 / 10 / 2016$ & 09/01/2017 & 10 & & & & & & & & & & 1 & & & & & & \\
\hline Ingeniería del proyecto & 09/01/2017 & $27 / 02 / 2017$ & 7 & & & & & & & & & & Ex & 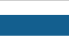 & & & & & \\
\hline Constitución y Organización & $23 / 01 / 2017$ & $13 / 02 / 2017$ & 3 & & & & & & & & & & & 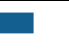 & & & & & \\
\hline Adquisiciones & $27 / 02 / 2017$ & $20 / 03 / 2017$ & 3 & & & & & & & & & & & & 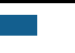 & & & & \\
\hline Instalación & $27 / 02 / 2017$ & $08 / 05 / 2017$ & 10 & & & & & & & & & & & & & & ם & & \\
\hline Pruebas & 08/05/2017 & 05/06/2017 & 4 & & & & & & & & & & & & & & 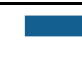 & & \\
\hline Puesta en marcha & $05 / 06 / 2017$ & $03 / 07 / 2017$ & 4 & & & & & & & & & & & & & & & & \\
\hline
\end{tabular}

Elaboración propia

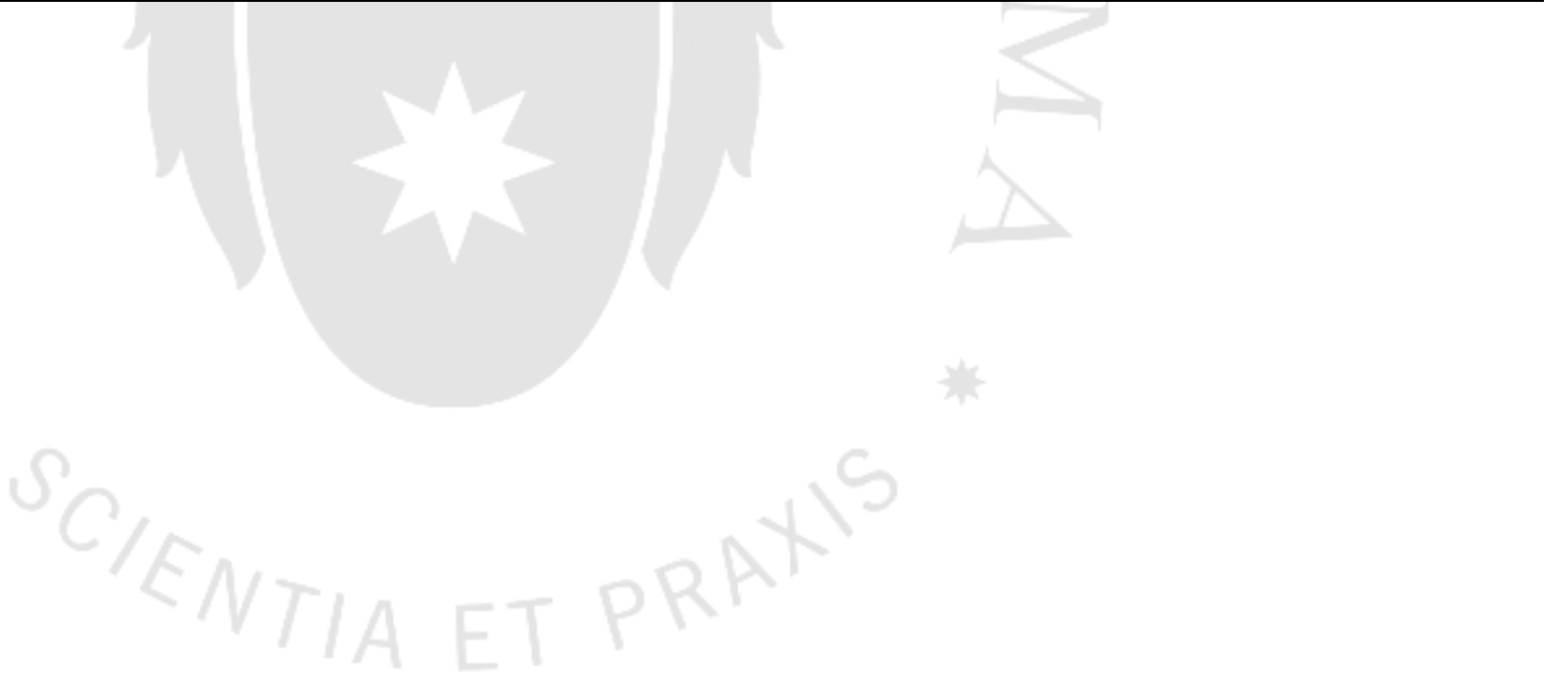




\section{CAPÍTULO VI. ORGANIZACIÓN ADMINISTRATIVA}

\subsection{Organización empresarial}

La forma legal de organización de la empresa será: Empresa Individual de Responsabilidad Limitada (E.I.R.L.).

Como la orientación del negocio se encuentra inicialmente dirigida al sector de pequeña empresa, se considera apropiado este tipo de organización, ya que, contrario a las sociedades anónimas, esta persona jurídica no cuenta con el requisito de pluralidad de socios, por tanto, su estructura jerárquica en la toma de decisiones es de menor complejidad. En ese sentido, las diferencias señaladas se ven reflejadas en menores costos para su constitución y en el ejercicio por parte del titular de un control directo y total del negocio.

Adicionalmente, como la responsabilidad de la empresa es limitada, esta responde a sus deudas con patrimonio propio distinto al de su titular, salvaguardando los bienes propios de este como persona natural.

\subsection{Requerimientos de personal directivo, administrativo y de soporte interno} del servicio

A continuación, se detallarán las funciones que desarrollará el personal.

- Dirección General: Se encarga de la contabilidad y finanzas de la empresa. Asimismo, la generación de estrategias de crecimiento para la empresa.

- Asistente: Realiza funciones básicas como registrar datos de los pacientes, archivar documentos, atender llamadas, reservar citas, cobro a pacientes y llevar un registro de atención del paciente.

- Jefe comercial: Se encarga de la publicidad y promoción del centro, así como de la administración de recursos humanos.

- Jefe de operaciones: Se encarga del mantenimiento de los equipos, compra de materiales y de la supervisión del servicio brindado por los médicos y fisioterapeutas. 
- Médico: Brinda la primera atención a los pacientes, diagnostica y evalúa la situación del paciente.

- Fisioterapeutas: Evalúan al paciente y determinan la rutina de terapia del paciente.

- Técnico especializado: Asiste al fisioterapeuta.

\subsection{Estructura organizacional}

\section{Figura 6.1}

Organigrama de la empresa

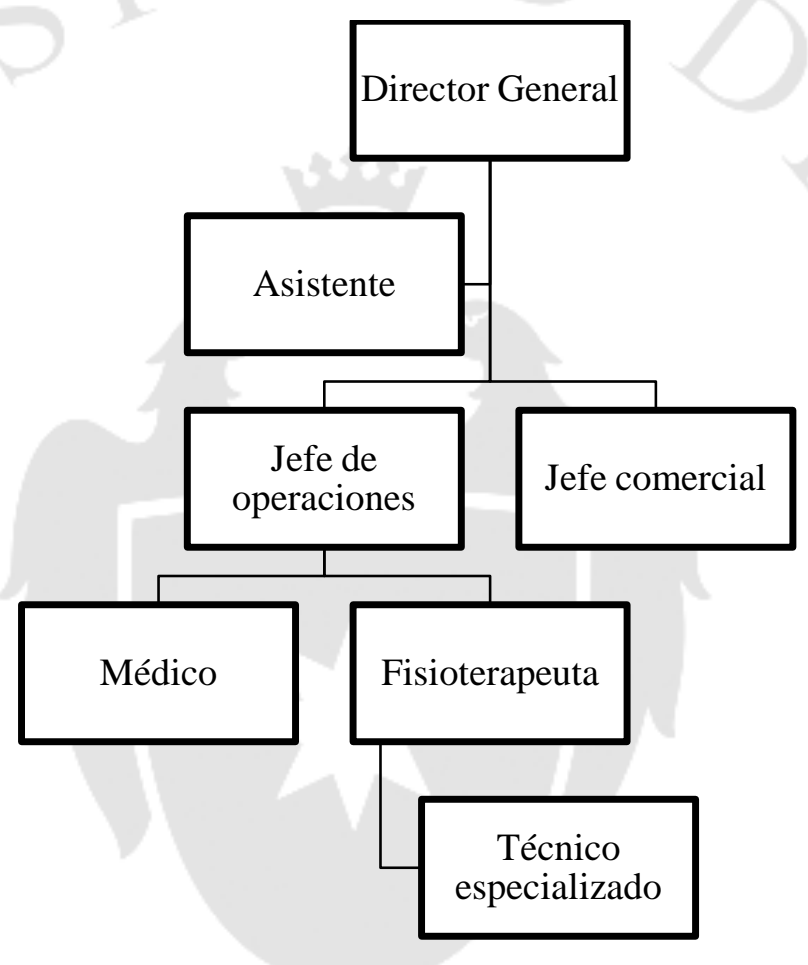

Elaboración propia 


\section{CAPÍTULO VII. ASPECTOS ECONÓMICOS}

\subsection{Inversiones}

\subsubsection{Inversión en la infraestructura para el servicio}

Para el cálculo de la inversión del proyecto se considerarán tanto la inversión tangible como la intangible.

Primero, se estimará la inversión de los tangibles; es decir, el costo total de todos los equipos, accesorios, muebles y enseres que serán necesarios para el servicio.

\section{Tabla 7.1}

Costo de los equipos

\begin{tabular}{|l|r|r|r|r|}
\hline Equipos & Costo c/ IGV & Costo s/IGV & Cantidad & Costo Total (S/.) \\
\hline Tanque compresas frías & $11.470,00$ & $9.720,34$ & 1 & $9.720,34$ \\
\hline Tanque compresas calientes & $7.130,00$ & $6.042,37$ & 1 & $6.042,37$ \\
\hline Electroterapia & $6.510,00$ & $5.516,95$ & 1 & $5.516,95$ \\
\hline Ultrasonido & $6.200,00$ & $5.254,24$ & 1 & $5.254,24$ \\
\hline Láser terapéutico & $11.160,00$ & $9.457,63$ & 2 & $18.915,26$ \\
\hline Magnetoterapia & $5.580,00$ & $4.728,81$ & 3 & $14.186,44$ \\
\hline Ondas de choque & $114.700,00$ & $97.203,39$ & 1 & $97.203,39$ \\
\hline \multicolumn{5}{|r}{} \\
\hline
\end{tabular}

Elaboración propia 
Tabla 7.2

Costo de los accesorios de rehabilitación

\begin{tabular}{|l|r|r|r|r|}
\hline Accesorios & Costo c/ IGV & Costo s/IGV & Cantidad & Costo Total (S/.) \\
\hline Tubos y ligas elásticas & 80,00 & 67,80 & 4 & 271,19 \\
\hline Plataformas de equilibrio & 200,00 & 169,49 & 3 & 508,47 \\
\hline Pelotas de ejercicio & 135,00 & 114,41 & 4 & 457,63 \\
\hline Pesas y mancuernas & 50,00 & 42,37 & 12 & 508,47 \\
\hline Barras paralelas & 280,00 & 237,29 & 2 & 474,58 \\
\hline Colchonetas para ejercicios & 80,00 & 67,80 & 6 & 406,78 \\
\hline Espaldera de madera & 450,00 & 381,36 & 2 & 762,71 \\
\hline Espejos & 30,00 & 25,42 & 5 & 127,12 \\
\hline Banda sin fin & $2.500,00$ & $2.118,64$ & 1 & $2.118,64$ \\
\hline Escaladora & $1.500,00$ & 1.271 .19 & 1 & 1.271 .19 \\
\hline Bicicleta fija & $1.200,00$ & $1.016,95$ & 1 & $1.016,95$ \\
\hline & & & Total & $\mathbf{7 . 9 2 3 , 7 3}$ \\
\hline
\end{tabular}

Elaboración propia

Tabla 7.3

Costos de muebles y enseres

\begin{tabular}{|c|c|c|c|c|}
\hline Muebles y enseres & Costo c/ IGV & Costo s/IGV & Cantidad & Costo Total (S/.) \\
\hline \multicolumn{5}{|l|}{ ÁREA DE TRATAMIENTO } \\
\hline Camillas & 350,00 & 296,61 & 5 & $1.483,05$ \\
\hline Taburete & 90,00 & 76,27 & 5 & 381,36 \\
\hline Biombos & 300,00 & 254,24 & 2 & 508,47 \\
\hline \multicolumn{5}{|l|}{ ÁREA DE REHABILITACIÓN } \\
\hline Mueble para almacenar accesorios & 200,00 & 169,49 & 2 & 338,98 \\
\hline Soporte para pesas y mancuernas & 800,00 & 677,97 & 1 & 627,97 \\
\hline \multicolumn{5}{|c|}{ OFICINA, CONSULTORIO Y RECEPCIÓN } \\
\hline Computadoras & $2.000,00$ & $1.694,92$ & 5 & $8.474,58$ \\
\hline Impresora multifuncional & 800,00 & $-677,97$ & 1 & 677,97 \\
\hline Escritorios & 300,00 & 254,24 & 5 & $1.271,19$ \\
\hline Sillas de oficina & 100,00 & 84,75 & 7 & 593,22 \\
\hline Estantes para oficina & $1.000,00$ & 847,46 & 4 & $3.389,83$ \\
\hline Asientos de espera & 250,00 & 211,86 & 2 & 423,73 \\
\hline \multicolumn{5}{|l|}{ OTROS } \\
\hline Estantes para almacén & 300,00 & 254,24 & 2 & 508,47 \\
\hline \multicolumn{4}{|r|}{ Total } & $18.728,81$ \\
\hline
\end{tabular}

Elaboración propia 
A continuación, se estimará el costo de los intangibles.

Tabla 7.4

Costo de intangibles

\begin{tabular}{|l|r|r|r|}
\hline Intangibles & Costo c/ IGV & Costo s/IGV & Costo Total (S/.) \\
\hline Estudio de pre-factibilidad & $3.000,00$ & $2.542,37$ & $2.542,37$ \\
\hline Constitución y organización & 600,00 & 508,47 & 508,47 \\
\hline Licencia de funcionamiento & 693,51 & 587,72 & 587,72 \\
\hline Sistemas de información & $3.000,00$ & $2.542,37$ & $2.542,37$ \\
\hline Imprevistos & $3.000,00$ & $2.542,37$ & $2.542,37$ \\
\hline \multicolumn{2}{|r}{} & Total & $\mathbf{8 . 7 2 3 , 3 1}$ \\
\hline
\end{tabular}

Elaboración propia

\subsubsection{Capital de trabajo}

El capital de trabajo se define como todos los desembolsos que realiza la empresa para cubrir los primeros gastos de operación, hasta la obtención de las ganancias propias del servicio. Para el proyecto se ha estimado cubrir los gastos de materiales para el primer mes de servicio; incluyendo el costo total de materiales, remuneraciones y servicios al primer mes. Esto debido a que el cobro del servicio se realiza inmediatamente, por lo tanto, a partir del segundo mes se contará con dinero para realizar las compras de los materiales que se requieren para continuar con la atención. 
Tabla 7.5

Costo de materiales para el primer mes

\begin{tabular}{|l|r|r|r|r|}
\hline Materiales & Costo c/ IGV & Costo s/IGV & Cantidad & Costo Total (S/.) \\
\hline Papel para camillas (rollos 100m) & 25,00 & 21,00 & 15 & 317,80 \\
\hline Sábanas (juego de dos) & 60,00 & 50,85 & 5 & 254,24 \\
\hline Almohadas & 15,00 & 12,71 & 10 & 127,12 \\
\hline Toallas & 20,00 & 16,95 & 24 & 406,78 \\
\hline Guantes (caja de 100 pares) & 50,00 & 42,37 & 10 & 423,73 \\
\hline Alcohol & 10,00 & 8,47 & 5 & 42,37 \\
\hline Algodón & 10,00 & 8,47 & 10 & 84,75 \\
\hline Crema para masaje terapéutico & 15,00 & 12,71 & 5 & 63,56 \\
\hline Papel toalla (200m) & 100,00 & 84,75 & 2 & 169,49 \\
\hline Papel higiénico (550m) & 50,00 & 42,37 & 2 & 84,75 \\
\hline Vendaje Neuromuscular & 70,00 & 59,32 & 2 & 118,64 \\
\hline Vestimenta de personal & 50,00 & 42,37 & 16 & 677,97 \\
\hline Artículos de oficina & 20,00 & 16,95 & 5 & 84,75 \\
\hline Fichas médicas & 0,05 & 0,04 & 10,000 & 423,73 \\
\hline Elab & & & Total & $\mathbf{3 . 2 7 9 , 6 6}$ \\
\hline
\end{tabular}

Elaboración propia

Tabla 7.6

Capital de trabajo

\begin{tabular}{|l|r|}
\hline & Costo para el primer mes (S/.) \\
\hline Materiales & $3.279,66$ \\
\hline Remuneraciones & $37.723,2$ \\
\hline Servicios & $15.543,50$ \\
\hline Total KW & $\mathbf{5 6 . 5 4 5 , 8 6}$ \\
\hline
\end{tabular}

Elaboración propia 
Tabla 7.7

Inversión total del proyecto

\begin{tabular}{|c|c|}
\hline & Costo Total (S/.) \\
\hline \multicolumn{2}{|l|}{ Tangible e Intangible } \\
\hline Equipos de terapia & $156.838,98$ \\
\hline Accesorios de rehabilitación & $7,923.73$ \\
\hline Muebles y enseres & $18.728,81$ \\
\hline Intangibles & $8.723,31$ \\
\hline Total Inversión Tangible e Intangible & $192.214,84$ \\
\hline Capital de Trabajo & $56.545,86$ \\
\hline Inversión Total & $248,760.70$ \\
\hline
\end{tabular}

Elaboración propia

Por lo tanto, la inversión total necesaria para el presente proyecto es de S/. $248.760,70$.

\subsection{Costos de las operaciones del servicio}

\subsubsection{Costos de materiales del servicio}

Para las operaciones del servicio, se requiere la compra de los siguientes materiales.

\section{Tabla 7.8}

Costo de materiales por año

\begin{tabular}{|l|r|r|}
\hline & Cantidad & Costo Total (S/.) \\
\hline Papel para camillas (rollos) & 10 & 211,86 \\
\hline Sábanas (juego de dos) & 3 & 152,54 \\
\hline Almohadas & 5 & 63,56 \\
\hline Toallas & 8 & 135,59 \\
\hline Guantes (caja de 100 pares) & 20 & 847,46 \\
\hline Alcohol & 12 & 101,69 \\
\hline Algodón & 12 & 101,69 \\
\hline Crema hidratante & 12 & 152,54 \\
\hline Papel toalla (6 rollos) & 24 & $2.033,90$ \\
\hline Papel higiénico (6 rollos) & 36 & $1.525,42$ \\
\hline Vendaje Neuromuscular & 24 & $1.423,73$ \\
\hline Vestimenta de personal & 16 & 677,97 \\
\hline & Total & $\mathbf{7 . 4 2 7 , 9 7}$ \\
\hline
\end{tabular}

Elaboración propia 


\subsubsection{Costo de los servicios}

Los servicios con los que contará el servicio y sus respectivos costos de adquisición, se detallarán en la siguiente tabla.

Tabla 7.9

Costo de los servicios

\begin{tabular}{|c|c|c|c|c|}
\hline Servicio & Descripción & Proveedor & $\begin{array}{l}\text { Monto } \\
\text { mensual }\end{array}$ & $\begin{array}{l}\text { Monto } \\
\text { anual }\end{array}$ \\
\hline Internet & Internet negocios $4 \mathrm{Mbps}$ & Telefónica & 109,00 & $1.308,00$ \\
\hline Telefonía fija & Central telefónica con 4 anexos & Telefónica & 424,00 & $5.088,00$ \\
\hline Limpieza & 2 operarios tercerizados & SILSA & $1.500,00$ & $18.000,00$ \\
\hline Vigilancia & $\begin{array}{l}1 \text { vigilante turno diario, } 1 \text { turno } \\
\text { nocturno }\end{array}$ & $\begin{array}{l}\text { Orelia Group } \\
\text { SAS }\end{array}$ & $1.500,00$ & $18.000,00$ \\
\hline Mantenimiento & Preventivo, correctivo y reactivo & J.P. Rehab S.R.L. & 700,00 & $8.400,00$ \\
\hline Alquiler & $285 \mathrm{~m}^{2}$ & & 10.000 & $\begin{array}{l}120.000,0 \\
0\end{array}$ \\
\hline Agua & Agua y desagüe & Sedapal & 600,00 & $7.200,00$ \\
\hline $\begin{array}{l}\text { Energía } \\
\text { eléctrica }\end{array}$ & Consumo de máquinas e iluminación & Luz del Sur & 710,00 & $8.520,00$ \\
\hline
\end{tabular}

Elaboración propia

De esta manera, se calculará el monto anual a pagar por los servicios.

Tabla 7.10

Costo de los servicios proyectado

\begin{tabular}{|l|l|l|l|l|l|}
\hline & 2017 & 2018 & 2019 & 2020 & 2021 \\
\hline Total & $\mathbf{1 8 6 . 5 1 6 , 0 0}$ & $\mathbf{1 8 6 . 5 1 6 , 0 0}$ & $\mathbf{1 8 6 . 5 1 6 , 0 0}$ & $\mathbf{1 8 6 . 5 1 6 , 0 0}$ & $\mathbf{1 8 6 . 5 1 6 , 0 0}$ \\
\hline
\end{tabular}

Elaboración propia

\subsubsection{Costo del personal}

\subsubsection{Personal de atención al cliente}

A continuación, se mostrarán las remuneraciones del personal de atención al cliente: fisioterapeutas, técnicos y médico. 
Tabla 7.11

Costo de remuneraciones a fisioterapeutas

\begin{tabular}{|c|c|c|c|c|c|}
\hline & 2017 & 2018 & 2019 & 2020 & 2021 \\
\hline RBC mensual & $3.500,00$ & $3.570,00$ & $3.641,40$ & $3.714,23$ & $3.788,51$ \\
\hline Gratificaciones & $7.000,00$ & $7.140,00$ & $7.282,80$ & $7.428,46$ & $7.577,03$ \\
\hline CTS & $3.500,00$ & $3.570,00$ & $3.641,40$ & $3.714,23$ & $3.788,51$ \\
\hline Sueldo anual bruto & $52.500,00$ & $53.550,00$ & $54.621,00$ & $55.713,42$ & $56.827,69$ \\
\hline EsSalud anual $(8,40 \%)$ & $4.410,00$ & $4.498,20$ & $4.588,16$ & $4.679,93$ & $4.773,53$ \\
\hline Costo anual empleado & $56.910,00$ & $58.048,20$ & $59.209,16$ & $60.393,35$ & $61.601,21$ \\
\hline Total anual (2) & $113.820,00$ & $116.096,40$ & $118.418,33$ & $120.786,69$ & $123.202,43$ \\
\hline
\end{tabular}

Elaboración propia

Tabla 7.12

Costo de remuneraciones a técnicos

\begin{tabular}{|c|c|c|c|c|c|}
\hline & 2017 & 2018 & 2019 & 2020 & 2021 \\
\hline RBC mensual & $1.700,00$ & $1.734,00$ & $1.768,68$ & $1.804,05$ & $1.840,13$ \\
\hline Gratificaciones & $3.400,00$ & $3.468,00$ & $3.537,36$ & $3.608,11$ & $3.680,27$ \\
\hline CTS & $1.700,00$ & $1.734,00$ & $1.768,68$ & $1.804,05$ & $1.840,13$ \\
\hline Sueldo anual bruto & $25.500,00$ & $26.010,00$ & $26.530,20$ & $27.060,80$ & $27.602,02$ \\
\hline EsSalud anual $(8,40 \%)$ & $2.142,00$ & $2.184,84$ & $2.228,54$ & $2.273,11$ & $2.318,57$ \\
\hline Costo anual empleado & $27.642,00$ & $28.194,84$ & $28.758,74$ & $29.333,91$ & $29.920,59$ \\
\hline Total anual (2) & $55.284,00$ & $56.389,68$ & $\mathbf{5 7 . 5 1 7 , 4 7}$ & $58.667,82$ & $59.841,18$ \\
\hline
\end{tabular}

Elaboración propia

Tabla 7.13

Costo de remuneraciones a médico

\begin{tabular}{|c|c|c|c|c|c|}
\hline & 2017 & 2018 & 2019 & 2020 & 2021 \\
\hline RBC mensual & $5.000,00$ & $5.100,00$ & $5.202,00$ & $5.306,04$ & $5.412,16$ \\
\hline Gratificaciones & $10.000,00$ & $10.200,00$ & $10.404,00$ & $10.612,08$ & $10.824,32$ \\
\hline CTS & $5.000,00$ & $5.100,00$ & $5.202,20$ & $5.306,04$ & $5.412,16$ \\
\hline Sueldo anual bruto & $75.000,00$ & $76.500,00$ & $78.030,00$ & $79.590,60$ & $81.182,41$ \\
\hline EsSalud anual $(8,40 \%)$ & $6.300,00$ & $6.426,60$ & $6.554,52$ & $6.685,61$ & $6.819,32$ \\
\hline Costo anual empleado & $81.300,00$ & $82.926,00$ & $84.584,52$ & $86.276,21$ & $88.001,73$ \\
\hline Total anual (1) & $81.300,00$ & $82.926,00$ & $84.584,52$ & $86.276,21$ & $88.001,73$ \\
\hline
\end{tabular}

Elaboración propia 


\subsubsection{Personal de soporte interno del servicio}

Tabla 7.14

Costo de remuneraciones a asistente

\begin{tabular}{|c|c|c|c|c|c|}
\hline & 2017 & 2018 & 2019 & 2020 & 2021 \\
\hline RBC mensual & $1.400,00$ & $1.428,00$ & $1.456,56$ & $1.485,69$ & $1.515,41$ \\
\hline Gratificaciones & $2.800,00$ & $2.856,00$ & $2.913,12$ & $2.971,38$ & $3.030,81$ \\
\hline CTS & $1.400,00$ & $1.428,00$ & $1.456,56$ & $1.485,69$ & $1.515,41$ \\
\hline Sueldo anual bruto & $21.000,00$ & $21.420,00$ & $21.848,40$ & $22.285,37$ & $22.731,08$ \\
\hline EsSalud anual $(8,40 \%)$ & $1.764,00$ & $1.799,28$ & $1.835,27$ & $1.871,97$ & $1.909,41$ \\
\hline Costo anual empleado & $22.764,00$ & $23.219,28$ & $23.683,67$ & $24.157,34$ & $24.640,49$ \\
\hline Total anual (1) & $22.764,00$ & $23.219,28$ & $23.683,67$ & $24.157,34$ & $24.640,49$ \\
\hline
\end{tabular}

Elaboración propia

Tabla 7.15

Costo de remuneraciones a jefes

\begin{tabular}{|c|c|c|c|c|c|}
\hline & 2017 & 2018 & 2019 & 2020 & 2021 \\
\hline RBC mensual & $5.500,00$ & $5.610,00$ & $5.722,20$ & $5.836,64$ & $5.953,38$ \\
\hline Gratificaciones & $11.000,00$ & $11.220,00$ & $11.444,40$ & $11.673,29$ & $11.906,75$ \\
\hline CTS & $5.500,00$ & $5.610,00$ & $5.722,20$ & $5.836,64$ & $5.953,38$ \\
\hline Sueldo anual bruto & $82.500,00$ & $84.150,00$ & $85.833,00$ & $87.549,66$ & $89.300,65$ \\
\hline EsSalud anual $(8,40 \%)$ & $6.930,00$ & $7.068,60$ & $7.209,97$ & $7.354,17$ & $7.501,25$ \\
\hline Costo anual empleado & $89.430,00$ & $91.218,60$ & $93.042,97$ & $94.903,83$ & $96.801,91$ \\
\hline Total anual (2) & $178.860,00$ & $182.437,20$ & $186.085,94$ & $189.807,66$ & $193.603,82$ \\
\hline
\end{tabular}

Elaboración propia

Tabla 7.16

Costo de remuneraciones a director general

\begin{tabular}{|l|r|r|r|r|r|}
\hline & \multicolumn{1}{l|}{2017} & \multicolumn{1}{l|}{2018} & \multicolumn{1}{l}{2019} & \multicolumn{1}{l}{2020} & \multicolumn{1}{l|}{2021} \\
\hline RBC mensual & $7.000,00$ & $7.140,00$ & $7.282,80$ & $7.428,46$ & $7.577,03$ \\
\hline Gratificaciones & $14.000,00$ & $14.280,00$ & $14.565,60$ & $14.856,91$ & $15.154,05$ \\
\hline CTS & $7.000,00$ & $7.140,00$ & $7.282,80$ & $7.428,46$ & $7.577,03$ \\
\hline Sueldo anual bruto & $105.000,00$ & $107.100,00$ & $109.242,00$ & $111.426,84$ & $113.655,38$ \\
\hline EsSalud anual (8,40\%) & $8.820,00$ & $8.996,40$ & $9.176,33$ & $9.359,85$ & $9.547,05$ \\
\hline Costo anual empleado & $113.820,00$ & $116.096,40$ & $118.418,33$ & $120.786,69$ & $123.202,43$ \\
\hline Total anual (1) & $\mathbf{1 1 3 . 8 2 0 , 0 0}$ & $\mathbf{1 1 6 . 0 9 6 , 4 0}$ & $\mathbf{1 1 8 . 4 1 8 , 3 3}$ & $\mathbf{1 2 0 . 7 8 6 , 6 9}$ & $\mathbf{1 2 3 . 2 0 2 , 4 3}$ \\
\hline
\end{tabular}

Elaboración propia 
Así, el total de remuneraciones del personal de atención al cliente y de soporte interno es el siguiente:

Tabla 7.17

Costo total de remuneraciones

\begin{tabular}{|l|l|l|l|l|l|}
\hline & 2017 & 2018 & 2019 & 2020 & 2021 \\
\hline Total remuneraciones & $\mathbf{5 6 5 . 8 4 8 , 0 0}$ & $\mathbf{5 7 7 . 1 6 4 , 9 6}$ & $\mathbf{5 8 8 . 7 0 8 , 2 6}$ & $\mathbf{6 0 0 . 4 8 2 , 4 2}$ & $\mathbf{6 1 2 . 4 9 2 , 0 7}$ \\
\hline
\end{tabular}

Elaboración propia

\subsection{Presupuestos operativos}

\subsubsection{Presupuesto de ingreso por ventas}

Para calcular los ingresos por ventas se utilizarán dos ingresos, el primero por cada consulta con el médico (S/.120,00) y el segundo por cada sesión de terapia (S/.80,00). El número de pacientes será calculado con la demanda en número de sesiones de terapia, considerando que cada paciente requiere 20 sesiones de terapia.

Tabla 7.18

Ingresos por consulta y terapia

\begin{tabular}{|l|r|r|r|r|r|}
\hline & \multicolumn{1}{|l|}{2017} & \multicolumn{1}{l|}{2018} & 2019 & 2020 & 2021 \\
\hline Pacientes & 560 & 576 & 592 & 599 & 599 \\
\hline Costo consulta (S/.) & 101,69 & 101,69 & 101,69 & 101,69 & 101,69 \\
\hline Ingreso por consulta (a) & $56.949,15$ & $58.576,27$ & $60.203,39$ & $60.915,25$ & $60.915,25$ \\
\hline \multicolumn{7}{|l|}{} \\
\hline $\mathrm{N}^{\circ}$ sesiones & 11.200 & 11.520 & 11.840 & 11.980 & 11.980 \\
\hline Costo sesión (S/.) & 67,80 & 67,80 & 67,80 & 67,80 & 67,80 \\
\hline Ingreso por terapia (b) & $759.322,03$ & $781.016,95$ & $802.711,86$ & $812.203,39$ & $812.203,39$ \\
\hline \multicolumn{7}{|l|}{} \\
\hline Ingreso por servicio (a+b) & $\mathbf{8 1 6 . 2 7 1 , 1 9}$ & $\mathbf{8 3 9 . 5 9 3 , 2 2}$ & $\mathbf{8 6 2 . 9 1 5 , 2 5}$ & $\mathbf{8 7 3 . 1 1 8 , 6 4}$ & $\mathbf{8 7 3 , 1 1 8 . 6 4}$ \\
\hline
\end{tabular}

Elaboración propia 


\subsubsection{Presupuesto operativo de costos}

Tabla 7.19

Presupuesto operativo de costos

\begin{tabular}{|l|r|r|r|r|r|}
\hline & \multicolumn{1}{|l|}{2017} & \multicolumn{1}{l|}{2018} & \multicolumn{1}{l|}{2019} & \multicolumn{1}{l|}{2020} & \multicolumn{1}{l|}{2021} \\
\hline Materiales & $15.267,80$ & $15.619,07$ & $15.987,29$ & $16.111,86$ & $16.111,86$ \\
\hline Remuneraciones MOD & $250.404,00$ & $255.412,08$ & $260.520,32$ & $265.730,73$ & $271.045,34$ \\
\hline Depreciación fabril & $-32.561,86$ & $-32.561,86$ & $-32.561,86$ & $-32.561,86$ & $-32.561,86$ \\
\hline Costo de venta & $\mathbf{2 3 3 . 1 0 9 , 9 3}$ & $\mathbf{2 3 8 . 4 6 9 , 2 8}$ & $\mathbf{2 4 3 . 9 4 5 , 7 5}$ & $\mathbf{2 4 9 . 2 8 0 , 7 3}$ & $\mathbf{2 5 4 . 5 9 5 , 3 4}$ \\
\hline
\end{tabular}

Elaboración propia

\subsubsection{Presupuesto operativo de gastos administrativos}

Tabla 7.20

Presupuesto operativo de gastos administrativos

\begin{tabular}{|l|r|r|r|r|r|}
\hline & \multicolumn{1}{|l|}{2017} & \multicolumn{1}{l|}{2018} & \multicolumn{1}{l}{2019} & \multicolumn{1}{l|}{2020} & \multicolumn{1}{l|}{ (18 } \\
\hline Salarios administrativos & $315.444,00$ & $321.752,88$ & $328.187,94$ & $334.751,70$ & $341.446,73$ \\
\hline Servicios & $186.516,00$ & $186.516,00$ & $186.516,00$ & $186.516,00$ & $186.516,00$ \\
\hline Depreciación no fabril & $-2.788,14$ & $-2.788,14$ & $-2.788,14$ & $-2.788,14$ & $-2.788,14$ \\
\hline Amortización intangible & $-1.744,66$ & $-1.744,66$ & $-1.744,66$ & $-1.744,66$ & $-1.744,66$ \\
\hline Publicidad & $4.000,00$ & $2.000,00$ & $2.000,00$ & $2.000,00$ & $2.000,00$ \\
\hline Gastos Administrativos & $\mathbf{5 0 1 . 4 2 7 , 2 0}$ & $\mathbf{5 0 5 . 7 3 6 , 0 8}$ & $\mathbf{5 1 2 . 1 7 1 , 1 4}$ & $\mathbf{5 1 8 . 7 3 4 , 9 0}$ & $\mathbf{5 2 5 . 4 2 9 , 9 3}$ \\
\hline
\end{tabular}

Elaboración propia

\subsection{Presupuestos Financieros}

\subsubsection{Presupuesto de Servicio de Deuda}

Para calcular el servicio de la deuda, primero se evaluó las diferentes tasas de interés que ofrecen los bancos, para ello se consultó la siguiente tabla publicada por la Superintendencia de Banca y Seguros (SBS). En la siguiente tabla se muestran las tasas activas anuales de las operaciones en moneda nacional realizadas en los últimos 30 días útiles por tipo de crédito al 25 de julio del 2016, para pequeñas empresas. La empresa financiera que ofrece la mejor tasa es el "BIF" con una tasa de $11,63 \%$. 
Tabla 7.21

Tasas de empresas bancarias en moneda nacional

\begin{tabular}{|l|r|r|r|l|r|r|r|l|}
\hline & Continental & Crédito & Financiero & BIF & Scotiabank & Interbank & MiBanco & GNB \\
\hline $\begin{array}{l}\text { Préstamo } \\
\text { a más de } \\
\text { 360 días }\end{array}$ & $13,63 \%$ & $13,63 \%$ & $22,46 \%$ & $11,63 \%$ & $24,03 \%$ & $19,90 \%$ & $23,11 \%$ & $15,42 \%$ \\
\hline
\end{tabular}

Fuente: SBS

Tabla 7.22

Estructura del capital

\begin{tabular}{|l|r|r|}
\hline & Monto (S/.) & Participación \\
\hline Accionistas & $158.760,70$ & $63,82 \%$ \\
\hline Préstamo & $90.000,00$ & $36,18 \%$ \\
\hline Inversión Total & $248.760,70$ & $100 \%$ \\
\hline
\end{tabular}

Elaboración propia

Para el presente proyecto, se considerará 1 año de gracia parcial, con una Tasa Efectiva Anual de 11,63\% y con cuotas crecientes debido a que conforme vaya avanzando el proyecto, se contará con mayor liquidez.

Tabla 7.23

Servicio a la deuda

\begin{tabular}{|l|r|r|r|r|r|}
\hline & \multicolumn{1}{|l|}{2017} & \multicolumn{1}{l|}{2018} & \multicolumn{1}{l|}{2019} & \multicolumn{1}{l|}{2020} & \multicolumn{1}{l|}{2021} \\
\hline Inicial & 90.000 & 90.000 & 81.000 & 63.000 & 36.000 \\
\hline Amortización & - & 9.000 & 18.000 & 27.000 & 36.000 \\
\hline Intereses & 10.467 & 10.467 & 9.420 & 7.327 & 4.187 \\
\hline Cuota & 10.467 & 19.467 & 27.420 & 34.327 & 40.187 \\
\hline Deuda & 90.000 & 81.000 & 63.000 & 36.000 & - \\
\hline Factor & - & 0,10 & 0,20 & 0,30 & 0,40 \\
\hline
\end{tabular}

Elaboración propia 


\subsubsection{Presupuesto de Estado de Resultados}

Tabla 7.24

Estado de resultados

\begin{tabular}{|l|r|r|r|r|r|}
\hline & \multicolumn{1}{|l|}{2017} & \multicolumn{1}{l}{2018} & \multicolumn{1}{l}{2019} & \multicolumn{1}{l}{2020} & \multicolumn{1}{l|}{2021} \\
\hline Ventas & 816.271 & 839.593 & 862.915 & 873.119 & \multicolumn{1}{|c|}{873.119} \\
\hline Costo de Ventas & -548.554 & -560.222 & -572.134 & -584.032 & -596.042 \\
\hline Utilidad Bruta & 267.717 & 279.371 & 290.782 & 289.086 & 277.077 \\
\hline Gastos Administración & -181.983 & -181.983 & -181.983 & -181.983 & -181.983 \\
\hline Gastos de Ventas & -4.000 & -2.000 & -2.000 & -2.000 & -2.000 \\
\hline Utilidad Operativa & 81.983 & 95.388 & 106.798 & 105.103 & 93.093 \\
\hline Gastos Financieros & -10.467 & -10.467 & -9.420 & -7.327 & -4.187 \\
\hline Utilidad Antes de Impuestos & 71.267 & 84.921 & 97.378 & 97.776 & 88.907 \\
\hline Impuesto a la Renta & -21.380 & -25.476 & -29.213 & -29.333 & -26.672 \\
\hline Utilidad Neta & $\mathbf{4 9 . 8 8 7}$ & $\mathbf{5 9 . 4 4 5}$ & $\mathbf{6 8 . 1 6 5}$ & $\mathbf{6 8 . 4 4 3}$ & $\mathbf{6 2 . 2 3 5}$ \\
\hline
\end{tabular}

Elaboración propia

\subsubsection{Presupuesto de Estado de Situación Financiera}

A continuación, se presenta el Estado de Situación Financiera al final del primer año.

Tabla 7.25

Estado de situación financiera

\begin{tabular}{|c|c|c|c|}
\hline \multicolumn{2}{|l|}{ ACTIVO } & \multicolumn{2}{|l|}{ PASIVO Y PATRIMONIO } \\
\hline Activo Corriente & 71.267 & Pasivo Corriente & 30.380 \\
\hline Caja y bancos & 71.267 & Impuestos por pagar & 21.380 \\
\hline 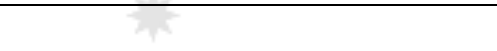 & & Préstamo por pagar CP & 9.000 \\
\hline $\mathrm{O}$ & & Pasivo No Corriente & 81.000 \\
\hline Activo No Corriente & 148.142 & Préstamo por pagar LP & 81.000 \\
\hline $\begin{array}{l}\text { Equipos de terapia } \mathrm{y} \\
\text { rehabilitación }\end{array}$ & 132.201 & Patrimonio & 108.028 \\
\hline Muebles y enseres & 15.941 & Capital Social & 108.028 \\
\hline Total Activo & 219.409 & $\begin{array}{l}\text { Total Pasivo } \quad y \\
\text { Patrimonio }\end{array}$ & 219.409 \\
\hline
\end{tabular}

Elaboración propia 


\subsection{Flujo de fondos netos}

A continuación, se detallarán los flujos de fondo económico y financiero para posteriormente realizar las evaluaciones económicas y financieras del proyecto, respectivamente.

\subsubsection{Flujo de fondos económicos}

En el flujo de fondos económicos se sumarán la depreciación y amortización de los activos ya que estos costos no son desembolsados, así como el escudo fiscal generado por los gastos financieros.

Tabla 7.26

Flujo de fondos económicos

\begin{tabular}{|l|l|r|r|r|r|r|}
\hline & \multicolumn{1}{|l|}{2016} & \multicolumn{1}{l|}{2017} & \multicolumn{1}{l|}{2018} & \multicolumn{2}{l|}{2019} & \multicolumn{2}{l|}{2020} & \multicolumn{1}{l|}{} \\
\hline Inversión & -248.761 & & & & & \\
\hline UN & & 49.887 & 59.445 & 68.165 & 68.443 & 62.235 \\
\hline Depreciación fabril & & 32.562 & 32.562 & 32.562 & 32.562 & 32.562 \\
\hline Depreciación no fabril & & 2.788 & 2.788 & 2.788 & 2.788 & 2.788 \\
\hline Amortización intangible & & 1.745 & 1.745 & 1.745 & 1.745 & 1.745 \\
\hline Valor residual & & & & & & 5.470 \\
\hline Gastos financieros * (1-t) & & 9.250 & 9.250 & 8.325 & 6.475 & 3.700 \\
\hline FFE & $\mathbf{- 2 4 8 . 7 6 1}$ & $\mathbf{9 6 . 2 3 1}$ & $\mathbf{1 0 5 . 7 8 9}$ & $\mathbf{1 1 3 . 5 8 4}$ & $\mathbf{1 1 2 . 0 1 3}$ & $\mathbf{1 0 3 . 4 9 9}$ \\
\hline
\end{tabular}

Elaboración propia

\subsubsection{Flujo de fondos financieros}

En cuanto al flujo de fondos financieros, se considerará además de la depreciación y amortización, el valor del préstamo y la amortización del mismo. 
Tabla 7.27

Flujo de fondos financieros

\begin{tabular}{|l|l|r|r|r|r|r|}
\hline & 2015 & 2016 & \multicolumn{1}{|l}{2017} & \multicolumn{2}{l|}{2018} & \multicolumn{2}{l|}{2019} & \multicolumn{2}{l|}{2020} \\
\hline Inversión & -248.761 & & & & & \\
\hline UN & & 49.887 & 59.445 & 68.165 & 68.443 & 62.235 \\
\hline Dep. fabril & & 32.562 & 32.562 & 32.562 & 32.562 & 32.562 \\
\hline Dep. no fabril & & 2.788 & 2.788 & 2.788 & 2.788 & 2.788 \\
\hline Amortización intangible & & 1.745 & 1.745 & 1.745 & 1.745 & 1.745 \\
\hline Valor residual & & & & & & 5.470 \\
\hline Préstamo & 90.000 & & & & & \\
\hline Amortización deuda & & & -9.000 & -18.000 & -27.000 & -36.000 \\
\hline FFE & $\mathbf{- 1 5 8 . 7 6 1}$ & $\mathbf{8 6 . 9 8 2}$ & $\mathbf{8 7 . 5 3 9}$ & $\mathbf{8 7 . 2 5 9}$ & $\mathbf{7 8 . 5 3 8}$ & $\mathbf{6 8 . 8 0 0}$ \\
\hline
\end{tabular}

Elaboración propia 


\section{CAPÍTULO VIII. EVALUACIÓN ECONÓMICA Y FINANCIERA DEL PROYECTO}

Para la evaluación económica y financiera del proyecto, se utilizará el modelo CAPM para estimar el costo de capital.

$$
\text { COK }=r_{f}+\beta \times\left(r_{m}-r_{f}\right)
$$

Donde, el $\beta$ del proyecto es 1,18 , el cual se obtuvo de la página web de A. Damodaran apalancado con la relación deuda/capital y la tasa de impuesto a la renta. Para hallar la tasa libre de riesgo $\left(r_{f}\right)$, se utilizó la información brindada por Invertia, el cual muestra que el rendimiento de un bono del tesoro americano a 5 años es de $1.30 \%$. La rentabilidad del mercado $\left(r_{m}\right)$ es de $13,31 \%$, la cual se obtuvo a partir de la rentabilidad de las principales clínicas que ofrecen el servicio de terapia física.

Aplicando la ecuación CAPM:

$$
\begin{gathered}
\text { COK }_{\text {proy }}=1,30 \%+1,18 \times(13,31 \%-1,30 \%) \\
C O K_{\text {proy }}=15,51 \%
\end{gathered}
$$

Esta tasa es lo que pedirían los accionistas de haber ejecutado el proyecto en Estados Unidos. Para ello, se ajustará la tasa de rentabilidad por el riesgo país, utilizando la aproximación simple; es decir, sumar el riesgo país al COK. Según el Banco Central de Reserva del Perú (BCRP), el riesgo país al 4 de octubre del 2016 es de 1,48\%.

Así, se obtiene un COK del proyecto de 16,99\%.

\subsection{Evaluación económica: VAN, TIR, B/C, PR}

Tabla 8.1

Evaluación económica

\begin{tabular}{|l|r|}
\hline VAN & S/. 91.036,67 \\
\hline TIR & $32 \%$ \\
\hline Relación B/C & 1,37 \\
\hline Periodo de Recupero & 0,73 \\
\hline Elaboración propia
\end{tabular}

Elaboración propia 
Tras la evaluación económica, se puede determinar que el proyecto es económicamente rentable con un periodo de recupero de aproximadamente 9 meses.

\subsection{Evaluación financiera: VAN, TIR, B/C, PR}

Tabla 8.2

Evaluación financiera

\begin{tabular}{|l|r|}
\hline VAN & S/. 108.368,91 \\
\hline TIR & $45 \%$ \\
\hline Relación B/C & 1,68 \\
\hline Periodo de Recupero & 0,60 \\
\hline Elaboración propia
\end{tabular}

Tras la evaluación financiera, se puede determinar que el proyecto es financieramente rentable con un periodo de recupero de aproximadamente 8 meses.

\subsection{Análisis de ratios e indicadores económicos y financieros del proyecto}

En la siguiente tabla se muestran los principales indicadores económicos y financieros del proyecto que permitirán determinar la situación de la empresa al primer año.

\section{Tabla 8.3}

Ratios de liquidez

\begin{tabular}{|l|l|l|}
\hline Indicador & Ratio & Valor \\
\hline Razón Corriente & $\frac{\text { Activo Corriente }}{\text { Pasivo Corriente }}$ & 2,35 \\
\hline Razón Ácida & $\frac{\text { Activo Corriente - Inventario }}{\text { Pasivo Corriente }}$ & 2,35 \\
\hline
\end{tabular}

Elaboración propia

Los indicadores de liquidez miden la capacidad de pago de la empresa para sus obligaciones a corto plazo ( 1 año). En la tabla 8.4 se puede observar que la empresa mantiene un nivel de liquidez aceptable, ya que lo recomendable es mayor a 1. Esto muestra la capacidad de la empresa para atender sus deudas a corto plazo. Asimismo, se observa que la razón corriente y la razón ácida tienen el mismo valor ya que no se cuenta con inventarios. 
Tabla 8.4

Ratios de solvencia

\begin{tabular}{|l|l|r|}
\hline Indicador & Ratio & Valor \\
\hline Razón de Endeudamiento & $\frac{\text { Pasivo Corriente }}{\text { Activo Total }}$ & 0,14 \\
\hline Razón Deuda-Patrimonio & $\frac{\text { Pasivo Total }}{\text { Patrimonio }}$ & 1,03 \\
\hline Calidad de Deuda & $\frac{\text { Pasivo Corriente }}{\text { Pasivo Total }}$ & 0,27 \\
\hline
\end{tabular}

Elaboración propia

Los indicadores de solvencia permiten conocer la contribución de los propietarios e indica la capacidad que tiene la empresa para cumplir con sus obligaciones de pago. Como se observa en la tabla anterior, se tiene una razón de endeudamiento de 0,14 , esto indica la proporción de los activos totales que financian los acreedores de la empresa, así se puede mencionar que se tiene un bajo grado de apalancamiento financiero. La razón deuda patrimonio muestra que por cada sol aportado por los accionistas, se tiene 1,03 soles de deuda. Y en cuanto a la calidad de la deuda, al ser menor a 0,27, muestra que la empresa utiliza mayormente un financiamiento de largo plazo.

\section{Tabla 8.5}

Ratios de rentabilidad

\begin{tabular}{|l|l|r|}
\hline Indicador & Ratio & Valor \\
\hline Rentabilidad Bruta sobre Ventas & $\frac{\text { Utilidad Bruta }}{\text { Ventas }}$ & $32,80 \%$ \\
\hline Rentabilidad Neta del Patrimonio (ROE) & $\frac{\text { Utilidad Neta }}{\text { Patrimonio }}$ & $46,18 \%$ \\
\hline Rentabilidad Neta sobre Activos (ROA) & $\frac{\text { Utilidad Neta }}{\text { Activo Total }}$ & $22,74 \%$ \\
\hline
\end{tabular}

Elaboración propia

Los indicadores de rentabilidad permiten evaluar la eficiencia operativa de la empresa, mostrando la rentabilidad con respecto a las ventas y con respecto a la inversión. Tanto el ROE como el ROA, resultan valores muy satisfactorios para el accionista y la empresa, ya que mide el retorno del capital del accionista (ROE) y determina la rentabilidad de las ventas como resultado de usar los activos totales (ROA). 


\subsection{Análisis de sensibilidad del proyecto}

Para el análisis de sensibilidad del proyecto se considerarán 3 escenarios:

- Escenario pesimista: Los ingresos por ventas caen en un $20 \%$

- Escenario más probable: Calculado en los capítulos anteriores

- Escenario optimista: Los ingresos por ventas crecen en un $20 \%$

Así, los ingresos por ventas ponderados se muestran a continuación:

Tabla 8.6

Ingresos por ventas ponderados

\begin{tabular}{|l|r|l|r|r|r|r|}
\hline Escenario & Peso & Año 1 & \multicolumn{1}{|l|}{ Año 2 } & \multicolumn{1}{|l|}{ Año 3 } & \multicolumn{1}{|l|}{ Año 4 } & \multicolumn{1}{|l|}{ Año 5 } \\
\hline Pesimista & $45 \%$ & 653.017 & 671.675 & 690.332 & 698.495 & 698.495 \\
\hline Más probable & $35 \%$ & 816.271 & 839.593 & 862.915 & 873.119 & 873.119 \\
\hline Optimista & $20 \%$ & 979.525 & 1.007 .512 & 1.035 .498 & 1.047 .742 & 1.047 .742 \\
\hline Ingresos por ventas & $\mathbf{7 7 5 . 4 5 8}$ & $\mathbf{7 9 7 . 6 1 3}$ & $\mathbf{8 1 9 . 7 6 9}$ & $\mathbf{8 2 9 . 4 6 2}$ & $\mathbf{8 2 9 . 4 6 2}$ \\
\hline
\end{tabular}

Elaboración propia

Con los ingresos por ventas ponderados se calculó nuevamente el VAN, la TIR, la relación beneficio costo y el periodo de recupero.

Tabla 8.7

Evaluación financiera - escenario

\begin{tabular}{|l|r|}
\hline VAN & S/. 12.356,49 \\
\hline TIR & $21 \%$ \\
\hline Relación B/C & 1,08 \\
\hline Periodo de Recupero & 0,93 \\
\hline
\end{tabular}

Elaboración propia

Se observa que, aun considerando un escenario pesimista, el VAN es positivo y se recuperará la inversión en aproximadamente 12 meses. 


\section{CAPÍTULO IX. EVALUACIÓN SOCIAL DEL PROYECTO}

\subsection{Identificación de las zonas y comunidades de influencia del proyecto}

El Centro de Terapia Física y Rehabilitación (CTFR) estará ubicado en el distrito de San Borja, de acuerdo a lo indicado en el Capítulo III: Localización del Servicio. Dentro de este distrito existe un Comité de Apoyo Social cuya misión principal es la de trabajar de manera eficaz y sin fines de lucro, promoviendo y apoyando actividades en el campo social, canalizando sus acciones tanto en salud, educación, y recreación, beneficiando a las personas del distrito de San Borja (Municipalidad de San Borja, 2016). Por otro lado, en San Borja se realizan actividades de sostenibilidad con diversos programas como "San Borja en bici" y "Muévete". Se buscará participar activamente de la mano con el Comité para contribuir con el desarrollo del distrito.

\subsection{Análisis de indicadores sociales}

A continuación, se calculará el valor agregado, la densidad de capital y la intensidad de capital, para el análisis de indicadores sociales

\section{Valor agregado}

En primer lugar, se calculó el valor agregado, es decir el aporte que se hace a la sociedad. Este incluye: sueldos, gastos administrativos y de ventas, intereses, impuestos y utilidad después de impuestos.

Tabla 9.1

Valor agregado anual

\begin{tabular}{|l|r|l|l|l|l|}
\hline & \multicolumn{1}{l|}{2017} & \multicolumn{1}{l|}{2018} & \multicolumn{1}{l|}{2019} & \multicolumn{1}{l|}{2020} & \multicolumn{1}{l|}{2021} \\
\hline Gastos Administración & 181.983 & 181.983 & 181.983 & 181.983 & 181.983 \\
\hline Gastos de Ventas & 4.000 & 2.000 & 2.000 & 2.000 & 2.000 \\
\hline Gastos Financieros & 10.467 & 10.467 & 9.420 & 7.327 & 4.187 \\
\hline Impuesto a la Renta & 21.380 & 25.476 & 29.213 & 29.333 & 26.672 \\
\hline Valor Agregado Anual & $\mathbf{2 1 7 . 8 3 0}$ & $\mathbf{2 1 9 . 9 2 6}$ & $\mathbf{2 2 2 . 6 1 7}$ & $\mathbf{2 2 0 . 6 4 3}$ & $\mathbf{2 1 4 . 8 4 2}$ \\
\hline Elaboración propia & & & &
\end{tabular}

Elaboración propia

Así, el valor agregado actualizado considerando una tasa de descuento social de $16,99 \%$ es S/. 701.733,58. 


\section{Densidad de capital}

La densidad de capital es la relación de la inversión del capital, versus empleo generado. Para su cálculo, se consideró que la inversión total es de 248.760,70 nuevos soles y que se generan 9 puestos de trabajo, así:

$$
\text { Densidad de capital }=\frac{248.760,70}{9}=27.640,08 \text { nuevos soles } / \text { persona }
$$

Intensidad de capital

Nos muestra la relación de la inversión total y el valor agregado del proyecto y nos permite medir cual es el grado de aporte del proyecto a través del nivel de la inversión, para generar valor agregado.

$$
\text { Intensidad de capital }=\frac{248.760,70}{701.733,58}=0.35
$$

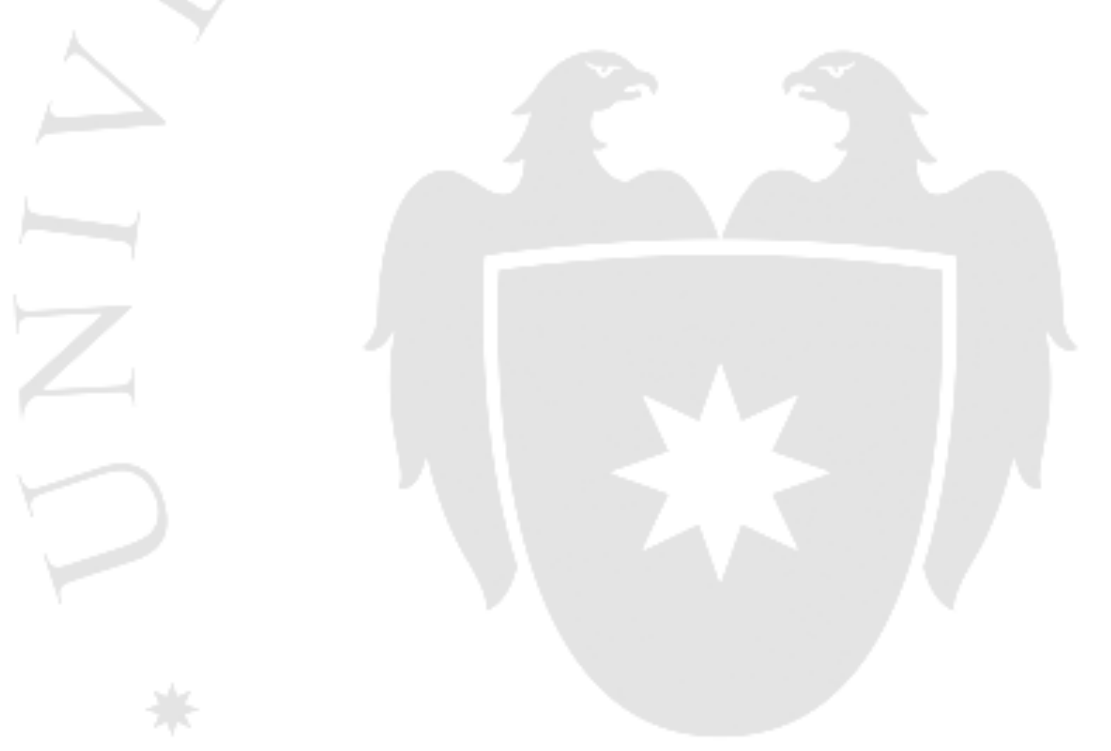




\section{CONCLUSIONES}

- La viabilidad de mercado se pudo determinar mediante la demanda del servicio, hallada utilizando información del servicio de atención de los centros que ya están en funcionamiento.

- Para determinar la localización del servicio, se utilizó el método de ránking de factores considerando aspectos importantes de cada distrito seleccionado, del cual se estableció que la mejor opción para el proyecto será San Borja.

- La viabilidad técnica del proyecto se pudo determinar ya que existen máquinas y equipos en el mercado que cumplen con los requerido, así como personas (médico especializado, fisioterapeutas y técnicos) altamente capacitados en tratamientos y rehabilitación física para deportistas.

- Se emplearon herramientas de ingeniería como el método Guerchet, diagrama relacional de actividades y espacio, y los análisis pertinentes acerca del soporte físico, para determinar una disposición adecuada del local que permita el óptimo funcionamiento del servicio.

- El proyecto resulta económica y financieramente viable ya que se obtiene un VAN positivo, y un periodo de retorno de 8 meses. Aun considerando un escenario pesimista con ingresos reducidos en $20 \%$ se obtiene un periodo de recupero de 12 meses y una TIR de $21 \%$.

- El proyecto es socialmente viable, ya que los indicadores sociales indican que se genera un valor agregado positivo y se generan nuevos puestos de trabajo. 


\section{RECOMENDACIONES}

- Se recomienda el alquiler del local, debido a que es una pequeña empresa y de esta manera se reduce la inversión.

- Es posible considerar otros tratamientos como la acupuntura y la quiropraxia, dentro del servicio que se puede brindar.

- Se debe trabajar la etapa de Análisis Económico y Financiero bajo los siguientes supuestos: El riesgo no varía, la estructura de capital no varía, el costo de las diferentes fuentes financieras es función de la estructura de capital.

- Es importante considerar las implicancias del proyecto en el medio ambiente, para causar el menor daño posible al mismo.

- Mantener una relación de confianza con los proveedores, de manera que se pueda contar con precios más bajos y promociones en el futuro.

- El mantenimiento es un factor importante debido a que las fallas en los equipos pueden ocasionar problemas de satisfacción al cliente por ineficiencia en el servicio.

- El personal debe estar altamente calificado y capacitado para brindar una excelente atención a los clientes ya que el principal medio de publicidad es el boca a boca. 


\section{REFERENCIAS}

Álvarez, Javier. (2015). Estadística Poblacional 2015. Lima: IPSOS Perú.

Álvarez, Javier. (2015). Perfiles zonales 2015. Lima: IPSOS Perú.

Asociación Peruana de Empresas de Investigación de Mercado. (2015). Niveles socioeconómicos 2015. Lima: APEIM.

Berdejo Hurtado, R.S., López Concha, P.P. (2014). Plan de negocios centro de salud especializado en enfermedades urológicas. (Trabajo de investigación Magíster en Administración). Universidad del Pacífico, Perú.

Biblioteca Nacional de Medicina de los EE.UU. (2015). Temas de Salud. Recuperado del sitio de Internet de la Biblioteca Nacional de Medicina de los EE.UU. Recuperado de: http://www.nlm.nih.gov/medlineplus/spanish/healthtopics.html

BTLMED (2014). Nuevas indicaciones de la terapia de ondas de choque en la medicina deportiva. [Testimonios en Medicina Deportiva]. Recuperado de: http://www.ondasdechoque.eu/shockwave-homepage-es/menu-left/-/ondas-dechoque-en-la-medicina-deportiva/

Costa López, L.M. (2008). Estudio de pre factibilidad para la puesta en marcha de un centro de gimnasia y terapia geriátrica. (Tesis para optar el título de Ingeniero Industrial). Universidad de Lima, Perú.

Damodaran, A. (2016). Betas by sector (US). Recuperado de: http://pages.stern.nyu.edu/ adamodar/New_Home_Page/datafile/Betas.html

Huaraz Zuloaga, E.M. (2014). Plan de negocios para el establecimiento de una clínica gíneco obstétrica de Lima Norte. (Trabajo de investigación Magíster en Administración). Universidad del Pacífico, Perú.

Instituto Peruano del Deporte (2016). Compendio Estadístico 2015. Lima: Oficina de Presupuesto y Planificación - Unidad de Estadística y Pre inversión.

Invertia (2016). Renta fija Estados Unidos. Recuperado de: http://www.invertia.com/mercados/renta-fija/portada.asp

Ivo Valdivia, J.A. (1996). Estudio de pre factibilidad para la instalación de una clínica médica en la ciudad de Trujillo. (Tesis para optar el título de Ingeniero Industrial). Universidad de Lima, Perú.

J.P. Rehab S.R.L. (2011). Equipos de Rehabilitación. [Lista de equipos para rehabilitación]. Recuperado de: http://jprehab.com/productos/equiposrehabilitacion-fisioterapia 
LIMA COMO VAMOS (2015) Seguridad ciudadana. Recuperado de: http://www.limacomovamos.org/cm/wpcontent/uploads/2013/10/segciudadana.pdf

Ministerio de Salud. (2013). Red Nacional para la Promoción de la Actividad Física. Recuperado de:

http://www.minsa.gob.pe/portada/Especiales/2013/activate/index.html

Ministerio de Salud. (2009). Política Nacional de Calidad en Salud. Recuperado de: http://www.minsa.gob.pe/dgsp/archivo/politica_nacional_calidad.pdf

Ministerio de Salud. (1999). Normas técnicas para el diseño de elementos de apoyo para personas con discapacidad en los establecimientos de salud. Recuperado de: http://www.minsa.gob.pe/ogdn/cd1/pdf/NLS_24/RM072-99-SA.pdf

Ministerio de Vivienda, Construcción y Saneamiento. (2006). Reglamento Nacional de Edificaciones. Recuperado de: http://www.vivienda.gob.pe/direcciones/rne.html

Municipalidad de San Borja. (2016). Educación, Cultura y Deporte. Recuperado de: http://www.munisanborja.gob.pe/\#

Phymed S.R.L. (2015). Rehabilitación. [Lista de equipos para rehabilitación]. Recuperado de: http://www.phymed.com.pe/rehabilitacion.html

Santos Trinidad, M.Y., Alocen Oblitas, P.C. (2014). Estudio de pre factibilidad para la implementación de un centro de bienestar que brinda atención integral a pacientes con diabetes mellitus en Lima Metropolitana. (Tesis para optar el título de Ingeniero Industrial). Pontificia Universidad Católita del Peru, Perú.

Superintendencia Nacional de Fiscalización Laboral (2014). Ley de Seguridad y Salud en el Trabajo. Recuperado de:

http://www.sunafil.gob.pe/portal/images/docs/normatividad/LEYDESEGURID ADSALUDTRABAJO-29783.pdf

URBECORP (2015). Información Inmobiliaria. Recuperado de: http://www.urbecorp.com.pe/info-inmobiliaria. 


\section{BIBLIOGRAFÍA}

Bauchbauer, J., y Steininger, K. (2005). Rehabilitación de las lesiones ( $\left.1^{\mathrm{a}} \mathrm{ed}.\right)$. Barcelona, España: Editorial Paidotribo.

Bové, T. (2011). El vendaje funcional (5 ${ }^{\mathrm{a}}$ ed.). Barcelona, España: Elsevier.

Cameron, M.H. (2009). Agentes Físicos en Rehabilitación (3 ${ }^{\mathrm{a}}$ ed.). Barcelona, España: Elsevier.

Dahl, H., y Rössler, A. (2004). Fundamentos de terapia manual (1 ${ }^{\mathrm{a}}$ ed.). Barcelona, España: Paidotribo.

Frontera, W. (2008). Medicina deportiva clínica (1 ${ }^{\mathrm{a}}$ ed.). Madrid, España: Elsevier.

Hüter-Becker, A., Schewe, H., y Heipertz W. (2005). Terapia Física (1 $\left.{ }^{\mathrm{a}} \mathrm{ed}.\right)$. Barcelona, España: Paidotribo.

Kolt, G. (2004). Fisioterapia del deporte y el ejercicio ( $1^{\mathrm{a}}$ ed.). Madrid, España: Elsevier.

Kotler, P., y Gary A. (2013). Fundamentos de Márketing (1 ${ }^{\mathrm{a}}$ ed.). Estado de México, México: Pearson Educación.

O’Brien, F. (febrero, 2012). ¿Fisioterapeuta o Quiropráctico? Revisa de Internet, Tecnología Médica, (1), 22-23. Recuperado de:

http://issuu.com/abarcacomunicaciones/docs/revista_tm01\#/signin

Prentice, W. (2001). Técnicas de rehabilitación en medicina deportiva ( $3^{\mathrm{a}}$ ed.). Barcelona, España: Editorial Paidotribo.

Rodríguez, J. (2014) Electroterapia en fisioterapia ( $3^{\mathrm{a}}$ ed.). Buenos Aires, Argentina: Médica Panamericana.

Universidad Peruana de Ciencias Aplicadas (2013). Blog de Terapia Física [Artículos en un blog]. Recuperado de: http://blogs.upc.edu.pe/terapia-fisica/node

Woolf-May, K., y Bird, S. (2008). Prescripción de ejercicio: fundamentos fisiológicos ( $1^{\mathrm{a}}$ ed.). Barcelona, España: Elsevier. 


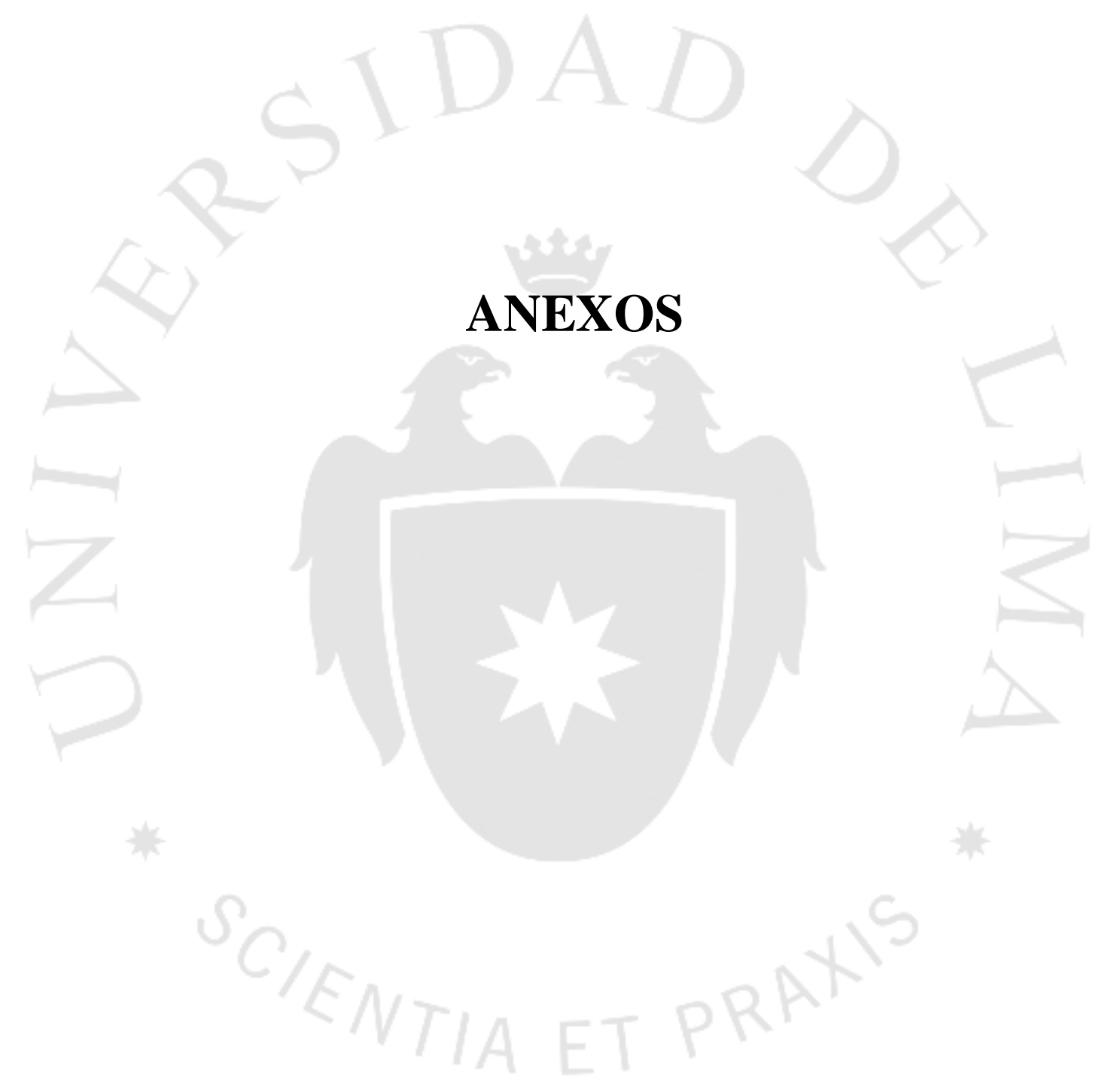




\section{Anexo 1 Encuesta}

1.- ¿En cuál de los siguientes rangos de edad, se encuentra usted?

○ Menos de 15 años

○ 15-29 años

○ 30-44 años

○ 45-59 años

2.- ¿En qué distrito vive?

- Miraflores

- San Isidro

- San Borja

- Santiago de Surco

- La Molina

3.- ¿Practica algún deporte?

- $\mathrm{Si}$

- No (Fin de la encuesta)

4.- ¿Cuántas veces a la semana practica deporte?

- 1-2 veces por semana

- 3-4 veces por semana

- 5-6 veces por semana

- Todos los días de la semana

5.- ¿Cuántas horas a la semana practica deporte aproximadamente?

- Menos de 6 horas

- De 6 a 12 horas

- De 12 a 30 horas

- Más de 30 horas

6.- ¿Durante la práctica deportiva, ha sufrido alguna lesión?

○ $\mathrm{Si}$

- No (Pasar a la pregunta 11)

7.- ¿Recurrió a algún servicio de terapia física y/o rehabilitación física?

○ $\mathrm{Si}$

- No (Pasar a la pregunta 11) 
8.- ¿A cuántas sesiones de terapia asistió?

- Menos de 10

- Entre 10 y 20

○ Entre 21 y 30

- Más de 30

9.- ¿En dónde tomó dicho servicio?

10.- ¿Cómo se enteró de ese lugar?

○ Internet

- Revistas

- Periódicos

○ Recomendación de algún conocido

○ Otros

11.- Si sufriera alguna lesión durante la práctica deportiva, ¿asistiría a un centro de terapia física con un servicio personalizado orientado al paciente y que cuente con equipos de última tecnología?

○ $\mathrm{Si}$

○ No (Fin de la encuesta)

12.- En la siguiente escala del 1 al 5 favor señale el grado de intensidad de asistir a un centro de servicio de terapia física. Siendo 1 probablemente asistiría y 5 de todas maneras asistiría.
$\circ 1$
○ 2
○ 3
$\circ 4$
○ 5

13.- ¿Cuánto estaría dispuesto usted a pagar por una sesión de terapia física y/o rehabilitación física?

○ Menos de 50 soles

- Entre 50 y 100 soles

- Más de 100 soles 